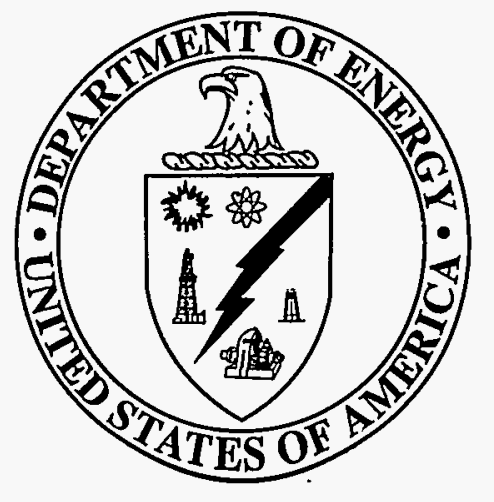

Office of Environmental Management

\title{
Technology Development
}

\section{CHARACTERIZATION, MONITORING, AND SENSOR TECHNOLOGY CROSSCUTTING PROGRAM}

\section{Technology Summary}

June 1995

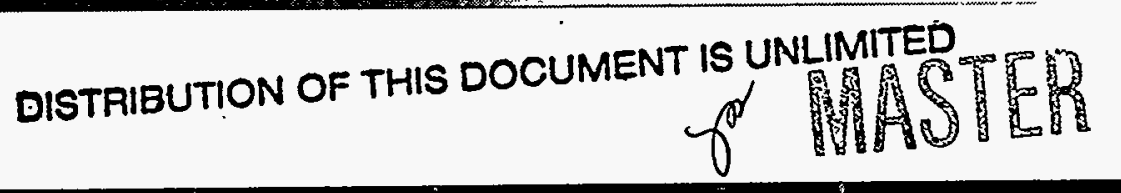




\section{DISCLAIMER}

This report was prepared as an account of work sponsored by an agency of the United States Government. Neither the United States Government nor any agency thereof, nor any of their employees, makes any warranty, express or implied, or assumes any legal liability or responsibility for the accuracy, completeness, or usefulness of any information, apparatus, product, or process disclosed, or represents that its use would not infringe privately owned rights. Reference herein to any specific commercial product, process, or service by trade name, trademark, manufacturer, or otherwise does not necessarily constitute or imply its endorsement, recommendation, or favoring by the United States Government or any agency thereof. The views and opinions of authors expressed herein do not necessarily state or reflect those of the United States Government or any agency thereof.

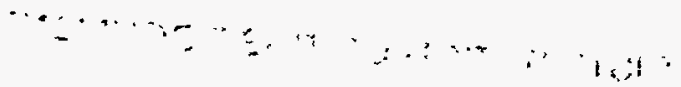




\section{DISCLAIMER}

Portions of this document may be illegible in electronic image products. Images are produced from the best available original document. 


\section{CHARACTERIZATION, MONITORING, AND SENSOR TECHNOLOGY CROSSCUTTING PROGRAM}

\section{TABLE OF CONTENTS}

Introduction vii

Characterization, Monitoring, and Sensor Technology Crosscutting Program Overview . xiii

1.0 CMST-CP PROJECTS FOR THE CONTAMINANT PLUME CONTAINMENT AND REMEDIATION FOCUS AREA

1.1 Savannah River Characterization 3

Expedited Site Characterization

1.2 Expedited Site Characterization - Application to Federal Facilities.................................... 8

1.3 Ames Laboratory's Expedited Site Characterization Demonstrations............................... 11 Field Analysis and Instrumentation

1.4 Time Domain Reflectometry and Fiber-Optic Probes for the Cone Penetrometer ......... 14

1.5 Site Characterization and Analysis Penetrometer System .................................................. 17

1.6 Technology Performance Specifications ........................................................................ 20

1.7 In Situ Measurement of Volatile and Semi-Volatile Organic Compounds in the Subsurface: Development of Screening and Quantitative Field Methods Coupled to the Cone Penetrometer.....

1.8 Miniature Pumps in the Cone Penetrometer Tip for Groundwater and Soil Gas Sampling.

1.9 Nuclear Borehole Logging: Passive and Neutron-Induced Spectral Gamma-Ray Techniques for Mapping Contaminants In Situ

Sensors

1.10 Multi-Analyte Single Fiber-Optical Sensor

1.11 Sol-Gel Indicator Program

1.12 Miniaturized Chemical Flow Probe Sensor Development Sandia National Laboratory.

1.13 Flow Probe Sensor Development - Center for Process Analytical Chemistry

1.14 Portable Acoustic Wave Sensor Systems for Volatile Organic Compounds 44

1.15 Surface Acoustic Wave Array Detectors 48 


\section{Contaminant Transport}

1.16 Analog Site for Characterization of Contaminant Transport

Through Fractured Rock

1.17 Integrated Geophysical and Hydrological Characterization of Transport

Through Fractured Media

1.18 International Environmental Assessment 54

2.0 CMST-CP PROJECTS FOR THE HIGH-LEVEL WASTE TANK

REMEDIATION FOCUS AREA

Safe Storage

2.1 Sensing of Head Space Gases: Continuous In Situ Monitoring of

Gaseous Components in Underground Storage Tanks Using

Piezoelectric Thin Film Resonator Sensors

2.2 Electrical Resistance Tomography for Subsurface Imaging ............................................. 62

2.3 Moisture Measurement by Electromagnetic Induction (EMI) ....................................... 65

2.4 In-Tank Interface Detection Using Time Domain Reflectometry ....................................6 68 Waste Retrieval

2.5 Acoustic Characterization of Wastes in Double Shell Underground Storage Tanks........ 71 .

2.6 Imaging Through Obscurations During Sluicing Operations............................................ 74 Waste Sampling/Analysis

2.7 Moisture Sensor in Cone Penetrometer for In-Tank Characterization ............................. 76

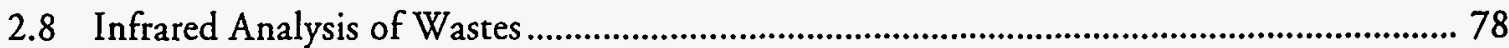

3.0 CMST-CP PROJECTS FOR MIXED WASTE CHARACTERIZATION, TREATMENT, AND DISPOSAL FOCUS AREA

Waste Process Monitoring and Controls

3.1 Diagnostic Instrumentation and Analysis Laboratory (DIAL) ........................................... 85

3.2 Support for RCRA Metal and Air Stream Characterization .............................................. 88 Off-Gas and Effluent Monitoring

3.3 Continuous Emission Monitor for Thermal Treatment Systems....................................... 91

3.4 Metal Emissions Monitor for DOE Mixed Waste Thermal Treatment ............................ 94

4.0 CMST-CP PROJECTS FOR DECONTAMINATION AND

DECOMMISSIONING FOCUS AREA

4.1 Associated Particle Imaging Development 99 
4.2 Defining Requirements for Evaluation and Testing of Radiological Sensor Technologies

4.3 A Robust Radiation Detector for Rapid Waste Characterization ................................. 104

4.4 Development of a Portable Heavy Metal Detector Using X-ray, K-Edge Analysis ........ 107

5.0 CMST-CP PROJECTS FOR LANDFILL STABILIZATION FOCUS AREA 109

Buried Waste Location/Characterization

5.1 Remotely Piloted Vehicles and Miniaturized Sensors

5.2 Remote Sensing Systems Development and Application

5.3 Laser-Induced Fluorescence Imaging for Surface Uranium............................................. 116

5.4 Rabbit Valley Geophysics Performance Evaluation Range ............................................. 120

5.5 Three-Dimensional/Three-Component Seismic Surveys for Site Characterization ........ 123 Containment

5.6 Laser Ablation-ICP-AES Using a High Resolution Fiber-Optic Interferometer

5.7 Inductively-Coupled Plasma - Mass Spectrometry (ICP-MS) for Analysis of Microliter Samples and Solids

5.8 Secondary Ion-Mass Spectroscopy Analysis: Development and Evaluation

5.9 RCRA Metals Analysis by Laser-Induced Breakdown Spectroscopy

6.0 DOE BUSINESS OPPORTUNITIES

7.0 ACRONYM LISTING

8.0 APPENDIX

\section{Figures}

A. EM Organizational Structure as of May 1, 1994 ..........................................................................

B. OTD Organizational Structure as of May 1, 1994.....................................................................

1.1 Three-Dimensional Image of Subsurface Contaminant Plume.................................................... 5

1.2a Expedited Site Characterization ................................................................................................ 8

1.2b A General Map of the Pantex Site Showing the Locations of Current Work Zones.................. 9

1.4 Cone Penetrometer Tip for Hydrologic Investigations .............................................................. 14

1.5 Site Characterization and Analysis Penetrometer System Description ..................................... 11

1.6 Technology Performance Specifications Diagram ........................................................................ 20

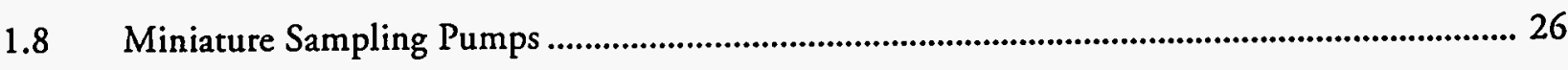

1.9 Variable Contaminant Borehole Test Facility ….......................................................................... 29 
1.11 a Diagram of Fiber-Optic Diode Array Spectrophotometer System with Sol-Gel Probe ............ 35

$1.11 \mathrm{~b}$ Response of Arsenazo III Sol-Gel Uranyl Probe .......................................................................... 36

1.12a Flow Probe Laboratory Prototype Components ................................................................... 39

1.12b Flow Probe Laboratory Model of Probe Head (diameter is 0.5 in) ......................................... 39

1.14a Bench-top Portable Acoustic Wave Sensor (PAWS) System .................................................... 44

1.14b Schematic of a Surface Acoustic Wave (SAW) Sensor ......................................................... 44

2.1 a W Wafer of TFRs After Processing and Prior to Packaging and Incorporation

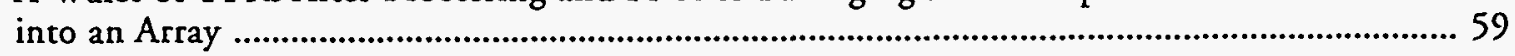

2.1b Responses of QCM/PdNi to $\mathrm{H} 2$ as a Function of Film Thickness ........................................... 60

2.1c Thin Film Resonator Sensors (TFRs) ..................................................................................... 61

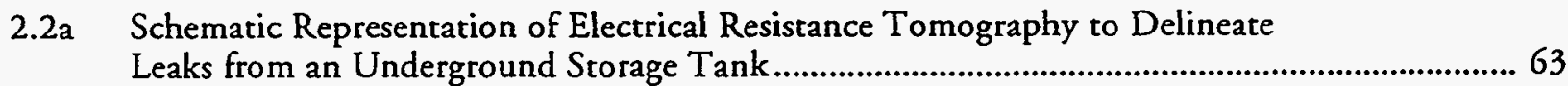

2.2b Computer Simulation of Electrical Resistance Tomography Below a Steel Tank With a Conductive Plume of 250 Ohm-m Beneath the Tank Center ......................................... 63

2.4a Twin Lead Laboratory Probe Data Collected with Cathetometer .............................................. 68

2.4b Waste Liquid Level/Sludge-Salt Cake Characterization Using Time Domain

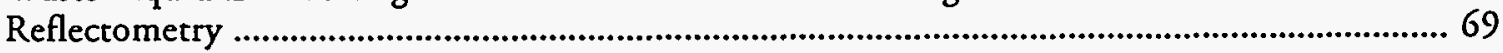

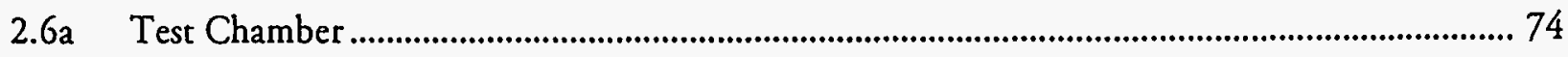

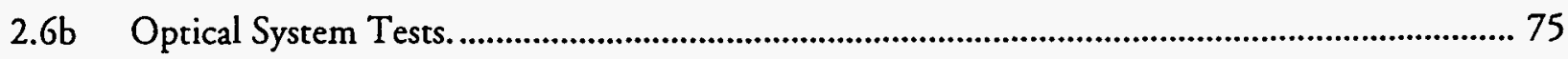

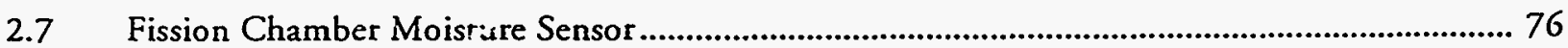

2.8a Fourier Transform Infrared (FTIR) Spectrometer ................................................................... 78

2.8b Schematic of the TIRS Unit on a Waste Encapsulation Line .................................................... 79

3.3a Prototype FTIR Continuous-Emission Monitor Used During the Field

Test at the K-25 Site ............................................................................................................. 91

3.3b The Toxic Substances Control Act Incinerator at the K-25 Site in

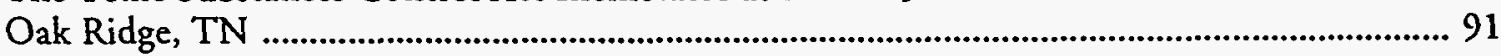

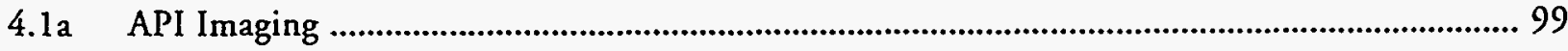

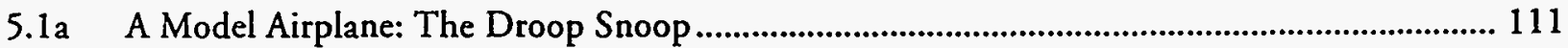

5.1b Aerial Photograph of Solid Waste Storage Area 6 on the Oak Ridge

5.1c A Picture Taken from Droop Snoop …................................................................................. 112

5.3a LIFI Pallet Layout for Helicopter Deployment ........................................................................... 117

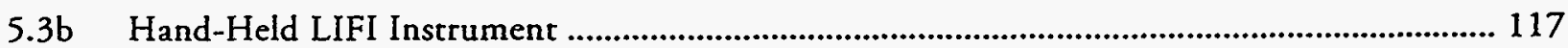




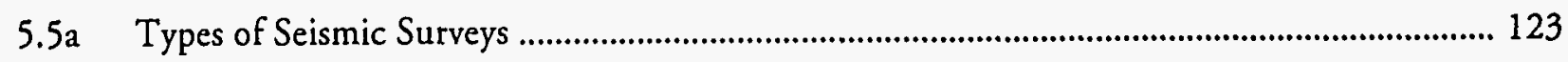

5.5b Vertically Polarized Shear-Wave Seismic Data ....................................................................... 124

5.5c Horizontally Polarized Shear-Wave Seismic Data ............................................................. 124

5.6a Schematic of the AOTF-FFP Interferometer System ................................................................. 126

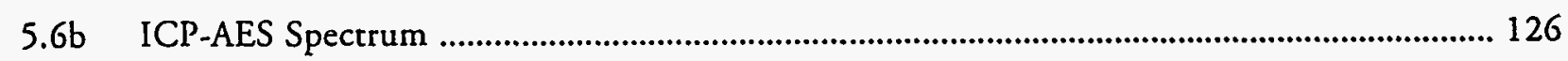

5.7a Schematic Diagram of MDMI and ICP-MS Components .................................................. 129

5.7b Schematic Diagram of Laser Ablation Cell Connected to MDMI for Calibration ................. 129

5.8a Depiction of SIMS Bombardment of Hg-Contaminated Soil .................................................. 131

5.8b Schematic Diagram of Prototype Ion Trap SIMS Instrument Being

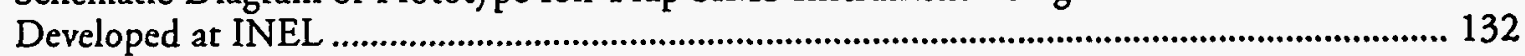

5.9a Schematic Representation of a Basic LIBS Instrument ........................................................... 134

5.9b Calibration Curve for Los Alamos Soil Spiked with Lead ........................................................ 135

\section{Tables}

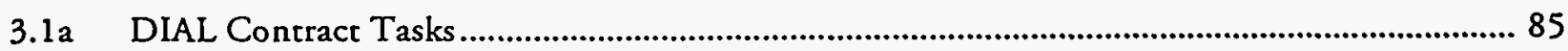

3.1b DIAL Measurements at WETO/MSE, October 1994 ................................................................ 86

4.1 Simultaneous Elemental and Positional Information from API............................................... 100

5.4 Static Cell Targets in Rabbit Valley GPER ............................................................................. 121 


\section{INTRODUCTION}

\section{THE NEW APPROACH}

\section{PURPOSE}

Although positive steps have been taken during the past three decades to remedy the world's environmental problems, the nation's ability to respond to many current and future environmental and economic challenges depends on technological advances produced by a well-organized and productive federal research and development program.

To ensure that such programs focus on the most pressing environmental restoration and waste management problems at the U.S. Department of Energy (DOE), the Assistant Secretary for the Office of Environmental Management (EM) established a Working Group in August 1993 to implement a new approach to environmental research and technology development. The goal of DOE's new approach is to conduct a research and technology development program that will overcome major obstacles in the cleanup of DOE sites. Integral to this new, solutions-oriented approach is an up-front awareness of program needs obtained from customers, users, regulators, and stakeholders. These needs can then be disseminated to the developers of technological solutions.

The key features of the new approach are:

- establishing five focus areas to address DOE's most pressing problems;

- teaming with the customers in EM to identify, develop, and implement needed technology;

- focusing technology development activities on major environmental management problems;

- coordinating management of scientific and development activities in support of EM;

- focusing resources in national laboratories more effectively;

- involving industry in developing and implementing solutions, including technology transfer into DOE and from DOE to the private sector;

- coordinating basic research by involving academia and other research organizations to stimulate technological breakthroughs; and

- enhancing involvement of regulators and stakeholders in implementation of technology development.

DOE has established a framework and strategy for coordinating efforts among DOE organizations, Management and Operations $(\mathrm{M \& O})$ contractors, the national laboratories, other government agencies, the scientific community, industry, academia, and the affected public. Full implementation of the new approach is planned for the FY $95 / 96$ timeframe. The new strategy will build upon existing programs and will seek continual improvement of all EM operations and processes.

Prior to implementation of the new approach, EM's Office of Technology Development (OTD) carried out an aggressive national program of applied research and development to meet environmental restoration and waste management needs based on the concepts of Integrated Programs (IP) and Integrated Demonstrations (ID). These concepts, introduced in 1989, were engineered to manage the research, development, demonstration, testing and evaluation (RDDT\&E) activities within EM.

An IP was the cost-effective mechanism which assembled a group of related and synergistic technologies to evaluate their performance to solve a specific aspect of a waste management or environmental problem. The problem can be unique to a site or common to many sites. An IP supports applied research to develop 
innovative technologies in key application areas organized around specific activities required in each stage of the remediation process (e.g., characterization, treatment, and disposal).

An ID was the cost-effective mechanism that assembled a group of related and synergistic technologies to evaluate their performance individually or as a complete system to correct waste management and environmental problems from cradle to grave.

\section{BENEFITS}

A keystone for implementation of the new approach is to encourage development of technologies that are better, faster, safer and more cost-effective than those currently available. More importantly, the new approach has been adopted to foster implementation of new and innovative environmental technologies, facilitating the national commitment to long-term environmental, energy, and economic goals.

An important benefit to the new approach is the creation of investment returns for developing new technologies - technology dividends. These technology dividends result from partnerships and leveraging within government and between government and the private sector. The partnerships can consist of technology developers, technology users, problem holders, and problem solvers.

EM technology dividends will include:

- Employment opportunities with new businesses and existing businesses

- Cleanup of sites posing the greatest threats to human health, safety, and the environment;

- Materials reused and recycled, instead of thrown away or freshly contaminated;

- Pollution prevented;

- More effective and efficient industrial processes, leading to greater U.S. competitiveness globally; and

- Technology transfer to other countries.

By implementing the new approach for the unique environmental problems associated with DOE sites, EM/ OTD, scientists, and engineers at the national laboratories stand at the threshold of opportunity to develop new technologies. This work will enhance quality of life through a cleaner environment, improved global competitiveness, and ensure job opportunities for American workers.

\section{FOCUS AREAS}

Five major remediation and waste management problem areas within the DOE Complex have been targeted for action on the basis of risk, prevalence, or need for technology development to meet environmental requirements and regulations. Other areas may be added or currently identified areas further partitioned to ensure that research and technology development programs remain focused on EM's most pressing remediation and waste management needs. These major problem areas, termed "Focus Areas," are described below.

Contaminant Plume Containment and Remediation. Uncontained hazardous and radioactive contaminants in soil and ground water exist throughout the DOE Complex. There is insufficient information at most sites on the contaminants' distribution and concentration. The migration of some contaminants threatens water resources and, in some cases, has already had an adverse impact on the off-site environment. Many current characterization, containment, and treatment technologies are ineffective or too costly. Improvements are needed in characterization and data interpretation methods, containment systems, and in situ treatment. 
Mixed Waste Characterization, Treatment, and Disposal. DOE faces major technical challenges in the management of low-level radioactive mixed waste. Several conflicting regulations, together with a lack of definitive mixed waste treatment standards hamper mixed waste treatment and disposal. Disposal capacity for mixed waste is also expensive and severely limited. DOE now spends millions of dollars annually to store mixed waste because of the lack of accepted treatment technology and disposal capacity. In addition, currently available waste management practices require extensive, and hence costly waste characterization before disposal. Therefore, DOE must pursue technology that leads to better and less expensive characterization, retrieval, handling, treatment, and disposal of mixed waste.

High-Level Waste Tank Remediation. Across the DOE Complex, hundreds of large storage tanks contain hundreds of thousands of cubic meters of high-level mixed waste. Primary areas of concern are deteriorating tank structures and consequent leakage of their contents. Research and technology development activities must focus on the development of safe, reliable, cost-effective methods for characterization, retrieval, treatment, and final disposal of the wastes.

Landfill Stabilization. Numerous DOE landfills pose significant remediation challenges. Some existing landfills have contaminants that are migrating, thus requiring interim containment prior to final remediation. Materials buried in retrievable storage pose another problem. Retrieval systems must be developed to reduce worker exposure and secondary waste quantities. Another high-priority need is in situ methods for containment and treatment.

Decontamination and Decommissioning. The aging of DOE's weapons facilities, along with the reduction in nuclear weapons production, has resulted in a need to transition, decommission, deactivate, and dispose of numerous facilities contaminated with radionuclides and hazardous materials. While building and scrap materials at the sites are a potential resource, with a significant economic value, current regulations lack clear release standards. This indirectly discourages the recovery, recycling, and/or reuse of these resources. The development of enhanced technologies for the decontamination of these materials, and effective communication of the low relative risks involved, will facilitate the recovery, recycle, and/or reuse of these resources. Improved material removal, handling, and processing technologies will enhance worker safety and reduce cost.

\section{CROSSCUTTING TECHNOLOGIES}

Crosscutting technologies are those which overlap the boundaries of the focus areas while providing simultaneous benefits. These technologies may be used in several or all focus area testing and evaluation programs, and include:

Characterization, Monitoring, and Sensor Technology. DOE is required to characterize more than 3,700 contaminated sites, 1.5 million barrels of stored waste, $385,000 \mathrm{~m}^{3}$ of high-level waste in tanks, and from 1,700 to 7,000 facilities before remediation, treatment, and facility transitioning commence. During remediation, treatment, and site closure, monitoring technologies are needed to ensure worker safery and effective cleanup. Cost-effective technologies are needed for all EM characterization requirements.

Efficient Separations and Processing. Separation and treatment technologies are needed to treat and immobilize a broad range of radioactive wastes. In some cases, separations technologies do not exist. In others, improvements are needed to reduce costs, reduce secondary waste volumes, and improve waste form quality. Separations technologies are also needed for environmental restoration of DOE sites, for groundwater and soils cleanup, and for decontamination and decommissioning of facilities. Many separations agents developed for waste treatment can be adapted for environmental restoration needs. 
Robotics. DOE's waste disposal efforts have particular issues-access, safety, final disposal, and cost efficiency. Due to hazardous radiation, massive waste loads, and restricted entry ways, many sites are inaccessible for human labor. It is unsafe to expose humans to radiation, harmful chemicals, and injurious mechanical objects. Human labor requires higher compensation, the need for expensive protective clothing, and stringent decontamination procedures. Robotics systems are safe, efficient, and cost-effective means to automate the handling and processing of mixed waste and characterizing and/or retrieving storage tank waste. Systems can also be designed for surveillance, characterization, cleanup, and decommissioning of retired DOE facilities.

Innovative Investment Area. DOE has set aside funding to foster research and development partnerships within the public and private sector, and to introduce innovative technologies into OTD programs. The Innovative Investment Area supports two types of technologies: (1) technologies that show promise to address specific EM needs, but require proof-of-principle experimentation, and (2) proven technologies in other fields that require critical path experimentation to demonstrate feasibility for adaptation to specific EM needs.

Pollution Prevention. DOE and the U.S. Department of Defense (DoD) have similar waste stream pollution problems and common environmental concerns. By combining their resources, these agencies can develop a coordinated interagency environmental research and technology development program that produces cost-effective technological solutions, particularly in the areas of process change or in-process recycling.

\section{TECHNICAL TASK PLANS}

Technical Task Plans (TTPs) are used to identify and to summarize work funded and managed by OTD at headquarters, the field, and the national laboratories. These plans include a project summary, technical rask description, budget schedule, and milestone schedule. The EM-50 FY 1994 Program Summary (DOE/ EM-0216) lists TTPs current as of the date of this document.

All tasks require a TTP number. Each TTP number contains information on the fiscal year in which the task is first funded, the DOE Operations Office funding allotment code, and the laboratory/contractor/ university designator. See appendix for further details.

\section{EM ORGANIZATIONAL STRUCTURE}

The Office of Environmental Management (EM) is responsible for managing the cleanup of DOE wastes from past nuclear weapons production and current operations. The EM mission is to bring DOE sites into compliance with all environmental regulations while minimizing risks to the environment, human health and safety posed by the generation, handling, treatment, storage, transportation, and disposal of DOE waste. The EM organization was established to provide focus, accountability, and visibility for DOE's waste management and remediation efforts. See Figure A. 


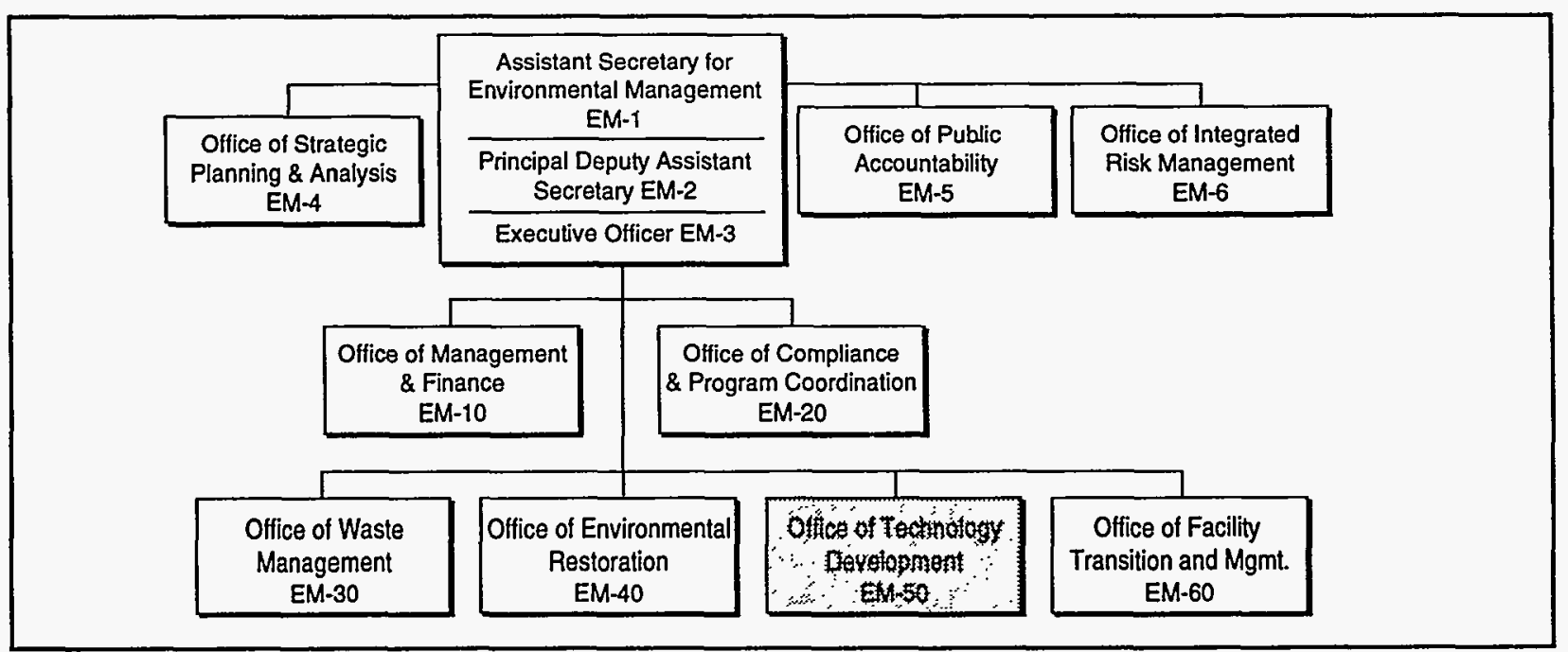

Figure A. EM Organizational Structure as of May 1, 1994.

\section{OFFICE OF TECHNOLOGY DEVELOPMENT}

The Office of Technology Development (EM-50) has the overall responsibility to develop technologies to meet DOE's goals for environmental restoration. OTD works closely with EM-30, -40 , and -60 in identifying, developing, and implementing innovative and cost-effective technologies. Activities within EM-50 include applied research and development, demonstration, testing, and evaluation (RDDT\&E), technology integration, technology transfer, and program support. See Figure B.

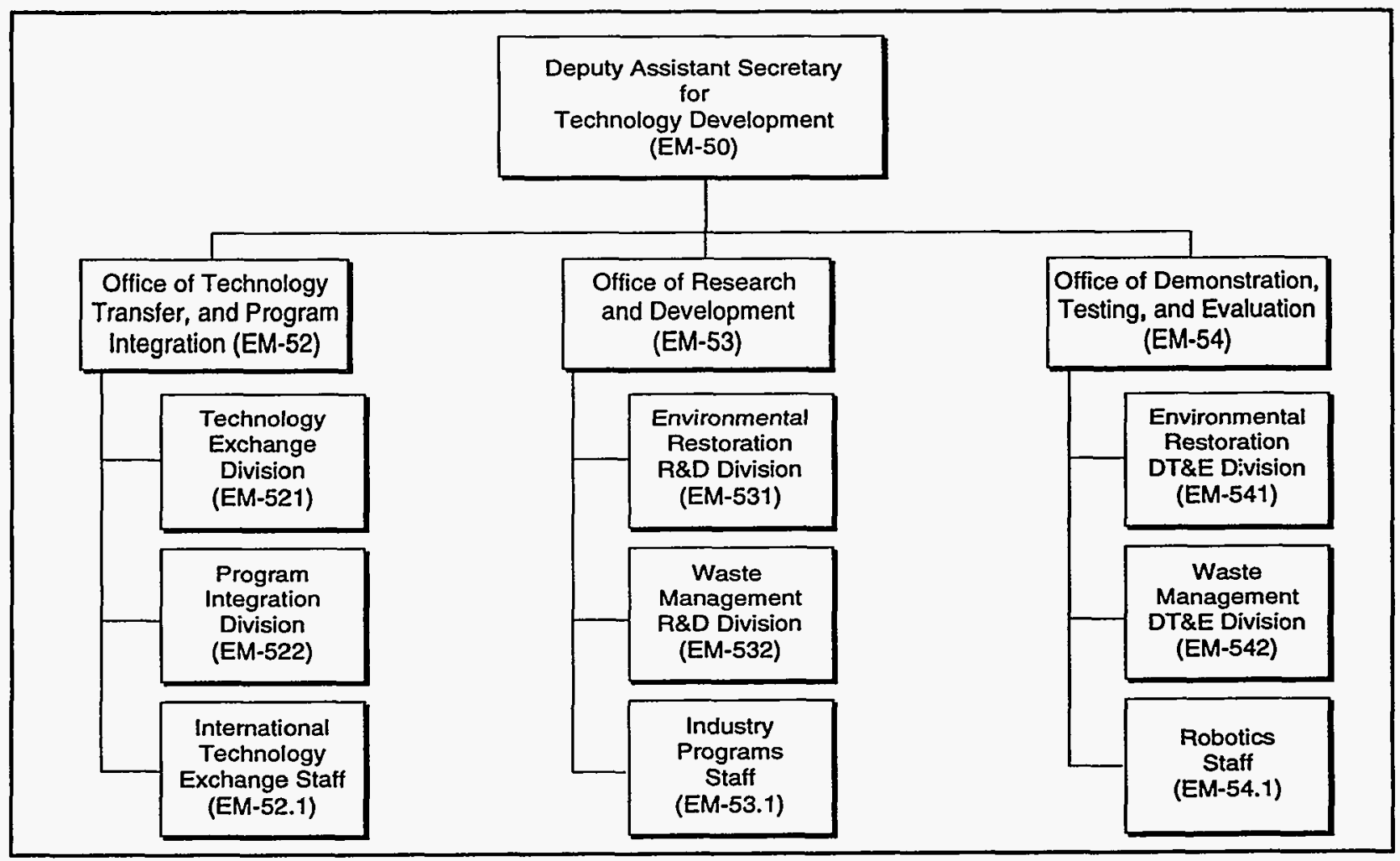

Figure B. OTD Organizational Structure as of May 1, 1994. 


\section{EM-50 ORGANIZATION}

The Office of Technology Transfer and Program Integration (EM-52) provides management, financial, and internal program support to line organizations that comprise EM-50. It also provides efforts to encourage and to facilitate the infusion and diffusion of innovative environmental technologies for internal and domestic application through collaborative partnerships with U.S. and foreign industry or organizations, the national laboratories, other federal agencies, and universities. Technology transfer and technology leveraging are important program components. Enhanced communication to internal and external stakeholders is a goal of this Office.

The Office of Research and Development (EM-53) is responsible for establishing applied research and development (R\&D) program at DOE sites nationwide. Programs are designed to identify operational needs in environmental restoration, waste operations, and corrective activities, and to provide solutions to key rechnical issues that, if not solved in a timely manner, would adversely affect DOE's ability to meet its cleanup goal.

The Office of Demonstration, Testing, and Evaluation (EM-54) is responsible for identifying environmental management technologies in the research and development stage that are ready for transition to the demonstration arena. Those technologies are complete systems to demonstrate a solution to a specific problem area. Programs are conducted to advance selected technologies so they can be utilized by DOE to meet its cleanup goal in a cost-effective manner.

\section{OTHER EM ORGANIZATIONS}

The Office of Waste Management (EM-30) has program responsibilities for managing waste generated at all DOE sites during weapons processing and manufacturing, research activities, and sire cleanup activities. This includes the treatment, storage, transportation, and disposal of several types of waste: transuranic, lowlevel radioactive, mixed, and solid sanitary wastes. EM-30 is also responsible for the storage, treatment, and processing of defense high-level radioactive waste (HLW), waste minimization efforts, and corrective activities at waste management facilities.

The Office of Environmental Restoration (EM-40) has program responsibilities for assessment and cleanup of inactive hazardous and radioactive facilities and waste sites at all DOE installations and some non-DOE sites. EM-40 oversees program activities to reduce or eliminate risks to human health and the environment.

The Office of Facility Transition and Management (EM-60) has the responsibility to ensure that shutdown facilities are brought to a deactivated state, are properly maintained, and are eventually decontaminated and/or decommissioned or released for other uses. 


\section{CHARACTERIZATION, MONITORING, AND SENSOR TECHNOLOGY CROSSCUTTING PROGRAM OVERVIEW}

\section{PURPOSE}

The purpose of the Characterization, Monitoring, and Sensor Technology Crosscutting Program (CMST$\mathrm{CP}$ ) is to deliver appropriate characterization, monitoring, and sensor technology (CMST) to the Office of Waste Management (EM-30), the Office of Environmental Restoration (EM-40), and the Office of Facility Transition and Management (EM-60).

The technology development must also be cost effective and appropriate to EM-30/40/60 needs. Furthermore, the required technologies must be delivered and implemented when needed. Accordingly, and to ensure that available DOE and other national resources are focused on the most pressing needs, management of the technology development is concentrated on the following Focus Areas:

- Contaminant Plume Containment and Remediation (PFA)

- Landfill Stabilization (LSFA)

- High-Level Waste Tank Remediation (TFA)

- Mixed Waste Characterization, Treatment, and Disposal (MWFA)

- Facility Deactivation, Decommissioning, and Material Disposition (FDDMDFA)

\section{TECHNOLOGY NEEDS}

The EM mission cannot proceed intelligently, safely, or economically unless the problems it addresses and the processes it employs are adequately characterized or monitored. A common problem is that, even in cases where currently available characterization and monitoring technologies are applicable, the costs are unacceptably high. Another is that critical characterization, monitoring, and sensor technologies needed to address several of the most important EM problems are not available, are not yet accepted by regulators, or have not been proven under EM mission conditions. Examples of needed characterization, monitoring, and sensor technologies are listed below, by Focus Area.

PFA. Instrumentation and methods for determination of the location, nature, level, and 3-dimensional extent of Dense Non-Aqueous Phase Liquids (DNAPLs) in the subsurface; automated systems for groundwater monitoring that are both economical and accepted by the regulators.

TFA. Safe, fast, economical methods and instruments for characterization and monitoring of the gaseous, liquid, and solid contents of high-level waste tanks to address safety questions, and for assurance of safety and quality during storage, retrieval, processing, and disposal.

MWFA. Safe, fast, and economical instrumentation and methods for characterization and monitoring of mixed waste in containers and mixed waste treatment processes, effluents, and final waste forms - for assurance of worker, public, process, and facility safety, and to assure the quality and public acceptance of treatment processes and final waste forms.

LSFA. Instrumentation and methods for establishing and monitoring the integrity of subsurface barriers and for real-time monitoring of the progress and quality of in situ stabilization processes. 
FDDMDFA. Non-laboratory instrumentation and methods for in situ identification, preferably in real time, of materials and surfaces contaminated with hazardous materials such as $\mathrm{PCBs}, \mathrm{U}, \mathrm{Hg}$, and tritoum; technologies for real-time monitoring of the progress and quality of decontamination.

All the Focus Areas have characterization and monitoring development needs; therefore technology that is developed for one Focus Area can often be adapted to solve problems in another. The CMST-CP identifies technology gaps, integrates technology development, and leverages resources to achieve synergy in development and to provide cost-effective solutions. The resources include those of other federal agencies, private companies, and universities as well as those within the DOE. The CMST-CP promotes private sector R\&D involvement through Cooperative Research and Development Agreements (CRADAs), Research Opportunity Announcements (ROAs), the Small Business Innovation Research (SBIR) program, and the Technology Reinvestment Project (TRP); collaboration with other federal agencies is promoted through interagency agreements (IAGs). The CMST-CP provides necessary coordination to achieve timely and cost-effective development and implementation of needed characterization, monitoring, and sensor technologies.

\section{WINDOWS OF OPPORTUNITY FOR THE CMST-CP}

Characterization, monitoring, and sensor technology is needed throughout the EM process. The functional needs include:

- initial location and characterization of wastes and waste sites prior to treatment;

- monitoring of waste retrieval and remediation processes;

- characterization and monitoring of waste treatment processes, products, and effluents; and

- site closure and long-term compliance monitoring.

The priorities and schedules for CMST development and implementation must conform to the directions and needs specified by the Focus Areas.

\section{ACCOMPLISHMENTS}

The CMST-CP currently supports technology development projects in all five Focus Areas. The CMST need statements in the solicitations for ROA and SBIR grant applications were developed by CMST-CP team members who worked closely with representatives of the Focus Area Management Teams and other customer representatives to discern and describe the Focus Area needs. The needs statements were subsequently reviewed and validated by the STCGs and DOE authorities.

Representatives from all five Focus Areas were invited to participate in the CMST-CP Program Meeting. Activities included their presentations on CMST needs, principal investigator (PI) presentations, and a panel session on plans for technology transfer and commercialization.

The CMST-CP conducted expert technical and customer review of all FY94 CMST-CP projects. It evaluated 165 technical task plans (TTPs) proposed for funding in FY95. Each was assigned for review by three persons from one of six Technical Focus Groups comprising 28 technical experts and Focus Area representatives. Forty TTPs were also sent to other EM-50 Programs. Evaluation information was transmitted to the PIs through the Technical Program Officers (TPOs) and Technical Program Managers (TPMs).

CMST-CP staff participated in the expert technical evaluation of 53 CMST proposals received in response to the ROA solicitation entitled, "Applied Research and Development of Technologies for Environmental Restoration and Waste Management." 
CMST-CP staff also coordinated the review of 115 SBIR grant applications received in response to the FY94 solicitation topic entitled, "Expedited Site Characterization." In addition, they either provided or arranged for expert technical review for numerous Phase I ROA and SBIR reports and Phase II extension proposals.

The CMST-CP sponsored Expedited Site Characterization at an industrial site, the DOE Pantex site, and the St. Louis Airport site.

CMST-CP personnel participated in:

- Characterization Technical Support Group or Program Review activities for all of the former EM-50 Integrated Demonstrations;

- Program Review for the former In Situ Remediation Integrated Program;

- Characterization Architecture Group of the Hanford TWRS activity; and

- EM-40 Steering Group in support of Technology Information Exchange Workshop sessions on Expedited Site Characterization, DNAPL Characterization, and Treatment of Secondary Waste.

The CMST Progress Reports, monthly compilations of technical progress reports for all CMST-CP projects, have been distributed since November 1993. With the cooperation and assistance of METC personnel, these compilations have also included progress reports for CMST projects funded through the PRDA and ROA activities since October 1994. This is part of continuing efforts to disseminate information on CMST development activities to potential customers.

\section{TECHNOLOGY TRANSFER/COLLABORATION}

CMST-CP team members consistently attempt to identify and promote adoption of applicable existing and new CMST from all sources and promote communication among potential CMST customers and technology providers, whether or not the latter are funded by the CMST-CP.

The CMST-CP fosters technology transfer and commercialization of the technologies it sponsors. The PI for each project develops and implements a technology commercialization action plan. The Office of Technology Integration within OTD helps support the development of these plans and is supporting market studies for 10 selected technologies in FY95.

The CMST-CP provided exhibits for several national and regional meetings:

- Technology Information Exchange Workshop

- Spectrum '94

- Hanford Regional Environmental Business Interchanges in Portland, Oregon and Hanford, Washington

- Hanford Summit II Conference.

Arrangements were also made for the PIs of four CMST-CP projects to champion their technologies to more than 100 managers from companies participating in the November 1994 Sponsor Meeting of the Center for Process Analytical Chemistry.

Recent publications and topical reports include the following:

- M.C. Edelson, et al., "Characterization, Monitoring, and Sensor Technology Integrated Program (CMST-IP)," Proceedings of the International Topical Meeting on Nuclear and Hazardous Waste Management, Spectrum '94, Atlanta, GA, p. 299, 1994.

- C.B. Purdy, et al., "Development of Site Characterization Technologies within the Characterization, Monitoring, and Sensor Technology Integrated Program (CMST-IP)," ibid., p. 433, 1994. 
- P. W. Wang et al, "Characterization, Monitoring, and Sensor Technology Integrated Program (CMSTIP): An Overview of Emerging Technologies in Site/Waste Characterization and Waste Treatment Monitoring," Proceedings of the Symposium on Waste Management '94, Tucson, AZ, p. 1085, 1994.

- B.J. Albers and C.B. Purdy, "Spatial Data Technologies for Environmental Applications within the Department of Energy," Earth Observation Magazine, pp. 18-24, December 1994.

\section{FUTURE DIRECTIONS}

Knowledge and understanding of the CMST needs of the Focus Areas is critical for success. Hence, the CMST-CP will continue to concentrate on establishing excellent communication with the Site Technology Coordination Groups and the Focus Area Management and Implementation Teams. Future activities will be influenced more by the specific needs of site technology customers and stakeholders, and less by the interests and capabilities of technology developers.

The chief rechnical responsibility of the CMST-CP will continue to be development and implementation of new and emerging CMST applicable to EM needs. Near-term thrusts will include:

- Promotion of Expedited Site Characterization including multidisciplinary ESC teams in the private sector.

- Promotion of the identification, evaluation, and application of adaptive sampling and analysis statistics and data visualization and interpretation tools.

- Development of more effective teaming with DoD, EPA, and other government agencies with interests in CMST.

- Collection and rapid dissemination of technology descriptions and performance information for emerging CMST applicable to customer needs.

In accordance with the best available information from the Focus Area Management and Implementation Teams and the STCGs, the CMST-CP will attempt to deliver required new technologies and technology improvements, when needed, through coordinated and focused development efforts in DOE and other federal laboratories, the private sector, and universities. The goal is rapid development and effective application of CMST needed for the EM mission.

The remainder of this document contains brief descriptions of CMST-CP projects funded in FY95. Please see the Morgantown Energy Technology Center Technology Summary and the Innovative Investment Area (IIA) Technology Summary for information on other EM-50 projects related to Characterization, Monitoring, and Sensor Technologies. Detailed information on any project can be obtained by contacting the PI. Contact information is provided in each project summary.

For further information, please contact:

Dr. Caroline Purdy

Program Manager, CMST-CP

U. S. Department of Energy

Office of Technology Development

Cloverleaf Building

19901 Germantown Road

Germantown, MD 20874-1290

(301) $903-7672$

\author{
Al Tardiff \\ Project Manager \\ U. S. Department of Energy \\ Office of Technology Development \\ Cloverleaf Building \\ 19901 Germantown Road \\ Germantown, MD 20874-1290 \\ (301) 903-7670
}


Eric Lightner

Project Manager

U. S. Department of Energy

Office of Technology Development

Cloverleaf Building

19901 Germantown Road

Germantown, MD 20874-1290

(301) 903-7935
Paul Wang

Technical Program Coordinator

Ames Laboratory

106 Spedding Hall

Iowa State University

Ames, IA 50011-3020

(515) 294-6773

xvii 


\section{CMST-CP PROJeCtS}

FOR THE

\section{Contaminant Plume CONTAINMENT AND}

Remediation Focus Area 


\subsection{SAVANNAH RIVER CHARACTERIZATION}

\section{TASK DESCRIPTION}

The major objective of the Savannah River Site (SRS) demonstration was to demonstrate and evaluate improved environmental restoration systems for the cleanup of volatile organic contaminants in soil and water. The primary purpose of characterization activities performed as part of this task was to document the physical, chemical, and biological characteristics of the remediation test sites. At each site in which a remediation system was demonstrated, appropriate geological, chemical, hydrological, and microbiological parameters were measured to evaluate the remediation systems. Preand post-test field characterization activities have been completed for demonstrations of in situ air stripping using horizontal wells, bioremediation using horizontal wells to deliver nutrients necessary for biodegradation, and in situ radio and ohmic heating of contaminated clay units.

Additional activities include analysis and documentation of field results of innovative technologies for environmental characterization and monitoring that were funded as part of the earlier demonstration of OTD technologies at Savannah River. This task includes implementation of the ion trap mass spectrometer in support of environmental restoration activities. This instrument, developed by Oak Ridge National Laboratory (ORNL), is being used for screening of quarterly groundwater samples required as part of a regulatory monitoring program. If the program is fully implemented, uncontaminated samples will not be sent off-site for analysis. This activity will reduce analytical costs for the environmental monitoring program.

Activities during FY95 will focus on deployment of the data fusion workstation for environmental waste site characterization and remediation developed by Coleman Research Corporation (CRC). This data fusion work station will combine several different types of environmental data, specifically geophysical, hydrologic, and chemical data, into 3-D models for interpretation and visualization. Data fusion tasks in FY95 are focused on development of a geophysical data fusion module and a steady-state geohydrology fusion module.

Specific tasks funded under this TTP include: (1) field and technical support for phase III geophysical data collection and interpretation, (2) testing with data previously collected from the Old Burial Ground data of the Paragon geohydrologic at SRS module, (3) evaluation of the Waterways Experiment Station ground water modeling system (GMS) software, (4) comparison of the two modeling packages [Coleman Research's Data Fusion Workstation (DFW) and Waterways Experiment Station (WES) GMS], and (5) general technical support for both the PARAGON geohydrological and geophysical data fusion programs.

\section{TECHNOLOGY NEEDS}

A major task confronting DOE is management of wastes at facilities. Previous waste disposal practices, once considered state-of-the art, have proven inadequate and have resulted in significant soil and ground water contamination. One of the most common environmental problems is contamination of soils and ground water with volatile chemical solvents that were used as degreasers and cleaning agents by industry and government facilities. DOE is committed to cleaning up contaminated sites to levels acceptable to state and federal regulators. Present technologies may not be capable of accomplishing these tasks within a reasonable period of time. A primary goal of OTD is to develop innovative solutions to environmental restoration problems. The first integrated demonstration of innovative technologies for cleanup of soils and sediments contaminated with solvents took place at SRS, where solvents (TCE and PCE) leaked from an underground process sewer line and contaminated underlying sediments and ground water. 


\section{ACCOMPLISHMENTS}

\section{Characterization of Demonstration Test Sites}

Pretest characterization of the site where horizontal wells were used for the in situ air stripping demonstration was completed in 1990. Baseline characterization included sediment coring, depth-discrete sampling of both sediments and ground water, geophysical logging of the boreholes, cone penetrometer [U.S. Army Corps of Engineers Site Characterization and Analysis Penetrometer (SCAPS)], and installation of a variety of monitoring wells below the water table and in the vadose zone. The characterization reports for the in situ air stripping demonstration include images of the distribution of clay sediments, pre- and post-test distribution of TCE and PCE, estimation of contaminant inventories, results of geotechnical testing of undisturbed sediment cores, detailed cross-sections of the demonstration site, and results of aquifer pumping tests conducted at the site. The post-test in situ air stripping report serves as the pretest characterization report for the in situ bioremediation demonstration site.

The characterization report for the radio frequency heating demonstration documents pretest and posttest data collected in support of the demonstration. The data presented and discussed in this report present a general description of the site, including piezometer and sensor installation, stratigraphy, lithology, and detailed geologic cross sections of the study site. It also includes tabulations of pre-test moisture and volatile organic compound (VOC) content of the sediments, sampling and analysis procedures for sediment samples, microbial abundance and diversity, and images of pretest and post test distribution of contaminants and volumetric calculations.

\section{Demonstration of Innovative Characterization and Monitoring Technologies}

Innovative characterization technologies successfully demonstrated include depth-discrete sampling and sensing of ground water, soil gas, and sediments, three-dimensional data imaging, video animation of contaminant plumes, innovative cone penetrometer applications, and high-resolution Pand S-wave seismic survey.

One of the systems installed for depth-discrete sampling was an in situ gas sampling system (SEAMIST ${ }^{\mathrm{TM}}$ ). The system can be used for initial characterization of contaminant plumes, characterization of intrinsic permeability, and monitoring of contaminant migration, restoration activities, and tracer tests. Three SEAMIST TM liners for depthdiscrete sampling of the vadose zone were used to monitor the helium tracer test performed at the site. The tracer test was successfully completed, and the results were used to estimate consumption of methane in the subsurface during the bioremediation demonstration.

An ion trap mass spectrometer developed by ORNL was transferred to Savannah River Site for use at the Demonstration Site and at ER waste sites. Preliminary activities focused on calibration and optimization of the instrument for detection of TCE and PCE in ground water at the various DOE demonstration sites. Subsequent efforts resulted in development of appropriate analysis modules for data reduction. Duplicate samples were collected during biweekly ground water sampling and were analyzed by both gas chromatography/mass spectrometry (GC-ECD) and ion trap mass spectrometry (ITMS). A report on the use of ITMS for analysis of ground water from thoroughly characterized wells has been completed. Analytical results obtained with the ITMS are comparable with results obtained using baseline methods. The goal of this task is to validate the use of ITMS as a screening device for groundwater samples from thoroughly characterized wells.

A presentation was made in January 1994 to DOESR, South Carolina Department of Health and Environmental Control, and EPA Region IV. The presentation was well-received and discussions focused on the use of ITMS for sample minimization as well as use in future remedial investigations. If regulatory approval is obtained, the ITMS will be used instead of off-site laboratories for a selected suite of wells. This activity should result in a significant reduction in the number of samples sent off-site to commercial laboratories for analysis. 
An overview report on those monitoring technologies demonstrated was completed in December 1993. The report summarizes the results of field demonstrations of innovative characterization and monitoring technologies funded as part of the demonstration. Technologies for measurement of physical parameters include the in situ permeable flow sensors and the colloidal borescope for measurement of ground water flow and seismic, electri$\mathrm{cal}$, and electromagnetic tomography for three dimensional imaging of physical changes induced by the remedial process. New technologies for depth-discrete sampling include the passive multilayer ground water sampler and the arrayed vadose zone sampler. Innovative technologies for chemical analysis include the fiber-optic TCE sensor for in situ detection of TCE and chloroform; both the portable acoustic wave sensor and the HaloSnif for continuous, on-line measurement of total chlorinated compounds over a wide dynamic range; and the direct sampling ion trap mass spectrometer for compound-specific determination of organic analytes at concentrations down to parts-per-billion (ppb) levels.

Comprehensive data evaluation and presentation is an essential component of cost-effective environmental characterization and remediation. Throughout the characterization and monitoring activities completed as part of the demonstration, new computational techniques for digital imaging and video animation of environmental data have been developed and utilized. See Figure 1.1.

This work has resulted in a new ability to communicate complex environmental issues and concepts in a format easily understood by individuals with a diverse range of technical abilities. These activities were synthesized in a videotape entitled, "New Technologies for Clean Up of Solvents - The SRS Integrated Demonstration," completed in January 1994. This videotape visually summarizes remedial

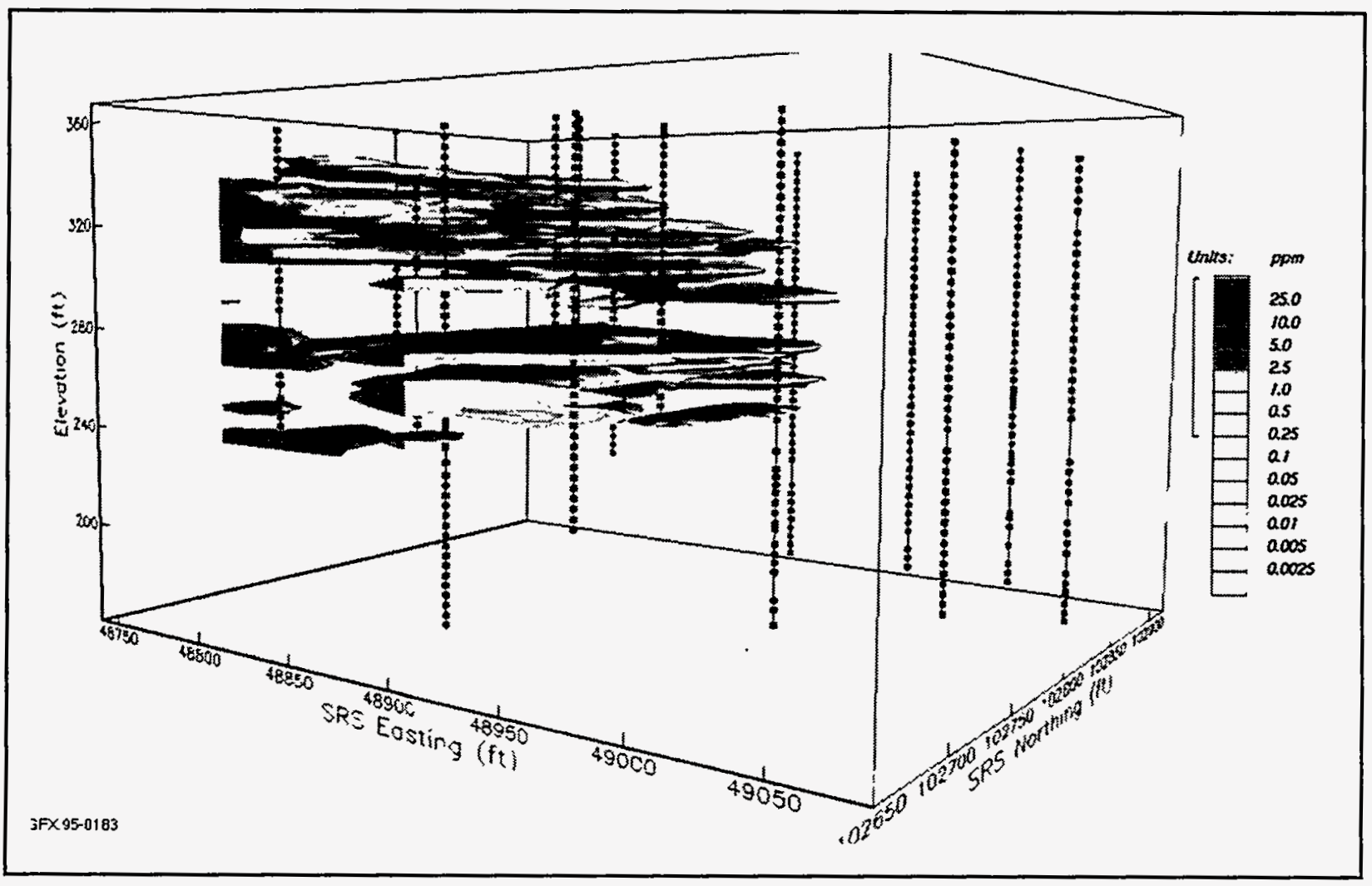

Figure 1.1. Three-dimensional Image of Subsurface Contaminant Plume. 
activities completed during the in situ air stripping and bioremediation demonstrations.

The characterization report for the ohmic heating demonstration documents pretest and post-test data collected in support of the field demonstration at SRS of ohmic hearing by researchers from Pacific Northwest Laboratory (PNL). The data presented and discussed in the report include a general description of the site, including piezometer, electrode, and monitoring sensor installation; stratigraphy; detailed geologic cross sections of the study site; tabulation of moisture content and VOC content of the sediments; and volumetric changes in contaminant distribution.

Field and technical support for deployment of the data fusion workstation for environmental waste site characterization and remediation include assistance with site selection for the surface and borehole seismic and radar surveys in support of the Data Fusion Program. Two field sites in the A- and Mareas of the SRS were selected for the field study. The technical focus of the work is to evaluate the continuity of the Ellenton Clay, which is a major aquitard in this area. This work is in direct support of the SRS Environmental Restoration Program need. Time domain electrical resistivity and compressional and shear wave seismic data were collected along both traverses.

\section{BENEFITS}

Innovative site characterization and monitoring technologies are integral to the objective of reducing environmental restoration costs and long-term, postclosure monitoring. Baseline methods for site characterization and monitoring tend to be costly, time-consuming, overly invasive, or imprecise. DOE has focused on demonstrating site characterization, sampling, and monitoring technologies that have the capability to provide significant technological advances. Better technologies can be quicker (e.g., field measurement of contaminants), or cheaper (e.g., headspace analysis of sediment samples). In many cases, these new technologies may provide new kinds of information (e.g., in situ groundwater flow direction and velocity), or may provide a better definition of the subsurface conditions due to the collection of depth-discrete informarion. The improved data can be used to construct a more accurate model of the subsurface. Better characterization and monitoring systems should provide a cost payback many times over because they allow for maximum optimization of remedial systems.

\section{COLLABORATION/TECHNOLOGY TRANSFER}

During FY95, the tasks will be in direct support of deployment of the Data Fusion Workstation developed by Coleman Research Corporation. The characterization activities previously performed as part of this technical task plan were in direct support of monitoring and remediation activities funded to principal investigators located at other DOE sites including PNL, LLNL, SNL, and LANL.

The demonstrations have provided timely transfer of new technologies to environmental restoration groups at SRS for use in full-scale remediation projects. The technologies demonstrated for sampling and analysis of sediment cores and depthdiscrete water sampling were transferred to SRS-ER and used in a number of waste site investigations. The support for deployment of the ITMS is in direct support of environmental activities at SRS. Commercialization plans for the ITMS will be prepared by the developers of the ITMS at ORNL. A patent application for the depth-discrete ground water sampler, Cone Sipper ${ }^{\mathrm{TM}}$, is pending. 
For further information, please contact:

C. A. Eddy-Dilek

Principal Investigator

Westinghouse Savannah River Company

P.O. Box 616

Aiken, SC 29802

(803) $725-2418$

\section{J. Rossabi}

Principal Investigator

Westinghouse Savannah River Company P.O. Box 616

Aiken, SC 29802

(803) $725-5220$

\section{J. L. Steele}

Technical Program Manager

Westinghouse Savannah River Company

P.O. Box 616

Aiken, SC 29802

(803) $725-1830$

Dr. Caroline Purdy

Program Manager, CMST-CP

U. S. Department of Energy

Cloverleaf Building

19901 Germantown Road

Germantown, MD 20874-1290

(301) $903-7672$

\section{BIBLIOGRAPHY OF KEY PUBLICATIONS}

An interactive digital database of the technical publications completed as part of the demonstration is available from C. A. Eddy-Dilek. For each of the technical reports, a Technology Data File (TDF) was completed that indexes the documents by subject, author, organization, TDF number, and key words and contains the abstract and bibliographic citation for the document. The summary report of demonstrated technologies is listed below.

Rossabi, J., et al., Demonstration of Innovative Monitoring Technologies at the Savannah River Integrated Demonstration Site. WSRC-TR-93-671, Westinghouse Savannah River Company, Aiken, SC, 1993. 


\subsection{EXPEDITED SITE CHARACTERIZATION APPLICATION TO FEDERAL FACILITIES}

\section{TASK DESCRIPTION}

A technically innovative approach to environmental site characterization has been developed that integrates all appropriate scientific disciplines to provide a more cost- and time-efficient answer for DOE's site characterization needs. The Expedited Site Characterization (ESC) process, developed by Argonne National Laboratory (ANL), emphasizes the use of a variety of non-intrusive or minimally intrusive technologies (surface geophysics, cone penetrometer, HydroPunch sampling, vegetation sampling, etc.) to optimize sampling locations and minimize monitoring well installation. Technologies are selected on the basis of site-specific problems and requirements. The results of these technologies are often analyzed, interpreted, and integrated on site by a full team of scientists through the use of a dynamic work plan. Decisions on sampling and analysis requirements are made daily and used for planning the next day's program. This approach has cut the time necessary for full site characterization from programs lasting many months or years, to a matter of a few weeks. See Figure 1.2a.

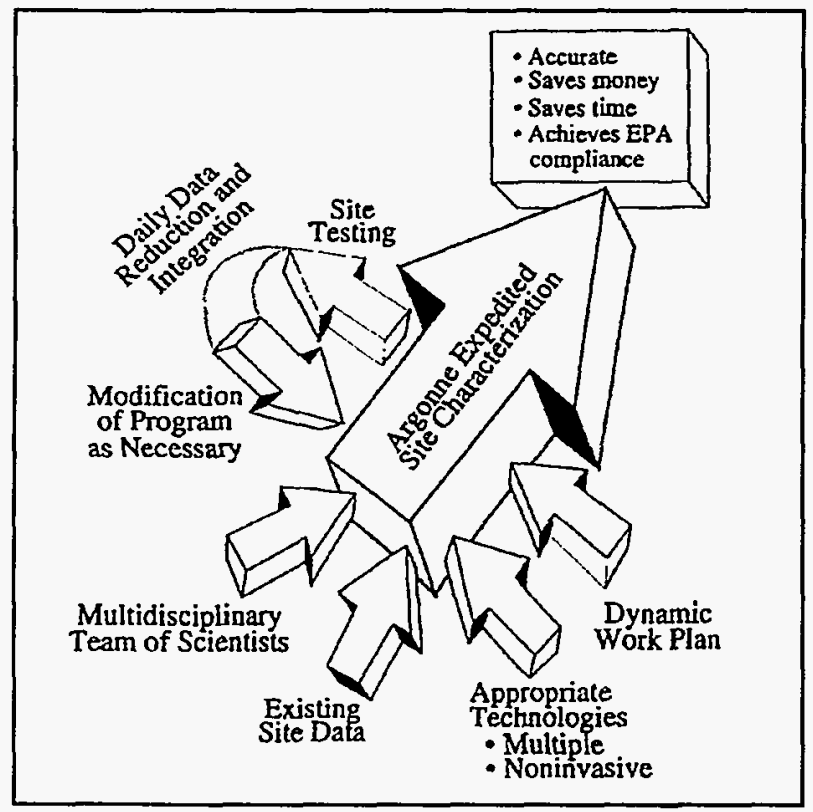

Figure 1.2a. Expedited Site Characterization.

\section{TECHNOLOGY NEEDS}

With the increased pressure on federal agencies and regulators to accelerate the remedial activities and final cleanup of federal facilities across the nation, there is a growing need to broaden the approach to characterize entire facilities, rather than proceeding one-by-one through the evaluation of the thousands of smaller CERCLA sites or RCRA-defined waste units. In response, DOE has identified the need for new site characterization technology and approaches as one of its highest priorities. The objective of the ESC process is to provide a more efficient, scientific, innovative, and integrated approach to solving DOE's site characterization needs, and ultimately to clean up sites and facilities across the DOE Complex.

\section{ACCOMPLISHMENTS}

During FY93, a demonstration of the ESC process was performed by ANL at a former facility site of the Commodity Credit Corporation (CCC), U. S. Department of Agriculture (USDA), in York, Nebraska. Prior to field demonstration of the methodology, an ESC work plan specific to the chosen site was developed. The program emphasized the maximum use of non-intrusive technologies, field analytical procedures, and daily integration of data via various computer programs. Private industry and universities participated in the demonstration as needed, providing certain services, such as cone penetrometer, auger drilling, and field analytic capabilities. More than 100 representatives from private industry, DOE, and other government agencies attended the field demonstration. The field demonstration lasted approximately three weeks and included three separate demonstration sessions.

During FY94, the Pantex Plant near Amarillo, Texas was chosen for a DOE pilot program. A preliminary background study suggested that characterization of the Zone 12 perched aquifer at Pantex would be 
a suitable test of Argonne's ESC process. Argonne reviewed the previous work done at the Pantex site, and developed a Dynamic Work Plan for characterization of the Pantex Zone 12 perched aquifer. Phase I of Argonne's ESC activities at Pantex included ground water sampling of the perched aquifer, reprocessing and reinterpretation of existing seismic data, and water level monitoring. After the evaluation and integration of the Phase I results, Argonne formulated a preliminary hydrogeologic model and finalized plans for the Phase II field program. Field activities include drilling and coring through the perched aquifer, borehole geophysics, soil sampling utilizing DOE's cone penetrometer vehicle, and further ground water sampling and analysis. This work is aimed at completing characterization of the perched aquifer at Pantex in FY95.

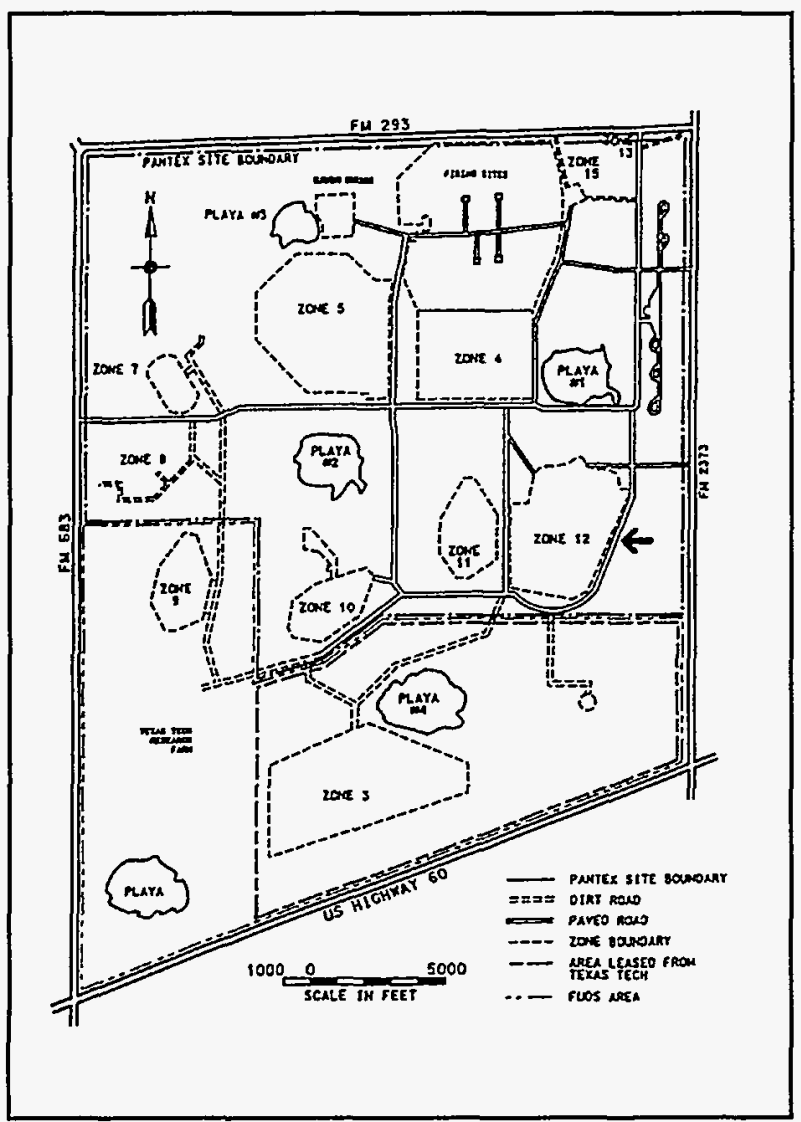

Figure 1.2b. A General Map of the Pantex Site Showing the Locations of Current Work Zones.

\section{BENEFITS}

Full-scale demonstrations of ESC have been conducted at three Bureau of Land Management (Department of Interior) sites located in New Mexico and multiple Commodity Credit Corporation (Department of Agriculture) sites located in Nebraska and Kansas. The experience in the CCC/USDA program has shown that the costs of ESC field programs are 10 percent to 20 percent of traditional approaches. In addition, the time required within the CCC/USDA program is as little as 3 percent of that needed in traditional approaches involving random sampling and multiple wells.

\section{COLLABORATION/TECHNOLOGY TRANSFER}

Argonne's ESC process is currently being transferred to DOE sites for application in the ongoing environmental restoration programs. During the first phase of the transfer process, the pilot program has been completed at the Pantex site in Amarillo, Texas.

Discussions are being held between Argonne and DOE's Amarillo office to consider ways in which Argonne can continue to provide support for the Pantex environmental restoration program. The proposed technology transfer activities include ongoing support of the DOE's Amarillo office and its contractors. Argonne's role will be to provide technical expertise and guidance in the application and implementation of Argonne's ESC process to characterize the hydrogeology of the Pantex site.

For further information, please contact:

Dr. Jacqueline C. Burton

Principal Investigator

Argonne National Laboratory

9700 S. Cass Avenue

Argonne, IL 60439-4843

(708) 252-8795 
James Helt

Technical Program Manager

Argonne National Laboratory

9700 S. Cass Avenue

Argonne, IL 60439-4843

(708) 252-7335

\section{Dr. Caroline Purdy}

Program Manager, CMST-CP

U.S. Department of Energy

Cloverleaf Building

19901 Germantown Road

Germantown, MD 20874-1290

(301) $903-7672$
Wilder, William L., "Dynamic Site Characterization: A General Approach for Conducting Field Investigations at Potential Hazardous Waste Sites," Workbook for Hydrocarbon Contaminated Soils and Groundwater: Analysis, Environmental Fate, Assessment, and Remediation, Houston, TX: Association for the Environmental Health of Soils. (Available from HAZWRAP, Oak Ridge National Laboratory, P. O. Box 2003, Oak Ridge, TN 37831-7606), 1993.

TTP Number: $\mathrm{CH} 231004$

\section{BIBLIOGRAPHY OF KEY PUBLICATIONS}

Burton, J. C., "Prioritization to Limit Sampling and Drilling in Site Investigations," Proceedings of Federal Environmental Restoration Conference and Exhibition, pp. 242-251, Vienna, VA, April 15-17, 1992 , CONF-9204110, Argonne National Laboratory Report No. ANL/CP-74721, Hazardous Materials Control Resources Institute. (NTIS Order No. DE922010513), 1992. 


\subsection{AMES LABORATORY'S EXPEDITED SITE CHARACTERIZATION DEMONSTRATIONS}

\section{TASK DESCRIPTION}

This project is promoting the adoption of the Expedited Site Characterization (ESC) methodology and innovative technologies, so that the costs and time associated with DOE's site characterization program can be dramatically reduced.

The ESC methodology, pioneered for DOE by Argonne National Laboratory, incorporates on-site decision-making technologies that permit site characterizations to be completed in one continuous phase. It has demonstrated that the characterization phase can be streamlined without compromising data quality. By using both on-site analytical and multiple hydrogeologic technologies, the need to send nearly all samples off-site and the need to perform massive subsurface sampling in the absence of local hydrogeologic information is removed. By providing on-site decision-making capability, (e.g., a dynamic work plan) ESC can significantly reduce the probability of having to return to the site to fill data gaps. As a result, the current multiphase time sequence of data acquisition, consisting of sample, analyze, plan, and sample, becomes compressed into a single real-time phase.

\section{TECHNOLOGY NEEDS}

Because technology gaps exist, even within the context of ESC, the scope of this project will encompass both state-of-the-practice technologies (SOPTs) as well as innovative characterization technologies (ITs). Nontechnical as well as technical barriers can be simultaneously identified by fielding ITs at actual sites. Of prime importance is an opportunity for involvement of regulators in the evaluation and fielding of these technologies. The point of the Ames ESC is not to obtain prior approval of an IT, but to obtain the commitment on the part of the regulator to give serious critical review of the necessary elements required for approval at future DOE or non-DOE sites. Side-by-side comparison of ITs with SOPTs, documented standard operating procedures, and confirmatory off-site analysis are some of the necessary criteria for encouraging regulatory acceptance of ITs.

The adoption of ESC and its technologies requires not only field demonstrations but widespread dissemination of the ESC story. As in FY94, it will be an integral part of the FY95 project to hold stakeholder tours at the selected site. A new task for FY95 is the production of a variety of ESC high-impact information packages targeting the environmental contractor, site manager, and regulatory communities. This task is designed to reach a much larger audience than can be accommodated just at the site tour level.

\section{ACCOMPLISHMENTS}

- Two ESC demonstrations were conducted in FY94 in which both SOPT and IT's were fielded.

- Nearly all technologies were contracted from an international suite of private sector, university, and DOE entities.

- Stakeholders participated in several daylong programs that included ESC presentations, panel discussions, technical overviews and exhibits, and on-site tours for a closeup view of the technologies in action.

- There was unanimous assent from the regulators from U.S. EPA Region VII, and the Iowa and Missouri Departments of Natural Resources to the practice of early, proactive regulator involvement.

- The evaluation of five soil extraction schemes for PAHs at Marshalltown site, MT, based on field-split samples, showed that the microwave and microscale extractions exhibited higher extraction percent- 
ages than either the sonication or supercritical fluid extractions, with thermal desorption somewhat lower than the rest.

- The power of the SCAPS Cone Penetrometer Truck (CPT) Laser-induced fluorescence (LIF) probe for PAH plume analysis was amply demonstrated at MT by providing continuous logs across three stratigraphic layers in both the vadose and saturated zones.

- A new Geoprobe conductivity probe provided detailed stratigraphic logs comparable to those from the CPT. Its ability to detect free product was confirmed.

- The three existing immunoassay (IMA) kits were all successful in delineating the PAH plume at the Marshalltown (MT) Iowa site.

- An innovative chemiluminescence kit at MT had somewhat slower analysis speed compared to that of the IMA, and also lacked chemical specificity of the passive soil gas technique.

\section{BENEFITS}

The benefits of this project can be divided into two categories, the ESC methodology development and the demonstration of the innovative field analytical and geotechnical technologies. The importance of early and continuous involvement of the regulators and the utility of an on-site mobile command center to enhance the ESC process were demonstrated at two FY94 sites. In FY95, attempts will be made to show whether a different management strategy can be used to execute ESC. Instead of permanent project personnel as the source of ESC management staff, task management responsibilities (e. g., analytical, geophysical, regulatory documentation, and field services) will be tasked to private-sector consultants and components of the DOE site management team in a manner consistent with ESC principles and standard operating procedures of the environmental services marketplace. Ames ESC project personnel will maintain the responsibility of overall program and project management. The benefits are improved ability to transfer this methodology to the private sector and proactive involvement of the ER site team. When this mode can be made to work, the ESC methodology will be much easier to bring to other DOE entities. By integrating the innovative ESC rechnologies into an actual ESC project, it is expected that a more realistic evaluation of these technologies will be possible. Part of this benefit accrues from the active role of the regulator in the evaluation of these technologies. Additional benefit comes from exposure of these technologies to site-specific stakeholders, as well as those who cannot attend the demonstration but who will be reached by the information packages.

This systematic approach, involving demonstrating multiple ESC technologies to those who are important for their adoption, all at one site, is very costeffective.

\section{COLLABORATION/TECHNOLOGY TRANSFER}

In addition to extensive efforts in FY94 to promote ESC methodology and innovative technologies (e. g., by on-site tours), a new effort will be launched in FY95. The limitation of our previous efforts was that they were confined to those 300 stakeholders at our two demonstrations. A commercialization plan focused on a variety of information products about ESC and its successes has been developed. It will be implemented in FY95 so that our reach will be considerably extended. Private sector partnering is in progress to produce a professional, high-impact video for national distribution to targeted customers, (e.g., state and federal regulators, DOE site managers, technology providers, and environmental contractors). Extensive video footage from our two FY94 sites is available for this effort. 
For further information, please contact:

Albert J. Bevolo

Principal Investigator

Ames Laboratory

Iowa State University

125 S. 3rd Street

Ames, IA 50010

(515) 294-5414

Jim Corones

Technical Program Manager

Ames Laboratory

Iowa State University

329 Wilhelm Hall

Ames, IA 50010

(515) 294-9636

\section{Steve Webster}

Technical Program Officer

U.S. Department of Energy

Chicago Operations Office

9800 S. Cass Avenue

Argonne, IL 60439

(708) 252-2822

Dr. Caroline Purdy

Program Manager, CMST-CP

U.S. Department of Energy

Cloverleaf Building

19901 Germantown Road

Germantown, MD 20874-1290

(301) 903-7672

\section{BIBLIOGRAPHY OF KEY PUBLICATIONS}

None at this time. 


\subsection{TIME DOMAIN REFLECTOMETRY AND FIBER-OPTIC PROBES FOR THE CONE PENETROMETER}

\section{TASK DESCRIPTION:}

Sandia National Laboratory (SNL) is fabricating, testing, and evaluating a new cone penetrometer application for characterizing hydrogeologic parameters and subsurface contaminant concentrations with chemical-specific, fiber-optic probes and a Time Domain Reflectometry (TDR) sensor. This development work should help meet DOE needs for characterization and monitoring technologies. Since this technology is based on a cone penetrometer system, its deployment is minimally intrusive. The technology therefore supplies needed subsurface information without waste products. The data collected with this system will meet critical needs for performing fate and transport modeling, as well as risk assessment analyses.

The basic work to be accomplished under this task plan is as follows:
- Complete testing of the fiber-optic probe for pore pressure determinations in unsaturated porous media.

- Design and fabricate a TDR probe to quantify soil-moisture content for downhole cone penetrometer deployment.

- Evaluate and test chemical-specific probes (e.g., fiber-optic) for possible inclusion in the cone penetrometer tip. This would include the evaluation of chemical-specific probes that might have adequate sensitivities for waste site characterization and/or monitoring purposes.

- Design and fabricate a cone penetrometer tip to accommodate the probes. See Figure 1.4 .

- Perform an in situ test of the new cone tip to evaluate its performance.

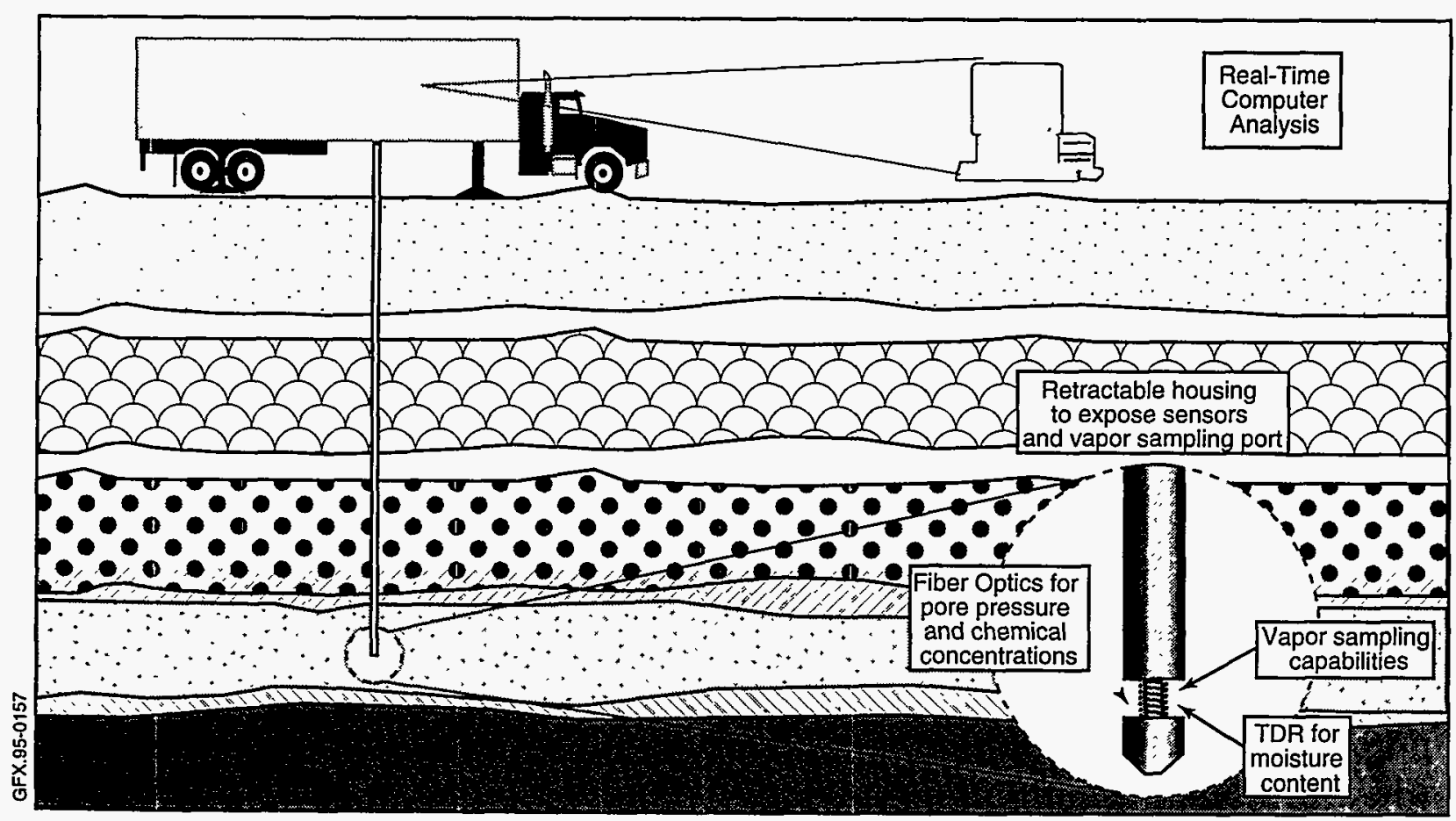

Figure 1.4. Cone Penetrometer Tip for Hydrologic Investigations. 


\section{TECHNOLOGY NEEDS}

This technology will supply needed information to waste site investigators on hydrogeologic parameters and chemical-specific concentrations in the subsurface. Moisture content and pore pressure measurements in unsaturated soils are critical parameters for inclusion in fate and transport modeling, and also in risk assessment evaluations. Whether a waste site poses a possible threat to human health and the environment is the ultimate driver for acceprability of a site for a remedial alternative. Risk assessment methods help to quantify whether a site poses a threat. Critical data needs for risk assessment are therefore critical characterization needs.

The nature and extent of contamination is also very important in the risk assessment analysis. This new cone penetrometer system will meet many critical needs of these modeling efforts.

\section{ACCOMPLISHMENTS}

- The fiber-optic probe for pore pressure measurements in unsaturated soils was optimized for polymer composition, fabricated, and tested.

- The TDR moisture content probe was prototyped and tested. An off-shoot technology was derived as a result of the prototyping: a down hole logging configuration for the TDR moisture sensor.

- Commercial chemical sensors were surveyed, and no logical alternatives defined because of the need for additional development of the sensors, which would be outside the budget limitations on this contract. Candidate sensors have been defined for future work.

- The fiber-optic and TDR probes were tested during two field test activities, the first in Vermont at the Applied Research Associates, Inc. (ARA) facilities, and the second at Sandia. Results were excellent and the data are under analysis.
- A draft commercialization plan has been developed. Technical advance submissions for patenting are under development. Copyrighting of software is underway.

\section{BENEFITS}

Since this technology is based on a cone penetrometer application, the speed of collecting the data is greatly enhanced compared to conventional drilling and sampling methods. Therefore, significant cost savings result.

The hydrologic data needs within a zone of contamination are very important for the flow and transport modeling done for risk assessment. With conventional sampling methods, the hydrologic data are rarely acquired because the soil testing labs will not process contaminated soils for hydrologic parameters. Therefore, a critical data need is realized, where it was not available with conventional methods.

Investigation derived waste (IDW) is essentially zero for this cone penetrometer technology, as compared to drilling and sampling, which can generate appreciable IDW. Therefore, costs for waste disposal are significantly less.

Environmental safety and health issues are minimized using this technology because there is no direct contact with subsurface soils or IDW. Therefore, work can be done inside the cone truck in Level $\mathrm{D}$ protective gear.

\section{COLLABORATION/TECHNOLOGY}

\section{TRANSFER}

This technology should result in a number of copyrights/patents with commercialization potential. The TDR probes were developed at SNL, and the final design of the cone probe was assisted by ARA, a cone penetrometer development and service company. ARA has expressed interest in commercializing the TDR probe through a licensing venture. GEOCENTERS, Inc. has a patented, proprietary process for their fiber-optic probe. GEOCENTERS 
plans on commercializing their probe as part of their overall package of sensors. We estimate that the development of sensor packages for the cone penetrometer will greatly enhance the ability of the cone to meet waste site investigator needs in a more time efficient and less costly manner than conventional drilling and sampling. As much as 50 percent of the sampling market may be taken away from the drilling industry.

For further information, please contact:

\section{Robert Knowlton}

Principal Investigator

Sandia National Laboratory

Organization 6603, MS0715

Albuquerque, New Mexico 87185-0715

(505) 848-0425

\section{George Allen}

Technical Program Manager

Sandia National Laboratory

P.O. Box 5800

Albuquerque, NM 87815-5800

(505) 845-7015

\section{Eric Lightner}

Projects Manager, CMST-CP

U.S. Department of Energy

Cloverleaf Building

19901 Germantown Road

Germantown, MD 20874-1290

(301) 903-7935
TTP Number: AL241010

\section{BIBLIOGRAPHY OF KEY PUBLICATIONS}

Knowlton, R, J. Onsurez, S. Bayliss, and W. Strong, "Environmental Applications of Time Domain Reflectometry at Sandia National Labs," Symposium and Workshop on Time Domain Reflectometry in Environmental, Infrastructure, and Mining Applications, September 7-9, 1994, Northwestern University, Evanston, Illinois, Special Publication SP 19-94, pp. 183-192, 1994.

R. Knowlton, L. Everett, S. Bayliss, S. Cullen, J. Kramer, J. Onsurez, E. Rogoff, and W. Strong, "Environmental Monitoring Techniques for Characterization and Post-Closure Monitoring Needs," First Hawaii National Technologies Conference: Remediation and Environmental Monitoring, September 12-16, Honolulu, Oahu, Hawaii, 1994. 


\section{TASK DESCRIPTION}

DOE is seeking new technologies to assist in its efforts to characterize and remediate hazardous waste sites under department control. It is DOE's goal to use technologies that will reduce costs and improve quality and timeliness of both site characterization and remediation. To help meet this goal, DOE has purchased a cone penetrometer truck to be used to conduct research and investigations at various sites throughout the country. This system is referred to as a Site Characterization and Analysis Penetrometer System (SCAPS). See Figure 1.5. tenance of the cone penetrometer, as well as for managing the execution of the subcontract. Technical oversight of the subcontractor will also be provided.

Argonne will be responsible for technical evaluations of all sensors, samplers, and in situ analyses developed. The rechnology will be evaluated by comparison of the performance to the functional and operating requirements of the potential users of the technology. Once selected, the sensor or sampler device will be interfaced to the cone penetrometer.

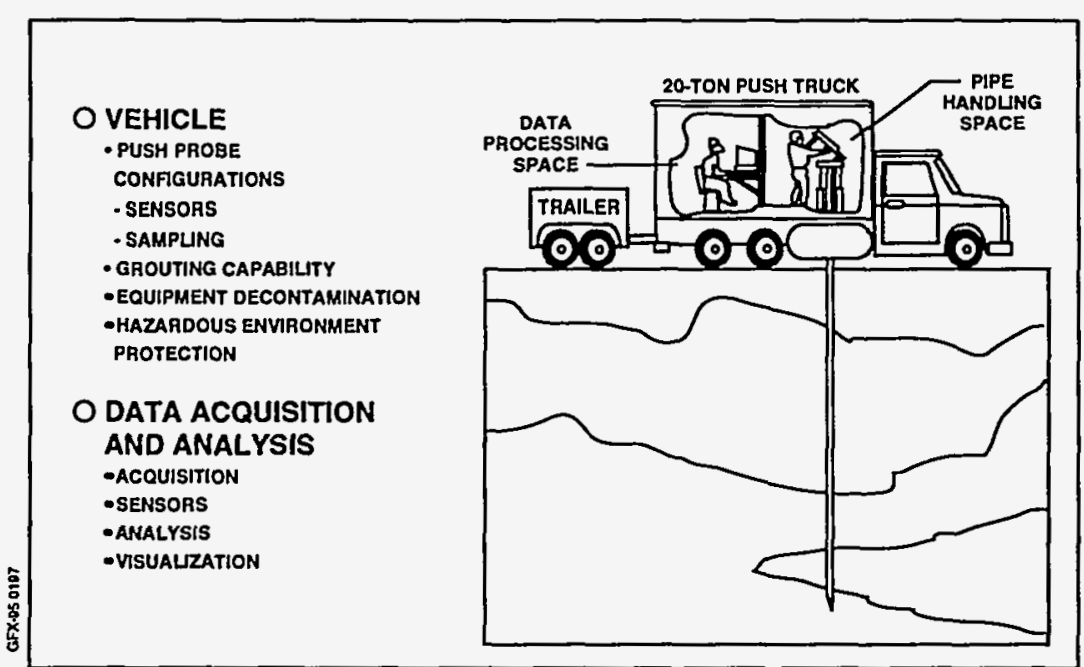

Figure 1.5. Site Characterization and Analysis Penetrometer System Description.

DOE's major objective is to operate the SCAPS for evaluation and for further technology improvements to both the vehicle and its components. In addition, it is also DOE's objective to ensure that this technology is then transferred to industry, thus providing a rapid and cost-effective tool for implementation in site characterization investigations at hazardous waste sites throughout the country.

This program will assist $D O E$ in the integration of the SCAPS operations with other facets of its EM technology development program. Argonne National Laboratory (ANL) will be responsible for negotiating a contract with a company for the operation and main-

\section{TECHNOLOGY NEEDS}

The SCAPS, and technology associated with its operation, is expected to provide an improved, rapid, and cost-effective tool to be used in site characterization investigations at hazardous waste sites. The technique will allow in situ measurements of geophysical and physical properties of soils and stratigraphic units, as well as the determination of the presence of contaminants at a site without the extensive use of drilling and monitoring well installation. The SCAPS will also be used to collect soil and water data that will provide better definition of the zones of contamination, enabling more accurate placement of remediation systems and monitoring wells.

\section{ACCOMPLISHMENTS}

- Award of the operation and maintenance contract to ARA;

- Field demonstration of SCAPS capabilities at Uranium Soils Technology Exposition at Fernald; 
- Field demonstration of SCAPS capabilities as part of Expedited Site Characterization (ESC) field programs at Pantex;

- Demonstration of SCAPS at the CRU-1 at Fernald; and

- Demonstration ofSCAPS at the Portsmouth Gaseous Diffusion Site in Piketon, OH.

\section{BENEFITS}

This technology will make the integrated approach to site characterization more universally applicable to DOE hazardous waste sites. Use of the cone penetrometer reduces the potential for exposure of site exploration personnel to hazardous materials, since no wastes are brought to the surface. The approach also significantly reduces the volume of hazardous material that must be controlled and discarded as a result of the characterization. Similar benefits are realized when the cone penetrometer is used to place sampling devices in the subsurface for site monitoring.

This technology will also provide greater versatility in sampler and sensor techniques, including borehole geophysics. Improved interactive computer software systems for real-time data acquisition and analysis will allow rapid on-site decision making.

\section{COLLABORATION/TECHNOLOGY} TRANSFER

ARA is the operations and maintenance contractor for the SCAPS. In addition to the operation and maintenance of the SCAPS truck, ARA will be a major implementor of the evaluated sensors.

After demonstrations of the SCAPS capabilities are completed, Argonne will begin technical evaluations of sensors, samplers, and in situ analysis methods that can be adapted to the SCAPS. A brochure outlining the SCAPS program and the benefits and opportunities offered to eligible DOE sites has been completed. A second informational brochure to outline the evaluation phase of the program is being prepared. The evaluation phase will determine emerging and existing technologies that may be adapted to cone penetrometer technology, those being requested, and those under development.

For further information, please contact:

Candace M. Rose

Principal Investigator

Argonne National Laboratory

ER 203

9700 S. Cass Avenue

Argonne, IL 60439-4843

(708) 252-3499

John Walker

Principal Investigator

Argonne National Laboratory

ER 203

9700 S. Cass Avenue

Argonne, IL 60439-4843

(708) 252-4843

\section{James Helt}

Technical Program Manager

Argonne National Laboratory

9700 S. Cass Avenue

Argonne, IL 60439-4843

(708) 252-7335

\section{Steve Webster}

Technical Program Officer

U.S. Department of Energy

Chicago Operations Office

9800 S. Cass Avenue

Argonne, IL 60439

(708) 242-2822

\section{Eric Lightner}

Projects Manager, CMST-CP

U.S. Department of Energy

Cloverleaf Building

19901 Germantown Road

Germantown, MD 20874-1290

(301) 903-7935 
TTP Number: $\mathrm{CH} 231006$

\section{BIBLIOGRAPHY OF KEY PUBLICATIONS}

None at this time. 


\subsection{TECHNOLOGY PERFORMANCE SPECIFICATIONS}

\section{TASK DESCRIPTION}

Technology Performance Specifications (TPSs) are program management tools. The general TPS approach is to document what currently exists or is nearing completion and compare that baseline to the customers' needs to identify unmet requirements. These unmet requirements then form the basis for the technology development needs that OTD investigators must address. The process needs to be quantitative where appropriate, to focus project goals away from vague generalities like "cheaper" and toward specifics like "reduction of labor costs for Step A from 4 hr to $0.5 \mathrm{hr}$."

\section{Technology Performance Specifications}

Identify baseline technologies

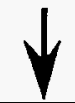

Establish the customer requirements

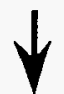

Compare and list unmet requirements

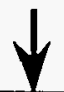

Identify technology development needs

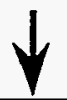

Determine performance specifications

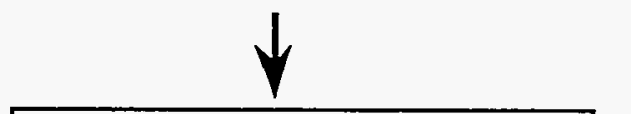

Assess the quality of estimates

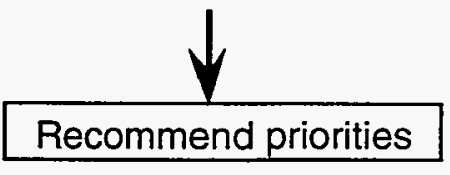

Figure 1.6. Technology Performance Specifications Diagram.
This project will establish and implement TPSs for RDDT \&E projects within the DOE Offics of Technology Development (EM-50). TPSs will be used to establish milestones, evaluate the status of ongoing projects, and determine the success of completed projects. Preliminary performance specifications will be required in TTPs and included as part of the TTP evaluation.

\section{TECHNOLOGY NEEDS}

Currently, the performance specifications for technologies are not generally specified. For some technologies, externally applied criteria (e.g., EPA limits of detection), cheaper performance than a baseline, or general good scientific practice are understood to be the performance criteria, but even these criteria tend not to be codified in work plans, final reports, and other documents. OTD's technologies should meet certain minimum performance specifications to be accepted for implementation by OTD's customers. These performance specifications will act as guidelines to address how well the technology performs (e.g., turnaround time on a radioanalytical method) and how much it costs. Performance specifications establish a goal for meeting the user's needs.

\section{ACCOMPLISHMENTS}

- A Performance Specifications Model has been prepared.

- A technology baseline document on VOC characterization, "Performance Specifications for Technology Development: Application to VOC Characterization and Monitoring in the Environment," by S.E. Carpenter, P.V. Doskey, M.D. Erickson, and P.C. Lindahl, was produced and distributed to all CMST-CP participants, OTD management, and other interested participants. 
- Implementation of performance specifications at both the program and project levels is underway.

- A logic diagram and associared text were prepared and distributed.

\section{BENEFITS}

Performance specifications will establish a baseline to measure how well a technology performs, how fast the technology operates, and how much it costs in relation to other available technology. TPS is a management tool to establish and monitor specific technical goals of individual projects as well as overall programs. Quantitative measures of OTD accomplishments provide customers with a measure of programmatic success. This project will provide programmatic support by developing quantifiable performance specifications for the development of technologies.

\section{COLLABORATION/TECHNOLOGY TRANSFER}

Not applicable.

For further information, please contact:

\section{Mitchell D. Erickson}

Principal Investigator

Argonne National Laboratory

ER 203

9700 S. Cass Avenue

Argonne, IL 60439-4843

(708) 242-7772

\section{James Helt}

Technical Program Manager

Argonne National Laboratory

9700 S. Cass Avenue

Argonne, IL 60439-4843

(708) 252-7335

\section{Steve Webster}

Technical Program Officer

U.S. Department of Energy

Chicago Operations Office

9800 S. Cass Avenue

Argonne, IL 60439

(708) 242-2822

Dr. Caroline Purdy

Program Manager, CMST-CP

U. S. Department of Energy

Cloverleaf Building

19901 Germantown Road

Germantown, MD 20874-1290

(301) 903-7672

TTP Number: $\mathrm{CH} 231001$

\section{BIBLIOGRAPHY OF KEY PUBLICATIONS}

\section{REPORTS}

Carpenter, S.E., P.V. Doskey, M.D. Erickson, and P.C. Lindahl. Performance Specifications for Technology Development: Application to VOC Characterization and Monitoring in the Environment, July 1994.

\section{PRESENTATIONS}

Purdy, C.B., M.D. Erickson, S.E. Carpenter, P.V. Doskey, P.C. Lindahl, and A.D. Pflug, "Development of Technology Performance Specifications for Volatile Organic Compounds," Waste Testing and Quality Assurance Symposium, Arlington, VA, July 1993.

Erickson, M.D., S.E. Carpenter, P.V. Doskey, P.C. Lindahl, A.D. Pflug, and C.B. Purdy, "Technology Performance Specifications," 34th ORNL-DOE Conference on Analytical Chemistry in Energy Technology, Gatlinburg, TN, October 1993.

Erickson, M.D., S.E. Carpenter, P.V. Doskey, P.C. Lindahl, "Performance Specifications for Technology Development," 35th ORNL-DOE Conference on Analytical Chemistry in Energy Technology, Gatlinburg, TN, October 1994. 
Erickson, M. D., "Performance Specifications for Technology Development," Fourth International Symposium on Field Screening Methods for Hazardous Wastes and Toxic Chemicals, Las Vegas, NV, February 1995. 


\subsection{IN SITU MEASUREMENT OF VOLATILE AND SEMI-VOLATILE ORGANIC COMPOUNDS IN THE SUBSURFACE: DEVELOPMENT OF SCREENING AND QUANTITATIVE FIELD METHODS COUPLED TO THE CONE PENETROMETER}

\section{TASK DESCRIPTION}

The overall goal of this investigation is to develop methods and technology that will couple a cone penetrometer truck (CPT) with field-deployable gas chromatography/mass spectrometry (GC/MS) instrumentation to directly transfer volatile organic compounds (VOCs) and semi-volatile organic compounds (SVOCs) from subsurface material at depth to the analytical instrument in the field. Sampling, preconcentration, and analytical equipment will be directly coupled to a CPT to provide on-line, nearreal-time analyses for VOCs (e.g., trichloroethylene, benzene) and SVOCs (e.g., polynuclear aromatic hydrocarbons, polychlorinated biphenyls) in subsurface materials. Preconcentration devices will be interfaced to GC/MS instrumentation and coupled to sampling devices housed in a CPT for in situ quantitative measurement of VOCs in soil gas and ground water, and for screening of VOC and SVOC levels in the soil external to the penetrometer wall. The VOCs or SVOCs liberated from subsurface material will be carried to the surface by an inert, heated transfer line, preconcentrated, and analyzed by thermal desorption GC/MS.

\section{TECHNOLOGY NEEDS}

The projected costs for hazardous waste site assessment and cleanup in the United States are staggering. Environmental contaminants on DOE sites include radionuclides, toxic heavy metals (e.g., mercury), VOCs, SVOCs, and extractants such as tributylphosphate. Decisions concerning remediation require reliable information about the presence and extent of contamination at the facili- ties. The most cost-efficient means of obtaining this information is use of minimally intrusive sampling techniques and on-site (field) analysis of samples. CPTs and in situ ground water samplers provide a minimally intrusive, efficient, and costeffective method for obtaining subsurface materials for analysis of contaminants. On-site analysis of samples has been shown to facilitate the characterization of sites by making real-time, interactive sampling decisions possible. Sampling techniques for VOCs in subsurface materials have been developed, and methods that are accepted by the EPA have been reported. These methods, although currently accepted, are cumbersome even when they are applied during on-site analyses. Consequently, there is a need to provide on-line, near-real-time methods of analyses for VOCs and SVOCs in subsurface materials that maintain sample integrity and improve the accuracy of the analytical results by eliminating the manipulation of samples during collection, transportation, and storage.

\section{ACCOMPLISHMENTS}

- Established research partnership through a subcontract to Tufts University (A. Robbat).

- Designed, built, and tested a laboratory prototype purge device.

- Designed, built, and tested laboratory prototype Thermal Desorption Device.

- Evaluated transfer line materials.

- Designed and fabricated transfer line. 


\section{BENEFITS}

Real-time characterization of VOCs and SVOCs in conjunction with the CPT will dramatically improve the capabilities for Expedited Site Characterization. Time savings of real-time, depth-discrete analysis will yield rapid on-site decision-making and reduce the time required to characterize a site.

The in situ extraction of the VOCs and SVOCs reduces waste, not only in the generation of a sample, which must ultimately be disposed of under applicable hazardous and/or radioactive waste disposal rules, but also in the elimination of the secondary waste generated in the laboratory with solvent extraction, column cleanup, etc.

Extensive cost savings should be realized with this approach. Substantial indirect cost savings will be realized by the rapid turn-around time of the information to those making site characterization decisions. In addition, there are quantifiable direct cost savings relative to the fixed-based laboratory analytical costs. A cost reduction exceeding 90 percent has been estimated for use of field analysis for organic characterization. Specifically, laboratory analyses using SW -846 cost $\$ 600$ per sample, while field analysis can be accomplished for as little as $\$ 60$ per sample, depending on the sample production per day. Based on DOE's estimate of 800,000 hazardous constituent analyses per year by 1994 and a typical cost of $\$ 600$ per sample, DOE will be spending about $\$ 480$ million per year for organics characterization or, over the stated life of the 30year program, a total of $\$ 14.4$ billion. If TDGC/ MS can trim 90 percent from the per-sample cost for only 20 percent of the total samples, a conservative estimate of the savings is $\$ 87$ million per year for an aggregate savings of $\$ 2.6$ billion.

\section{COLLABORATION/TECHNOLOGY TRANSFER}

Tufts University is a key technical partner on this project.
As part of the effort to make information about this technology and these results widely available to DOE site users, a follow-on demonstration of the technology at a contaminated site is planned.

Commercialization plans will be developed with the commercial vendor to incorporate hardware and software changes into the instrument to make the methods available to users as catalog items and to market the whole package for use at DOE sites.

For further information, please contact:

Mitchell D. Erickson

Principal Investigator

Argonne National Laboratory

ER 203

9700 S. Cass Avenue

Argonne, IL 60439-4843

(708) 242-7772

James Helt

Technical Program Manager

Argonne National Laboratory

9700 S. Cass Avenue

Argonne, IL 60439-4843

(708) 252-7335

Steve Webster

Technical Program Officer

U.S. Department of Energy

Chicago Operations Office

9800 S. Cass Avenue

Argonne, IL 60439

(708) 242-2822

Eric Lightner

Projects Manager, CMST-CP

U.S. Department of Energy

Cloverleaf Building

19901 Germantown Road

Germantown, MD 20874-1290

(301) 903-7935 
TTP Number: $\mathrm{CH} 241001$

\section{BIBLIOGRAPHY OF KEY PUBLICATIONS}

Doskey, P.V., Aldstadt, J.H., Erickson, M.D., Robbar, A., and Gorshetyn, A., "In Situ Measurement of VOCs and SVOCs in the Subsurface: Development of Screening and Quantitative Field Methods Coupled to the Cone Penetrometer: Site Characterization and Analysis" Penetrometer System Sensor Development Workshop, U.S. Army Corps of Engineers Waterways Experiment Station, Vicksburg, Mississippi, August 17, 1994.

Doskey, P. V., J. H. Aldstadt, M. S. Costanza, J. Kuo and M. D. Erickson, "In Situ Measurement of Volatile Organic Compounds in Groundwater by Methods Coupled to the Cone Penetrometer," Fourth International Symposium on Field Screening Methods for Hazardous Wastes and Toxic Chemicals, Las Vegas, NV, February 1995.

Aldstadt, J.H., P. V. Doskey, J. M. Kuo, M. S. Costanza and M. D. Erickson, "In Situ Determination of Volatile Organic Compounds in Soil," 46th Pittsburgh Conference and Exposition on Analytical Chemistry and Applied Spectroscopy, New Orleans, LA., March 1995. 


\subsection{MiNIATURE PUMPS IN THE CONE PENETROMETER TIP FOR GROUNDWATER AND SOIL GAS SAMPLING}

\section{TASK DESCRIPTION}

Fast, cost-effective analysis of groundwater is needed to characterize waste sites. Several analytical techniques are available for field use if samples could be obtained without well drilling and conventional sample removal. The objective of this project is directed at coupling small pumps to a cone penetrometer to demonstrate capability for real-time measurement of analytes as the cone is pushed, or for collection of liquid samples at discrete subsurface depths. See Figure 1.8.

\section{TECHNOLOGY NEEDS}

The goal of most environmental characterization studies is to acquire high quality information on the nature and extent of contamination in a cost- and time-effective manner. Conventional methods of site characterization, specifically installation of clus- ters of ground water wells accessing different layers of the subsurface, are expensive and slow. Innovative methods using the cone penetrometer are rapidly becoming the tools of choice for site characterization. The cone penerrometer is essentially a 1-3-inch diameter rod that is hydraulically pushed into the ground by a very heavy truck. The most common use of the cone penetrometer in environmental studies is for determination of soil type. This technique provides detailed definition of the distribution and nature of sediments in the subsurface with the correct tools, but no data are provided for the concentration of contaminants in ground water.

In addition to geophysical sensors, several innovative sensors are being developed to enhance the capabilities of the cone penetrometer that allow for plume delineation. These sensors include pressure sensors, geophysical tools, fiber-optic sensors for contaminant identification and quantification, and samplers. Studies to date suggest that these sam-

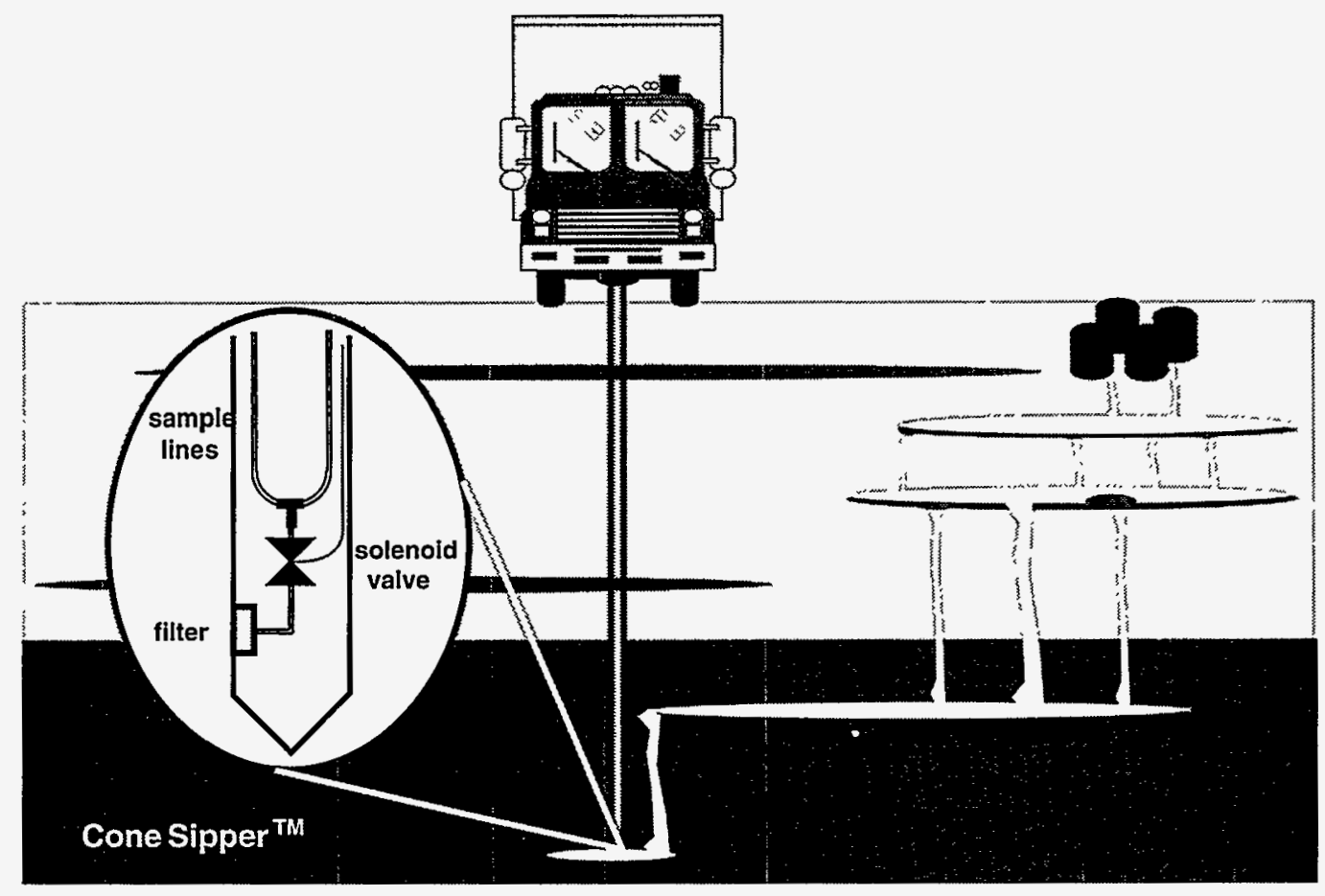

Figure 1.8. Miniature Sampling Pumps. 
plers and sensors will improve both the quality and quantity of environmental data, reduce the cost of environmental characterization, and provide timely information that will allow for optimization in placement of monitoring and remediation wells.

\section{BENEFITS}

Currently available commercial samplers for use with the cone penetrometer are cumbersome and subject to routine operational failures. Use of these samplers requires removal of all cone penetrometer push rods from the ground to deploy the samplers. Depending on the depth of investigation, this process can take several hours, and each sample requires that the sampler be deployed to depth and be retrieved for sample collection at the surface. The miniature pumps being developed by the Savannah River Technology Center eliminate most of these problems associated with water sampling using the cone penetrometer.

\section{ACCOMPLISHMENTS}

Miniature pumps can be installed in the tip of a cone penetrometer to allow depth-discrete semicontinuous sampling of ground water during a cone penetrometer push. By installing these pumps in the cone penetrometer, the need to exit and re-enter the hole is eliminated resulting in a significant time savings (30-60 minutes) for each sample collected. Two types of miniature pump are being developed and tested during FY95. The first is a gas lift pump, called the CONESIPPER TM, which uses alternating vacuum and pressure with a miniature valve to move liquid or gas samples. The second design is a miniature positive displacement pump that uses water as a hydraulic fluid to actuate the piston. Use of these pumps will allow collection of representative ground water samples required by environmental regulations without requiring installation of monitoring wells. Because samples can be collected without having to remove the penetrometer, the density of samples can be increased to significantly improve accuracy of a site conceptual model of contaminant distribution in the subsurface.

\section{FUTURE WORK/DIRECTION}

Prototype versions of both pump designs have been assembled to demonstrate proof of concept. Future work will be focused on improving pump designs and testing for field application. Pump performance under various conditions, such as water depth, particulate loading, and solvent contamination, will be evaluated to identify design improvements. Tests are also being designed to demonstrate pump ability to provide representative samples of RCRA and Toxic Substances Control Act (TSCA) contaminants in ground water.

\section{COLLABORATION/TECHNOLOGY TRANSFER}

A CRADA has been established with Applied Research Associates, Inc. (ARA) to support development and testing of miniature pumps for CPT. ARA is providing field testing of the miniature pumps. Funding for the SRS portion of this CRADA is provided by DOE's Defense Programs Small Business Initiative. Additional partnership arrangements are anticipated to support manufacture and sales of miniature pumps. Patents are being pursued for this technology.

\section{For further information, please contact:}

Louis Baylor

Principal Investigator

Savannah River Technology Center

Building 773A

Aiken, SC 29808

(803) $725-1421$

Eric Lightner

Project Manager, CMST-CP

U.S. Department of Energy

Cloverleaf Building

19901 Germantown Road

Germantown, MD 20874-1290

(301) 903-7935 
TTP Number: SR153002

BIBLIOGRAPHY OF KEY PUBLICATIONS

None at this time. 


\subsection{NUCLEAR BOREHOLE LOGGING: PASSIVE AND NEUTRON-INDUCED SPECTRAL GAMMA-RAY TECHNIQUES FOR MAPPING CONTAMINANTS IN SITU}

\section{TASK DESCRIPTION}

This project addresses two nuclear borehole logging techniques that are capable of identifying and mapping numerous contaminants and are nuclide-specific. Passive spectral gamma-ray (SGR) logging positively identifies gamma-emitting contaminants and is quite sensitive, but requires further development to be made quantitative. Neutron-induced spectral gamma-ray (multispectral) logging adds a pulsed neutron source to an SGR instrument, recording gamma-ray energy spectra during and/or after irradiation of the borehole environment with energetic neutrons. Multispectral logging can positively identify many nuclides including chlorine and a number of RCRA metals.

In the multispectral part of this project, a contaminant-doped concrete test facility was designed and constructed at Grand Junction, CO. See Figure 1.9. Working with an industry partner (Environmental Measurements Corp., Denham, TX), DOE assembled a hybrid test instrument composed of the

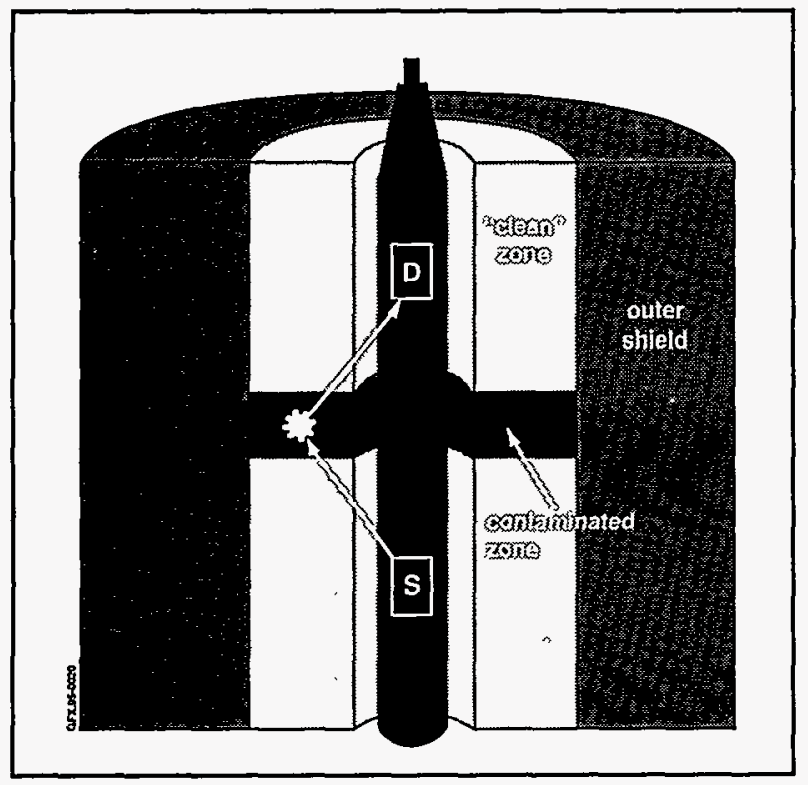

Figure 1.9. Variable Contaminant Borehole Test Facility. pulsed-neutron source section of the existing commercial instrument along with a laboratory-grade cryogenic detector and multichannel analyzer. DOE performed experiments in the test facilities using the hybrid test instrument to make direct assessments of detection thresholds for the contaminants in the test facilities. Computer simulations and analytical calculations were performed to extend the experimental results to estimate detection thresholds for other contaminants of concern. Planned work for FY95 is to construct a rugged field instrument, test and demonstrate the system at a contaminated DOE site, and commercialize the technology.

In the passive SGR part of the project, we used experimental data provided by Westinghouse Hanford Company (WHC), along with computer simulations, to develop data correction and deconvolution algorithms to establish a quantitative basis for this technique. In Phase 1, we determined the spatial response of the existing WHC instrument and adapted existing data processing techniques, including linear deconvolution, to correct for those conditions. The planned Phase 2 effort is to generalize the data correction algorithms to less well-behaved geologic conditions (such as the more typical heterogeneous, three-dimensional distributions of contaminants) where the assumption of linear system behavior is not valid. A more general approach that ties in full-spectral processing with physical sample results, geostatistics, and contaminant transport modeling will be developed to ensure highest possible data quality in such environments.

\section{TECHNOLOGY NEEDS}

This project responds to a number of needs identified by the CMST-CP:

- Field analysis equipment for real-time results; 
- Significantly improved analytical methods or sensors;

- Improved in situ measurements of subsurface properties;

- Instrumentation for deployment by cone penetrometers, etc.; and

- Statistically guided sampling and data quality assurance tools.

Letters of support for this project have been received from ER-funded groups at WHC, Sandia National Laboratory, Los Alamos National Laboratory, and Westinghouse Savannah River Company.

\section{ACCOMPLISHMENTS}

- A variable contaminant test facility was designed and constructed at Grand Junction, $\mathrm{CO}$, to evaluate the multispectral logging technique.

- An experimental prototype multispectral borehole logging instrument was assembled in cooperation with Environmental Measurements Corporation (EMC).

- Computer codes for simulating neutron and gamma-ray transport problems were installed and tested. It was determined based on the tests that substantial improvements were needed in the code and the supporting nuclear data tables. Those improvements were accomplished.

- Extensive experiments were performed with the experimental multispectral prototype in the variable contaminant test facility in cooperation with EMC and WHC. Detection thresholds for five elements were calculated based on the experimental data.

- The following detection thresholds have been estimated: Cadmium $0.2 \mathrm{mg} / \mathrm{Kg}$, Mercury $4 \mathrm{mg} / \mathrm{Kg}$, Samarium $0.1 \mathrm{mg} / \mathrm{Kg}$, Gadolinium $0.1 \mathrm{mg} / \mathrm{Kg}$, and Chlorine 10 $\mathrm{mg} / \mathrm{Kg}$.
- Computer simulations and analytical calculations were performed to extend the multispectral experimental results to estimate detection thresholds for other contaminants of concern. The data are being analyzed.

- A special-purpose deterministic computer simulation program was written and tested against existing general codes and experimental data for the SGR problem. This program provides accurate results and requires less than 0.1 percent as much computation time (i.e. hours instead of months).

- SGR data provided by WHC was analyzed to determine instrument response characteristics, leading to correction algorithm development.

- All work was on schedule and within budget when funding was interrupted.

\section{BENEFITS}

Some of the benefits of SGR logging are described in a General Accounting Office Report that states, "A simple 200-foot well currently costs over $\$ 150,000$ and a full analysis of soil samples every 5 feet costs about $\$ 200,000$. Given that the estimated cost of spectral gamma analysis is about $\$ 2,400$ per well, potential savings from using vadose zone technology [e. g., in situ SGR measurements] in existing and new wells as a substitute for physical sampling are large." It is further stated that, "This technology can also reduce the risks of contaminating groundwater and exposing workers to radiation during the drilling of wells."

Making SGR and multispectral logging quantitative will yield methods for analyzing the subsurface for gamma-emitters and other contaminants that is literally better, faster, safer, and cheaper than conventional approaches.

Better: Logging analyzes 1000 to 10,000 times more material than the conventional sampling approach and can produce a continuous record from the bottom of a borehole to the top; these measure- 
ments can also be made in cone penetrometers. It is estimated that a detection threshold on the order of $0.1 \mathrm{pCi} / \mathrm{g}$ for Cs-137 is achievable with SGR logging. This is roughly an order of magnitude below background concentrations and two orders of magnitude below typical screening action levels. Multispectral logging is capable of detecting some contaminants at levels below $1 \mathrm{mg} / \mathrm{Kg}$. There are no sample handling errors, and chain-of-custody difficulties are greatly reduced.

Faster: Logging can produce same-day or even realtime results.

Safer: The borehole instrument can be run inside sealed, uncontaminated casing or polymer membrane. There is no handling of contaminated samples, and SGR logging does not result in any contamination.

Cheaper: An entire borehole can generally be analyzed for the cost of obtaining and analyzing one or two samples. In addition to site characterization, these techniques are uniquely suited for long-term monitoring, allowing the same bo reholes, including cased boreholes, to be scanned at regular time intervals for as many years as required. The only alternative to logging for long-term monitoring of gamma-emitting contaminants is to extract and analyze samples repeatedly, at enormous expense and with great uncertainty about whether the environment has truly changed, because different material is analyzed each time.

\section{COLLABORATION/TECHNOLOGY TRANSFER}

The multispectral part of this project is being performed collaboratively by Los Alamos National Laboratory, RUST Geotech (DOE Grand Junction Projects Office), and the U.S. Geological Survey, under separate Technical Task Plans. WHC is participating under its own ER/WM funding. A potential industry partner, Environmental Measurements Corporation, has been providing support under contract. The passive spectral gamma-ray work is primarily a Los Alamos project in collaboration with WHC under its own ER/WM funding.
The Department of Civil and Environmental Engineering of the University of Wisconsin at Madison is participating under contract. A computer program embodying the new and improved processing algorithms developed in this project will be licensed to users upon completion of testing.

For further information, please contact:

John Conaway

Los Alamos National Laboratory

P.O. Box 1663

Los Alamos, NM 87545

(505) 667-2683

David George

RUST Geotech

2597 B 3/4 Road

Grand Junction, CO 81503

(303) 248-6699

Jon Mikesell

U.S. Geological Survey

Box 25046, MS 964 DFC

Golden, CO 80225-0046

(303) 236-1321

Bruce Erdal

Technical Program Manager

Los Alamos National Laboratory

P.O. Box 1663

Los Alamos, NM 87545

(505) 667-5338

Dr. Caroline Purdy

Program Manager, CMST-CP

U. S. Department of Energy

Cloverleaf Building

19901 Germantown Road

Germantown, MD 20874-1290

(301) 903-7672 
TTP Numbers: TTP AL131004, AL931001, AL031001

\section{BIBLIOGRAPHY OF KEY PUBLICATIONS}

Conaway, J.G. and J.R. Hearst, Mapping Contaminants with Nuclear Borehole Logging Techniques, Los Alamos, NM, LA-UR 93-1915, 13 pp., 1993.

Burnham, J., Conaway, J., Duray, J., Frankle, S., George, D., Mikesell, J., Nelson, P., and Wilson, R., Contaminant Detection Thresholds for the Multispectral Neutron Borehole Logging Method: Preliminary Report, J. Conaway and J. Duray, eds., DOE/ID/12584-188, GJPO-TP-6, 21 pp., 1994.

Hearst, J. R, Choice of Computer Software for Analysis of Spectra from the Multispectral Logging System, University of California Radiation Laboratory, UCRL-ID-118023, 7 pp., 1994.

Hearst, J.R, J.R. Brodeur, C.J. Koizumi, J.G. Conaway, J.L. Mikesell, P.H. Nelson, D.C. Stromswold, and R.D. Wilson, DOE Capabilities for In Situ Characterization and Monitoring of Formation Properties in the Vadose Zone, University of California Radiation Laboratory, UCRL-JC$113790,15 p p ., 1993$. 


\subsection{MULTI-ANALYTE, SINGLE-FIBER, OP'TICAL SENSOR}

\section{TASK DESCRIPTION}

Researchers at Tufts University have demonstrated and patented a unique technology that enables the placement of multiple sensors on a single optical fiber. Current estimates from Tufts researchers indicate the potential for up to 20 or more different sensors (for different target compounds) on a single 350 micrometer diameter optical fiber. This task describes a Lawrence Livermore National Laboratory/Tufts University collaboration for the development of such a technology for DOE site-specific requirements. The successful completion of this task will result in a single fiber sensor for the detection of four compounds, laboratory test results for same, and field prototype instrumentation for an FY95 demonstration at a DOE facility.

\section{TECHNOLOGY NEEDS}

Current methods for detecting nearly all priority contaminants require sampling and subsequent labo- ratory analysis. Sensors give the analyst the ability to measure contamination in situ, and in real-time, thus saving time and expense. However, many DOE sites have a multitude of contaminants present that challenge the current state-of-the-art in sensor technology. This challenge is in both analyte specificity and sensitivity and in the complexity of instrumentation that would be required to measure many analytes simultaneously. The work described herein not only provides sensors for needed measurements but also has the unique distinction of requiring only one sensor and instrument to make determinations of numerous analytes, thus greatly simplifying field applications. See Figure 1.10.

\section{ACCOMPLISHMENTS}

In collaborative work with potential customers we have selected a suite of four target analytes $\left(\mathrm{Al}^{+3}\right.$, $\mathrm{UO}_{2}{ }^{+2}$, nonspecific hydrocarbon, and $\mathrm{pH}$ ) as our initial multianalyte sensor. These analytes will be applied to a single sensor in a seven-element format
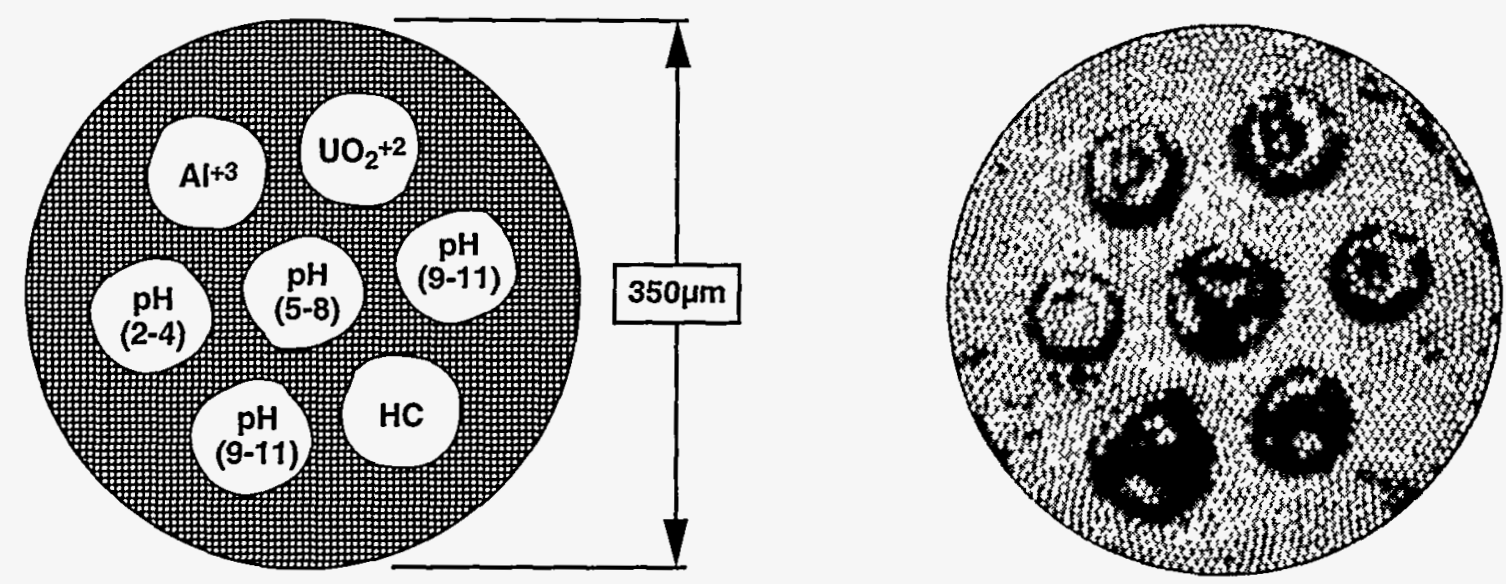

GFX.95-0024

Figure 1.10. Seven-Element Sensor 
See Figure 1.10. Optical indicators for all four analytes have been identified or synthesized as appropriate and have been thoroughly laboratory tested. A photo-polymerization regimen has been established and three of the indicators have been successfully immobilized onto the imaging fiber. A small, low cost, field-portable instrument has been designed and successfully laboratory-tested with prototype multianalyte sensors. This project is on schedule for a laboratory demonstration of a fouranalyte sensor by mid FY95.

\section{FUTURE WORK/DIRECTION}

Initial success with measuring $\mathrm{pH}$ optically has opened up the possibility of an Underground Storage Tank application. In this case we can place a wide range of $\mathrm{pH}$ sensors to monitor for corrosive conditions, as well as a redundant number of individual sensors to mitigate the effects of the harsh environment. We will also explore the potential application of a new concept recently demonstrated by Professor David Walt of Tufts University. Here the combination of slow release polymer technologies with fluoroimmuno-analysis has the potential for a continuous reading antibody-based biosensor. Success here would greatly increase the number of different analytes that could be measured with the multianalyte sensor.

\section{COLLABORATION/TECHNOLOGY} TRANSFER

This project is a major collaboration between researchers at Lawrence Livermore National Laboratory and the Chemistry Department at Tufts University. Tufts University has received three patents covering the core technology. We anticipate that application-specific technology developed under the collaboration will be available for field-ofuse licensing. We have also established informal collaborations with several instrument component manufacturers.
For more information, please contact:

Fred P. Milanovich

Principal Investigator

Lawrence Livermore National Laboratory

7000 East Avenue

P.O. Box 808, MS L-524

Livermore, CA 94550

(510) $422-6838$

\section{Jesse Yow}

Program Leader

Environmental Technologies Program

Lawrence Livermore National Laboratory

7000 East Avenue

P.O. Box $808, \mathrm{~L}-1$

Livermore, CA 94550

(510) 422-3521

\section{Dr. Caroline Purdy}

Program Manager, CMST-CP

U. S. Department of Energy

Cloverleaf Building

19901 Germantown Road

Germantown, MD 20874-1290

(301) $903-7672$ 


\subsection{SOL-GEL INDICATOR PROGRAM}

\section{TASK DESCRIPTION}

Sol-gel indicator (SGI) composites are being used by the Savannah River Technology Center to manufacture sensor elements to measure environmentally important species and conditions. The technology is based on incorporation of indicator materials into specially prepared porous silica, alumina, or titania glass matrices. The SGIs change color in response to analyte concentration. Sensors are prepared by coating SGI composites on optical components so that photometric measurements can be made.

Currently, an SGI sensor for uranium is being integrated into an analytical measuring system. Work is underway to identify a new target heavy metal and an organic contaminant for sensor development.

\section{TECHNOLOGY NEEDS}

Increased emphasis in recent years on environmental analyses has fueled a need for field-portable and remote monitoring instruments. An important contribution to this effort has been the development of portable fiber-optic diode array spectrometers and associared fiber-optic probes. These probes contain the sensing element or function as a measurement cell, and are small, rugged, and easily deployed.

Sol-gel technology has opened up a new route to sensor element fabrication; the indicator may be trapped in a porous sol-gel matrix. Pore sizes of the sol-gel can be controlled during synthesis to allow the desired analyte to react with the indicator molecule, while keeping the indicator trapped within the porous glass matrix. Sol-gel technology has the advantage of being able to distribute and incorporate the indicator in a chemically durable matrix at room temperature, therefore avoiding the high temperatures in conventional glass manufacture that degrade organic indicator molecules. Figure 1.11a shows how the sol-gel sensor element is integrated into a fiber-optic diode array spectrophotometer system.

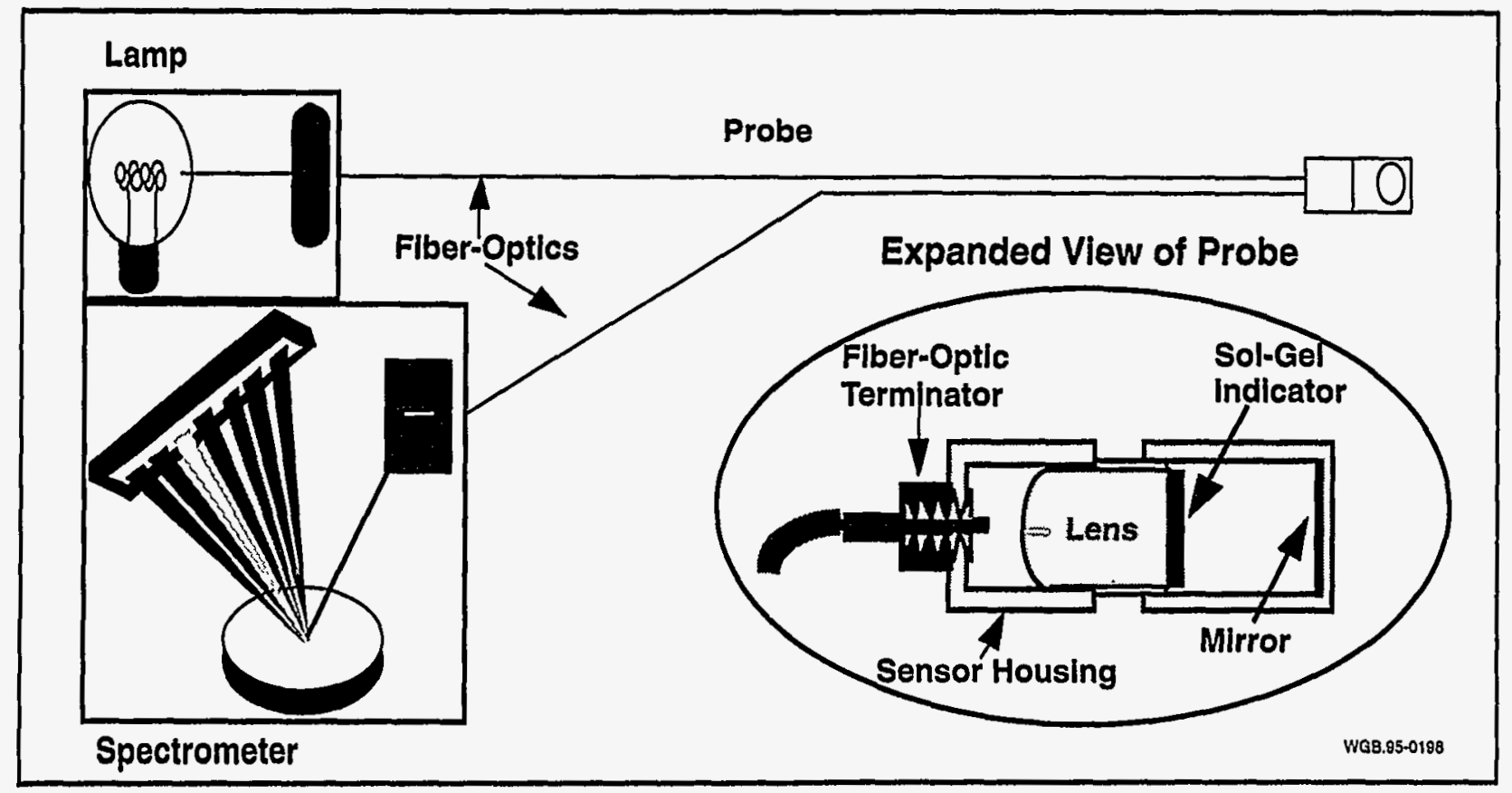

Figure 1.11a. Diagram of Fiber-Optic Diode Array Spectrophotometer System with Sol-Gel Probe. 


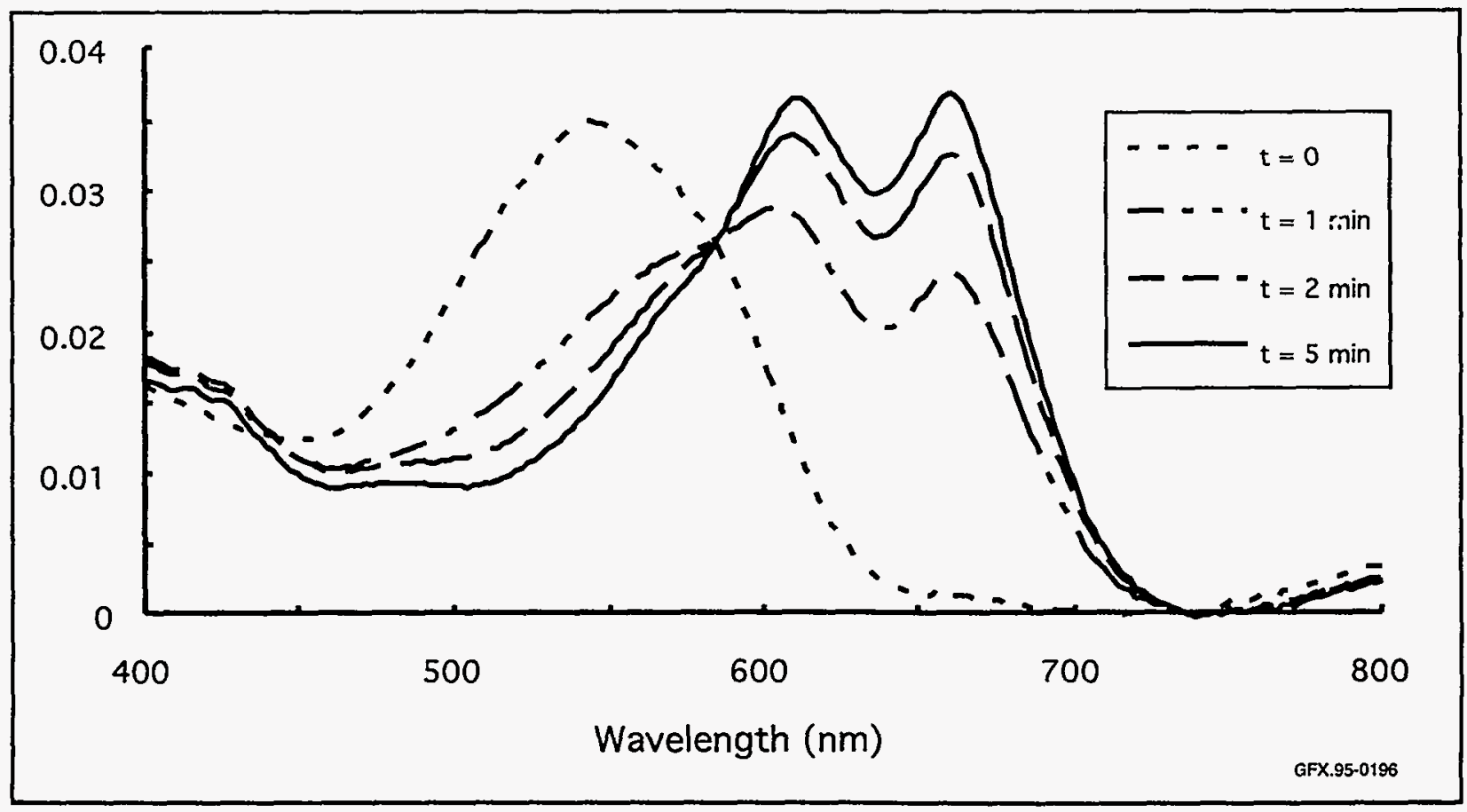

Figure 1.11b. Response of Arsenazo III Sol-Gel Uranyl Probe.

\section{ACCOMPLISHMENTS}

- SGI sensors have been prepared with pH indicators such as bromophenol blue.

- SGI pH sensors have an expanded response range relative to aqueous solutions of the indicator.

- An SGI sensor for uranyl has been prepared using the indicator arsenazo III. The response of this sensor is shown in Figure $1.11 \mathrm{~b}$.

- Response time is about 5 minutes (118 ppm uranyl, $\mathrm{pH} 1$ ); an improvement by a factor of 400 over earlier efforts.

A treatment for reversal of the uranyl sensor has been developed so that it can be reused for the recharge chemistry, miniaturized Flow Probe design.

\section{BENEFITS}

This technology will prove useful as a screening tool and for in-field measurements of properties such as $\mathrm{pH}$ and dissolved heavy metals content. Measurements of this type are needed at many sites nationwide that require environmental remediation.

\section{COLLABORATION/TECHNOLOGY TRANSFER}

- U.S. Patent \#796974 in process.

- Three private-sector companies have licensed this technology.

- One CRADA is under negotiation.

- Additional industry contacts/collaborations are in progress.

- Several presentations regarding SGI sensors have been made:

- Center for Process Analytical Chemistry (CPAC) Sponsor Meeting (Nov. '94) 
- Eastern Analytical Symposium (Nov. '94)

- Sensors Expo West (Feb. '94)

- TIE Meeting with Industry on Environmental Restoration Needs in the Northwest United States (Jan. '94)

- DOE Poster Session at Spectrum '94 (Aug. '94)

- Sensors Expo (Oct. '93)

- Environmental Restoration '93 (Oct. '93)

- Emerging Technologies in Hazardous Waste Management V (Sept. '93)

- Sixth Annual National Conference on Federal Quality (July '93)

- Fourth National TIE Workshop (May '93)

- Westinghouse Savannah River Company Technology Transfer Meetings (May'93 and Feb. '94)

- Fifth Winter Conference on Flow Injection Analysis (Jan. '93)

For further information, please contact:

Sol-Gel Team: Lewis Baylor, Ron

Livingston, Mike Whitaker, and George

Wicks (coordinator).

George Wicks

Team Coordinator

Westinghouse Savannah River Company

P.O. Box 616

Aiken, SC 29802

(803) 725-3190
John L. Steele

Technical Program Manager

Westinghouse Savannah River Company

P.O. Box 616

Aiken, SC 29802

(803) $725-1830$

Dr. Caroline Purdy

Program Manager, CMST-CP

U.S. Department of Energy

Cloverleaf Building

19901 Germantown Road

Germantown, MD 20874-1290

(301) $903-7672$

TTP Number: SR141005

\section{BIBLIOGRAPHY OF KEY PUBLICATIONS}

Development of Novel Sol-Gel Indicators (SGI's) For In situ Environmental Measurements; Part I Program and a New pH Sol-Gel Indicator (U), R.R. Livingston, L.C. Baylor, and G.G. Wicks, WSRC: RP-92-1276, Westinghouse Savannah River Company Report, 1992.

Sol-Gel Indicator Demo Kit (U), M.B. Odom, G.G Wicks, R.R. Livingston, L.C. Baylor, and M.J. Whitaker, WSRC-RP-93-645, Westinghouse Savannah River Company Report, 1993. 


\subsection{MINIATURIZED CHEMICAL FLOW \\ PROBE SENSOR DEVELOPMENT - \\ SANDIA NATIONAL LABORATORY}

\section{TASK DESCRIPTION}

A small, reconfigurable, and real-time chemical analysis instrument could provide field technicians performing screening operations with on-the-spot data to allow for smart field characterization studies. The flow probe will use a flowing reagent chemistry with fiber-optic-based detection and speciation enhanced by modern chemometric techniques. Two instrument types will be designed to demonstrate the broadness of chemical speciation possible from this technology. One of these types will be suitable for $\mathrm{Fe}$ and $\mathrm{Cu}$ in aqueous matrices and the other will be suitable for TCE, TCA, and chloroform in aqueous matrices. One instrument will be packaged for a cone penetrometer or downwell application (i. e., a typical DOE application) and the other for an open-space, human accessible application (i.e., a typical commercial application). The instrument will be contained in a $3 \times 2 \times 1-\mathrm{ft}$ suitcase.

\section{TECHNOLOGY NEEDS}

Current methods for preliminary field analysis include: a) technicians taking samples, followed by transport to an off-site analytical laboratory for analysis, and b) technicians taking samples to an onsite mobile analytic laboratory. Both methods involve the high costs of analytic laboratory technicians and equipment, and the off-site method involves the long time (up to months) delay of obtaining results. Flow probe research in the university environment has reached the point where the technology is ready to move into the commercial market. For this to happen, however, significant engineering development is needed to produce a viable commercial instrument. This project provides the collaboration of the university scientist with the national laboratory engineer to perform this development in a pre-competirive setting.

\section{ACCOMPLISHMENTS}

Since the project started in November 1993, the following has been accomplished:

- Obtained a wide set of requirements for a flow probe instrument; some 25 different responses from commercial users and instrument manufacturers were received.

- Using these requirements, partitioned the functions of the instrument into seven subsystems, six hardware-related and one chemistry-related.

- Held a conceptual design review in which CPAC industry sponsor representatives joined LANL and SNL to define the operational needs for the flow probe system model.

- Held a prototype design review in which CPAC industry sponsor representatives joined LANL and SNL to review the technical status of the project.

- Built test pieces of these subsystems as individual units.

- Assembled two probe heads for testing the subsystems as complete units.

- Developed single reagent systems for measuring $\mathrm{Fe}$ and $\mathrm{Cu}$, and for TCE, TCA, and chloroform, both in aqueous matries.

Figures $1.12 \mathrm{a}$ and $1.12 \mathrm{~b}$ show (1) the hardware implementation of the instrument as it existed in August 1994, and (2) a model of the flow probe head as it currently exists.

\section{BENEFITS}

The result of the project will be a commercially available analysis instrument system that can be 
used to detect a wide variety of chemical species. From the perspective of the field technician, only one set of probe operational instructions needs to be learned. That is, the measurements for organics and those for metals are the same from an operational viewpoint. The instrument will be suitcase-sized and the probe tip will be ruggedized for field usage. The tip and the support equipment will be suitable for cone penetrometer or other general field deployment (the demonstration instrument will need access to 120VAC power). Reduced time and cost for

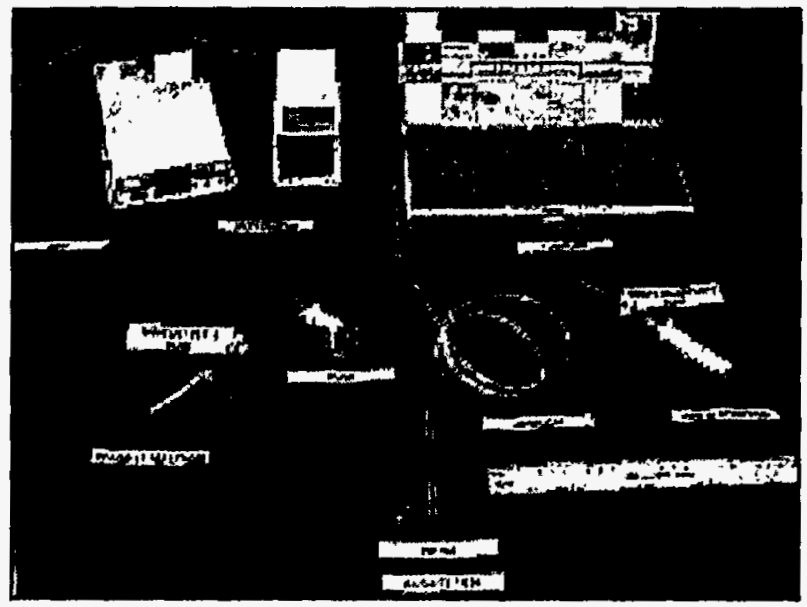

Figure 1.12a. Flow Probe Laboratory Prototype Components.

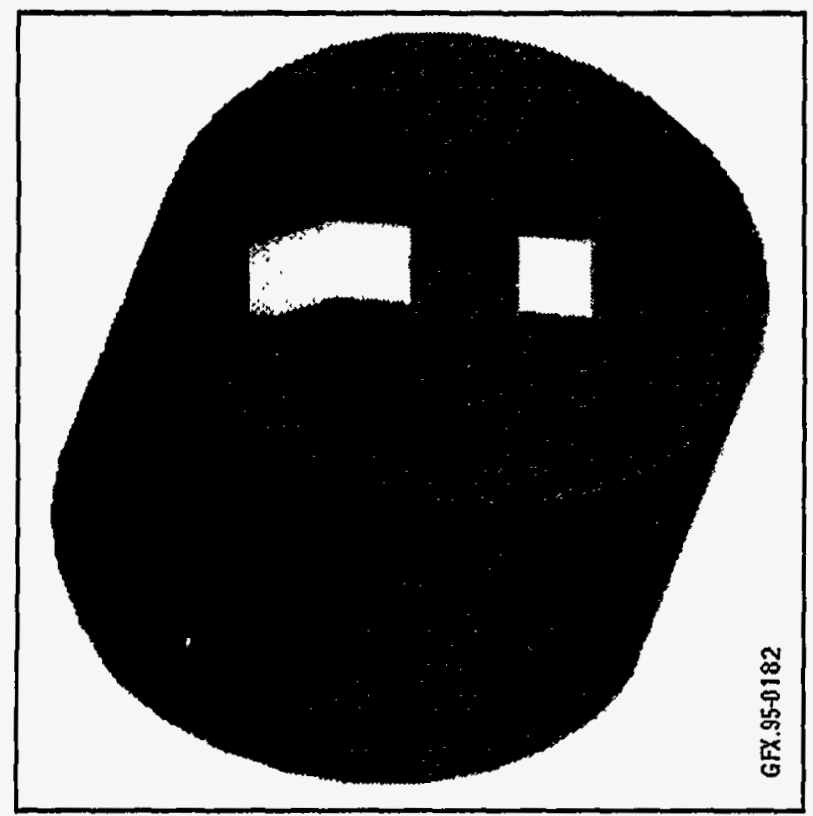

Figure 1.12b. Flow Probe Laboratory Model of Probe Head (diameter is $0.5 \mathrm{in}$ ). site characterization and monitoring should be achieved.

Applications for this instrument include:

- Rapid site surveys-since the instrument will provide in situ analysis, the field operator can make accurate decisions on where next to survey (this information aids in mapping plume dynamics that can be used to determine feasible and requisite remediation technology).

- Unmanned, long-term, and continuous monitoring/characterization of environmental remediation and restoration sitesan operator can place the instrument in the ground and return weeks or months later to review the results instead of having to return to the site each time a data reading is required.

- Continuous monitoring to ensure and prove compliance with environmental laws and regulations.

- In situ monitoring field applications-the ability to monitor the samples in the liquid phase, downhole, provides a more representative measurement of analyte concentration (when samples are sent off-site for analysis, volatilization of the chlorinated VOCs is a concern).

\section{COLLABORATION/TECHNOLOGY TRANSFER}

Technology transfer to commercial analytical chemistry instrument manufacturers is an integral part of the project. Close and regular contact with the Center for Process Analytical Chemistry (CPAC) at the University of Washington is being used to accomplish the transfer.

The project is a $50 / 50$ collaboration with CPAC at the University of Washington. The analytical chemistry aspects are addressed by the CPAC scientists. The engineering for a fieldable instrument is addressed by SNL. The project consists of three 
phases. The initial phase includes obtaining performance requirements from the various $C P A C$ sponsor chemical companies (i.e., users) and working with the CPAC instrument companies (i. e., suppliers) early in the development of the instrument. The middle phase is to demonstrate the instrument in the field at DOE and commercial sites. The final project phase is to include an instrument partner to make a pre-commercial prototype. Our collaboration with all parties is well underway, with representatives from Amoco, Inc. and Sippican, Inc. joining the design team discussions during the January 1994 three-day design review meeting.

Letters of interest from many CPAC companies, including in-kind support commitments that range from $\$ 200 \mathrm{~K}$ (Dow USA) to $\$ 50 \mathrm{~K}$ (Perkin-Elmer Corporation) have been received. Other companies expressing interest and in-kind support commitments include: Amoco, Calgon, Chevron, Sippican, Goodyear, Hewlett-Packard, Proctor \& Gamble, Shell, and ZymoGenetics.

For further information, please contact:

George R. Laguna

Sandia National Laboratory

P.O. Box 5800

MS 0503

Albuquerque, NM 87185-0503

(505) 844-5273
George Allen

Technical Program Manager

Sandia National Laboratory

P.O. Box 5800

Albuquerque, NM 87185-0503

(505) 844-9769

\section{Dennis Olona}

Technical Program Officer

Albuquerque Operations Office

P.O. Box 5400

Albuquerque, NM 87185-5400

(505) $845-4296$

\section{Dr. Caroline Purdy}

Program Manager, CMST-CP

U.S. Department of Energy

Cloverleaf Building

19901 Germantown Road

Germantown, MD 20874-1290

(301) $903-7672$

TTP Number: AL241009

BIBLIOGRAPHY OF KEY PUBLICATIONS

None at this time. 


\subsection{FLOW PROBE SENSOR DEVELOPMENT - CENTER FOR PROCESS ANALYTICAL CHEMISTRY}

\section{TASK DESCRIPTION}

The purpose of this task is to develop a chemical sensor technology for environmental monitoring and industrial process control.

The experimental approach focuses on the development of miniaturized chemical analyzers small enough to fit inside a syringe. These flow probes are based on the controlled delivery of very small quantities (microliter or less) of reagent to the sensor tip accomplished via capillary tubing with dimensions similar to typical optical fibers. By flowing the reagent to the sensor tip, and renewing the reagent phase, difficulties will be overcome and reagent photolability and reagent leaching reduced.

Experimentally, fiber-optic flow probes will be fabricated using two types of sensors: spectroscopic and tensorial. The spectroscopic sensor will facilitate the collection and analysis of an entire spectrum rather than a single datum per sample. The tensorial sensor, in combination with recently developed tensorial calibration methods, will allow for the qualitative detection of analytes in the presence of unknown interferences. This capability is especially important in environmental monitoring situations where the sample matrix is unknown or not fully characterized.

\section{TECHNOLOGY NEEDS}

The majority of fiber-optic chemical sensors currently being investigated utilize a reversible reagent chemistry physically confined or bound at or near the fiber endface. In such sensors, problems involving probe-to-probe reproducibility, reagent photolability, and reagent leaching are frequently encountered. In addition, the vast number of irreversible reagent chemistries that form optically detectable products are precluded from use on problems associated with limited probe lifetime and calibration of such devices. A practical way to overcome some of the difficulties of these devices is to renew the reagent phase in a controlled manner.

\section{ACCOMPLISHMENTS}

The cooperative project between CPAC and Sandia National Laboratory began in November 1993. The scope of work is to develop a generic chemical analyzer suitable for use in both field survey applications and process control and monitoring applications. The programmatic goals are to demonstrate an instrument in the field and to team with a commercial analytical chemistry instrument manufacturer to establish a flow probe product line.

A laboratory prototype has been designed and built. The general architecture of the instrument consists of seven major subsystems: (1) the probe head and membrane interface, (2) fluid handling, (3) chemistry and chemometrics, (4) spectrometer and light source, (5) interconnections, (6) data acquisition and control, and (7) computer and software. Separate efforts in each of the subsystems are coming to an end. Work to investigate how the subsystems work together is just beginning.

Field site evaluation has begun. CPAC and Sandia team members visited seven potential sites. Department of Energy and CPAC industrial sponsor sites are under consideration. Six instrument companies from within CPAC membership have expressed interest in the flow probe technology.

\section{BENEFITS}

The flow probe is designed to bring many of the capabilities of traditional chemical analysis techniques to the field. The probe is an ideal platform for in situ monitoring of a wide range of analytes. Selectivity is gained through the selection of the membrane interface and the specific reagent chemistry within the probe. Multiwavelength detection 
is used in all cases. Because the reaction cell and detection cell are co-located, spectral data combined with the reaction kinetics can provide two orthogonal sets of information in one analysis. These second order sensors, along with recently developed tensorial calibration methods, have the potential to quantitate multiple analytes in the presence of unknown interferents. This capability is especially important where the sample matrix is unknown or not fully characterized.

The flow probe has been designed with input from CPAC industrial sponsors. These instrument developers have driven many of the material choices (e.g., 316 stainless steel probe head). Work during the past year has been to move from complex designs to fewer and simpler designs. For example, the fluid delivery system eliminates a pump in favor of a pressurized bellow with a simple solenoid-driven valve.

\section{COLLABORATION/TECHNOLOGY}

\section{TRANSFER}

The project is funded by DOE through the $\mathrm{Na}$ tional Science Foundation (NSF) as part of an interagency agreement between DOE and NSF for research, development, and field testing of the fiber-optic flow probe. Research is conducted at CPAC at the University of Washington. The Center, an industry-university research consortium, collaborates with Sandia National Laboratory to support probe prototype development and field testing. With "in-kind" support from the Center's 50 industrial sponsors, this will allow the development and commercial use of a versatile, inexpensive miniature chemical analyzer for use in environmental monitoring industrial process control, and pollution prevention applications.
For further information, please contact:

Lloyd Burgess

Principal Investigator

University of Washington

MS BG-10

Center for Research Analytic Chemistry

Seattle, WA 98195

(206) 685-2326

\section{Isiah Sewell}

Program Manager

U.S. Department of Energy

Cloverleaf Building

19901 Germantown Road

Germantown, MD 20874-1290

(301) 903-8459

Dr. Caroline Purdy

Program Manager, CMST-CP

U.S. Department of Energy

Cloverleaf Building

19901 Germantown Road

Germantown, MD 20874-1290

(301) $903-7672$

TTP Number: AL241009

\section{BIBLIOGRAPHY OF KEY PUBLICATIONS}

Z. Lin, L. Burgess, "Chemically Facilitated Donnon Dialysis and its Application in a Fiber-Optic Heavy Metal Sensor", Analytical Chemistry, 66, 2544, 1994.

Z. Lin, L. Burgess, B. Kowalski, "Second Order Fiber-Optic Heavy Metal Sensor Employing Second Order Tensorial Calibration", Analalytical Chemistry, 66, 2552, 1994.

J. Henshaw, L. Burgess, B. Kowalski, et. al., "Multicomponent Determination of Chlorinated Hydrocarbons Using Reaction-Based Chemical Sensing" Part 1: "Multivariate Calibration of Fujiwara Reaction Products", Analytical Chemistry, 66, 3328, 1994. 
R. Tauler, L. Burgess, B. Kowalski, et. al., "Multicomponent Determination of Chlorinated Hydrocarbons Using Reaction-Based Chemical Sensing" Part 2: "Chemical Speciation Using Multivariate Curve Resolution", Analyrical Chemistry, 66, 3337, 1994.

A. Smilde, L. Burgess, B. Kowalski, et. al., "Multicomponent Determination of Chlorinated Hydrocarbons Using Reaction-Based Chemical Sensing" Part 3: "Medium Rank Second Order Calibration with Restricted Tucker Model", Analytical Chemistry, 66, 3345, 1994.

G. Laguna, L. Burgess, et. al., Miniaturized Chemical Flow Probe Sensor Development: Conceptual Design Report, DOE TTP AL2-4-10-09, March 1994.

G. Laguna, L. Burgess et. al. Miniaturized Chemical Flow Probe Sensor Development: Year One Progress Report, DOE TTP AL2-4-10-09, November 1994. 


\subsection{PORTABLE ACOUSTIC WAVE SENSOR SYSTEMS FOR VOLATILE ORGANIC COMPOUNDS}

\section{TASK DESCRIPTION}

The portable acoustic wave sensor (PAWS) technology consists of one or more surface acoustic wave (SAW) sensors utilizing sorbent coatings to detect chlorinated hydrocarbons (CHCs) and other VOCs. See Figure 1.14a. By measuring the velocity and attenuation of the sensor(s) as chemical species are sorbed into the coating(s), rapid and sensitive detection can be achieved. This project is being performed in collaboration with two U.S. companies, a major instrument manufacturer partnered with a leading surface acoustic wave (SAW) supplier, and Pacific Northwest Laboratory. See Figure 1.14b. This collaborative project involves designing, developing, and field-demonstrating a versatile handheld monitoring instrument for VOCs of environmental and occupational safety interest, including the chlorinated hydrocarbons (CHCs) of particular interest to DOE. These instruments will include an array of coated SAW sensors, environmental sampling and pretreatment systems, analog and digital electronics, microprocessors, and data analysis software. The systems will be designed to provide rapid, real-time monitoring of one or more VOCs with detection levels at or below regulatory levels. Species identification will be performed

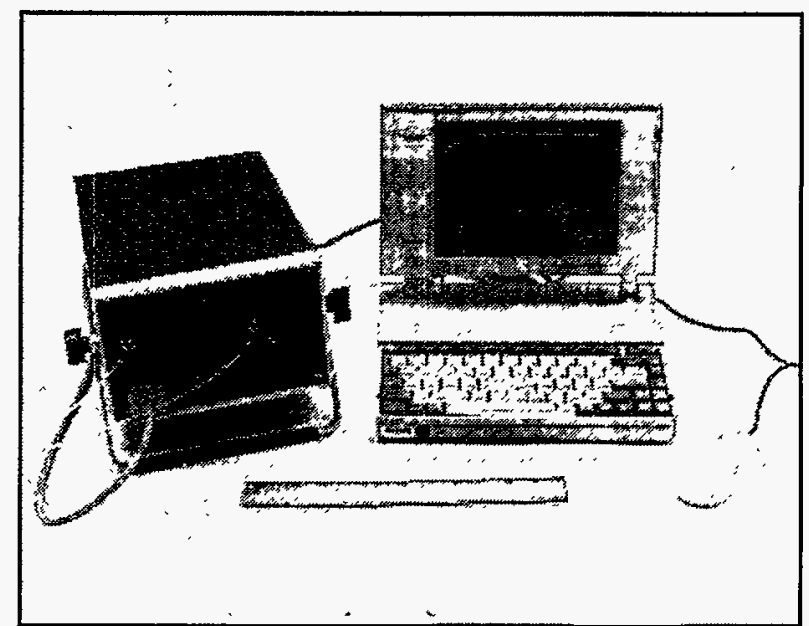

Figure 1.14a. Bench-Top Portable Acoustic Wave Sensor (PAWS) System.

using pattern recognition techniques on the multiple responses from the sensor array.

Current project activities are focused in three areas. The first task is completing the documentation of the capabilities of single sensor PAWS systems developed to date. The two systems developed are: a bench-top system the size of a shoe box and a downhole probe version that can be placed in vadose zone wells. This document will summarize the labora-

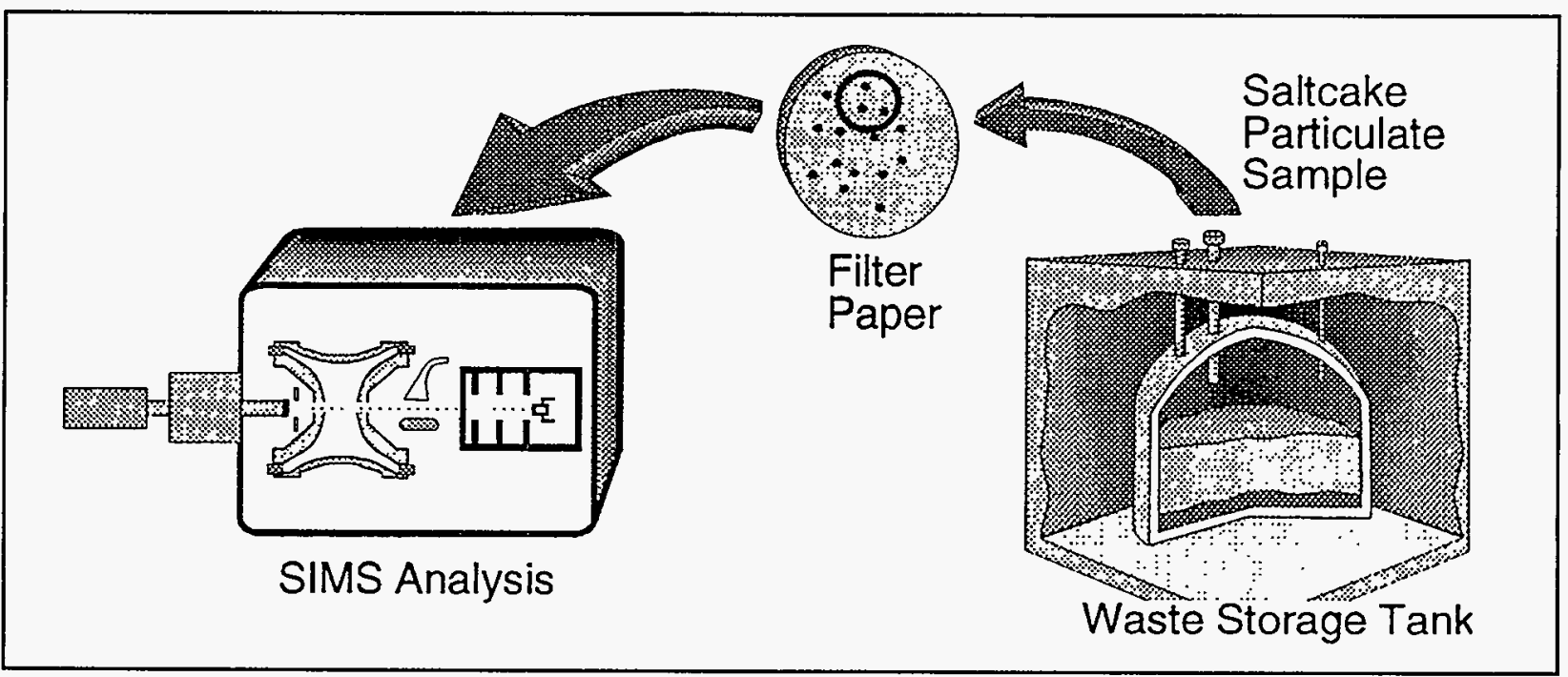

Figure 1.14b. Schematic of a Surface Acoustic Wave (SAW) Sensor. 
tory evaluations and the results of eight field demonstrations at the Hanford and Savannah River sites. The second task involves developing and demonstrating environmental sampling systems using preconcentrators and semi-permeable membranes that will increase the versatility and ruggedness of the PAWS technology. Sensing capabilities are being extended to provide lower detection levels (about a factor of 100 lower), an improved resistance to interfering chemicals, and an ability to provide rapid, field analysis of water samples. An example of an application being impacted by these improvements is the ability to monitor residual CHCs such as TCE after on-site destruction in offgas streams. This application requires sub-ppm detection levels for the TCE with a resistance to the high acid nature of these streams.

The third task involves developing and testing sensor coating materials to provide molecular discrimination of multiple VOCs in mixtures using an array of sensors. The improved chemical discrimination in this multi-sensor system will allow this upgraded system to impact a much wider range of applications than the single sensor systems that can only be used with isolated VOCs.

\section{TECHNOLOGY NEEDS}

Many DOE sites have been contaminated with VOCs, such as the carbon tetrachloride found at the Hanford Site and the TCE found at the Savannah River Site. In addition, there are a large number of non-DOE sites that have also been contaminated with VOCs. To characterize this contamination, sensors are needed that can provide rapid field screening before, during, and after remediation processes. Systems are also needed for real-time, on-line monitoring of contamination levels in process streams during the remediation. For example, monitoring of VOCs in off-gas streams during soil vapor extraction operations can help to document the effectiveness of the remediation and to optimize its performance. Finally, sensors that can be used for in situ monitoring can alleviate the many sampling problems that arise, especially with deep monitoring wells.

\section{ACCOMPLISHMENTS}

- A bench-top PAWS system about the size of a shoe box has been developed for real-time, on-line monitoring of isolated VOCs. Using a notebook computer with an easy to operate routine, real-time presentation of VOC concentrations is possible.

- The bench-top PAWS system has been demonstrated at both Hanford and Savannah River for real-time, on-line monitoring of VOCs in off-gas streams from soil vapor extractions systems. The system was shown to be easy to set up and use, and demonstrated its ability to provide rapid and accurate analysis.

- The benchtop PAWS system has been demonstrated at Hanford for rapid, real-time monitoring of samples pulled to the surface from a cone penetrometer probe.

- A downhole PAWS system with associated packers has been developed for in situ monitoring of isolated VOCs in vadose zone boreholes with diameters over 4 inches.

- The downhole probe has been demonstrated at Hanford, providing continuous in situ monitoring of carbon tetrachloride concentrations from 10 to over 20,000 ppm. Comparison of downhole detection to sampling from the surface demonstrated the difficulty of sampling from the surface of obtaining a representative sample due to loss or addition of VOCs in the sampling lines.

- A benchtop PAWS system for detecting residual VOCs in treated off-gas streams containing high acid concentrations has been developed. Laboratory tests show detection levels for carbon tetrachloride and TCE below one $\mathrm{ppm}$, even in the presence of $4,000 \mathrm{ppm}$ of hydrochloric acid vapor. 


\section{BENEFITS}

PAWS can perform continuous, on-line or in situ monitoring, with rapid and reversible response. In comparison to off-site analysis of grab samples, PAWS will perform real-time monitoring. This can be beneficial when conducting remediation activities. The systems are small, portable, and easy to set up and use. Combined with the low system cost, the low operating costs make the PAWS technology much less expensive. The sensor can be configured so that it can be placed downhole for in situ monitoring and can be automated to provide chemical information to site remediation workers on the distribution and concentration of a contaminant. Current PAWS systems have capabilities for determining molecular species and concentration of isolated chemicals. Systems under development will be able to analyze multiple species in mixtures in either air or water. Detection levels will be at or below typical regulatory action levels. PAWS is fast, cheap, and as safe as a gas chromatograph or infrared analyzer.

\section{COLLABORATION/TECHNOLOGY TRANSFER}

This project is being performed in collaboration with two U.S. companies, a major instrument manufacturer partnered with a leading SAW supplier (names withheld at the companies' requests until agreements are established), and Pacific Northwest Laboratory. These companies are providing significant development resources and will be the avenue for commercializing the technology. These two partners were chosen based on business plans submitted in response to a mailing to 175 companies identified by various sources, including contacts from public presentations and publications, a Commerce Business Daily announcement, a press release, and a market survey. Discussions are also being held with a variety of other companies interested in utilizing the technology being developed in selected applications ranging from leak detection to process monitoring and control. A bench-top PAWS system has already been provided to Hanford environmental restoration personnel for use in off-gas monitoring and discussions are ongoing with Savannah River regarding a similar system.

For further information, please contact:

Greg Frye

Principal Investigator

Sandia National Laboratory

P.O. Box 5800, MS-0351

Albuquerque, NM 87185-0351

(505) 844-0787

\section{Tom Brouns}

Pacific Northwest Laboratory

P.O. box 999, MS K9-D8

Richland, WA 99352

(509) 372-6265

\section{George Allen}

Technical Program Manager

Sandia National Laboratory

P.O. Box 5800 , MS- 0756

Albuquerque, NM 87185-0351

(505) 844-9769

Dr. Caroline Purdy

Program Manager, CMST-CP

U.S. Department of Energy

Cloverleaf Building

19901 Germantown Road

Germantown, MD 20874-1290

(301) 903-7672

TTP Numbers: AL221104

\section{BIBLIOGRAPHY OF KEY PUBLICATIONS}

R.W. Cernosek, G.C. Frye, and D.W. Gilbert, "Portable Acoustic Wave Sensor Systems for RealTime Monitoring of Volatile Organics", Procedures: Ideas in Science and Electronics, Albuquerque, NM, p. 44, 1993.

G.C. Frye and S.H. Pepper, "Techniques for Minimizing Environmental Interferences in Portable Acoustic Wave Sensor Systems", AT-OnSite, the Journal of OnSite/Real-Time Analysis (in press). 
G.C. Frye, S.J, Martin, R.W. Cernosek, and K.B. Pfeifer, "Portable Acoustic Wave Sensor Systems for On-Line Monitoring of Volatile Organics", International Journal of Environmentally Conscious Manufacturing, 1, 37, 1992.

G.C. Frye and S.J. Martin, "Velocity and Attenuation Effects in Acoustic Wave Chemical Sensors", Proceeding: 1993 IEEE Ultrasonics Symposium, (IEEE, Piscataway, NJ), p. 379, 1993.

G.C. Frye, S.J. Martin, R.W. Cernosek, K.B. Pfeifer, and J.S. Anderson, "Portable Acoustic Wave Sensor Systems", Proceeding: 1991 Ultrasonics Symposium (IEEE, Piscataway, NJ, 1991) p. 311. 


\subsection{SURFACE ACOUSTIC WAVE ARRAY DETECTORS}

\section{TASK DESCRIPTION}

The purpose of this task is to design, develop, and demonstrate array sensor systems for sensing VOCs, including chlorinated hydrocarbons and other vapors of interest to environmental cleanup and occuparional safery. These sensor arrays will be based on polymer-coated SAW vapor sensors and data processing using pattern recognition and chemometric techniques. Key elements of this effort include the rational choice of polymer materials for use as the selective sensing layers, a predictive method for sensor performance, experimental evaluation of sensor arrays for VOC detection, and pattern recognition and other chemometric techniques for converting data into chemical information.

The advantages of the SAW vapor sensor technology include the rugged planar design of the devices, the suitability of polymer-coated devices for use in arrays with pattern recognition, the fast response times (seconds), rapidly reversible responses-the selective material is not altered by the vapor, the high vapor sensitivities (ppm to ppb detection limits depending on the particular vapor), and the flexibility of the array approach to be adapted to many detection problems. The analyte or analytes to be detected by a SAW sensor array system can be changed merely by the selection of the polymer coatings and the pattern recognition algorithm used.

The sensor array approach provides greatly increased selectivity and reliability in field environments over a single sensor. Single sensors cannot determine if an interfering species is present that might invalidate the measurement. In addition, sensor arrays offer the possibility of detecting and quantifying multiple analytes with the same system. The handheld SAW sensor array systems envisioned will convert data into chemical information and communicate it in a form necessary for decision-making. Thus, SAW sensor technology will become the basis for practical fieldable solutions to characterization and monitoring problems.

\section{TECHNOLOGY NEEDS}

Characterization, monitoring, and cleanup of contaminated DOE sites will require field-deployable analytical techniques such as chemical sensors. Chlorinated hydrocarbons contaminate soil and groundwater at more than $10 \mathrm{DOE}$ sites. At each individual site, concentrations found vary widely. Sensors that are sensitive, selective, operate over a wide dynamic range, and suitable for deployment in field environments are required.

\section{ACCOMPLISHMENTS}

This new task, begun in FY95, will use a rational approach for the selection of polymeric sensor coating materials for SAW sensor arrays. This approach is based on models for the sorption of vapors by polymers. These models use linear solvation energy relationships (LSERs) and allow the prediction of polymer/gas partition coefficients. Using models for SAW sensor transduction mechanisms, these partition coefficients can be converted to sensor responses. The LSER database at PNL includes equations for 14 polymers of quite diverse structures. These equations are combined with solvation parameters for hundreds of vapors to permit calculation of thousands of partition coefficients. This database is being examined to assist in several aspects of sensor array development, including the determination of which polymers provide sensors with the best sensitivity for particular vapors and the selection of polymers for sensor arrays.

Future work will involve fabrication of sensors and sensor arrays based on the guidance from this approach, and testing against a diverse set of vapors. An automated multi-vapor test system has been developed and calibrated for 22 different vapors, including several chlorinated hydrocarbons. The resulting data will be used to develop pattern recognition algorithms and calibration models for vapor identification and quantification. 


\section{BENEFITS}

Appropriate sensing of VOCs during environmental cleanup will improve worker safety, aid in decision making on types of protective equipment required, length of time workers can stay in the environment, and reduce costs by measuring multiple vapors with a single instrument rather than requiring separate sensors for each vapor.

\section{COLLABORATION/TECHNOLOGY TRANSFER}

This work is being coordinated with SAW sensor development tasks at Sandia National Laboratory. In addition, a collaboration exists with a major U.S instrument manufacturer and discussions are in progress with a sensor manufacturer.

For further information, please contact:

\section{Jay W. Grate}

Principal Investigator

Pacific Northwest Laboratory

P.O. Box 999, MSIN K2-12

Richland, WA 99352

(509) 375-4547

\section{Steven Slate}

Technical Program Manager

Pacific Northwest Laboratory

P.O. Box 999

Richland, WA 99352

(509) 375-3903

\section{Deborah E. Trader}

Technical Program Officer

U.S. Department of Energy

Richland Operations Office

825 Jadwin Avenue

P.O. Box 550

Richland, WA 99352

(509) 372-4035

Dr. Caroline Purdy

Program Manager, CMST-CP

U. S. Department of Energy

Cloverleaf Building

19901 Germantown Road

Germantown, MD 20874-1290

(301) $903-7672$

TTP Number: RI353003

BIBLIOGRAPHY OF KEY PUBLICATIONS

None at this time. 


\subsection{ANALOG SITE FOR CHARACTERIZATION \\ OF CONTAMINANT TRANSPORT \\ THROUGH FRACTURED ROCK}

\section{TASK DESCRIPTION}

This project is designed to identify reliable tools and methodologies for characterizing the fractures that control flow and transport in specific geologic settings. Characterization tools will be used to predict the outcome of flow and transport experiments in fractured rock in order to assess the utility of these tools for characterizing important hydrologic features in similar contaminated sites.

At an analog site in the Snake River Basalts, two series of measurements will be performed. The first series would be designed to characterize the hydrology of the site. The second set would be a flow and transport experiment designed to test the predictive capability of the characterization methodology.

The characterization phase will begin with a geologic investigation designed to identify the style of fracturing and the likely fracture patrerns. Then a suite of geophysical investigations would be performed that are expected to give indications of fractures that control permeability. Techniques such as seismic tomography, three-dimensional seismic, EM tomography, radar reflection and tomography, hydraulic interference testing will be used. Any method judged to be useful at the particular site could be tried. The interpretation(s) of these measurements would consist of one or more estimates of the location of important hydrologic fractures. These features would then become the subject of a series of hydraulic tests designed to diagnose the hydrologic properties of the system. Tests could include fluid logging, interference testing and tracer tests. Conceptual models for flow and transport would be constructed based on this characterization.

The flow and transport tests would consist of tests designed to confirm the hydrologic flow paths. These might be tracer tests designed to prove the hydrologic connections between two or more points.
In addition, a combination of hydrologic and geophysical monitoring tests will be performed. These could include radar tomography done during the progress of a saline tracer test, or perhaps seismic monitoring during the injection of a gas or fluid of different elastic properties than water. The idea here is to image the flow through flow induced changes in geophysical properties. Comparison of the flow experiments with the flow patterns predicted in the first phase will provide a format for identifying those methods or combinations of methods that successfully identify the fractures that control flow.

\section{TECHNOLOGY NEEDS}

Many contaminated sites are located in fractured rock. For example, the Oak Ridge National Laboratory has significant contamination in fractured shale. INEL and the Hanford Sites have problems in fractured basalt. The characterization of these sites in order to predict the transport of contaminants can be problematic. The location of fractures is often a mystery, and their effect on flow can be dramatic. The fractures themselves may be leached by reactive waste material. Containment of the waste may require the sealing of fractures. Thus, the three key issues that influence remediation of these sites are:

- Finding the fractures that control fluid flow and transport;

- Analyzing fluid flow and transport in the fracture system; and

- Control of contaminant transport in the fracture system. 


\section{ACCOMPLISHMENTS}

A study site has been identified in the Snake River Basalts and a close collaboration with INEL has been established. Assessment of previous data is underway and plans for field studies are being formed. The Coordination Task Force has had its first meeting.

\section{BENEFITS}

The results of this project fall in two categories. First, the project would be conducted in a rock mass that is analogous to a significantly contaminated rock mass. Therefore, the tools developed and checked at this site would be reliable for use in the real contaminated site. Secondly, the methodology for characterizing fractured materials would be extended making it possible to move on to new geologic settings much more efficiently.

\section{COLLABORATION/TECHNOLOGY}

\section{TRANSFER}

Stanford University provides the geologic investigation of fracture systematics. EMI, Inc., a small business, is contracted for geophysical surveys. Traditional geophysical service companies and other geotechnical firms can learn from this project, either by direct participation or through the results of the project. Interest in the technology developed by the project could be quite large as there are many contaminated sites in fractured rock. There is a possible collaboration with a $\mathrm{DoD}$ database design project.

\section{For further information, please contact:}

Jane C. S. Long

Principal Investigator

Energy and Resource Development Dept.

Lawrence Berkeley Laboratory

Building 50C

Berkeley, CA 94720

(510) 486-6697

\section{Peter Zawislanski}

Lawrence Berkeley Laboratory

Building 50E

Berkeley, CA 94720

(510) 486-4157

\section{Chin Fu Tsang}

Technical Program Manager

Lawrence Berkeley Laboratory

1 Cyclotron Road

Berkeley, CA 94720

(510) 486-5782

\section{Dr. Caroline Purdy}

Program Manager, CMST-CP

U. S. Department of Energy

Cloverleaf Building

19901 Germantown Road

Germantown, MD 20874-1290

(301) 903-7672

TTP Numbers: SF141001, ID453001

BIBLIOGRAPHY OF KEY PUBLICATIONS

None at this time. 


\subsection{INTEGRATED GEOPHYSICAL AND \\ HYDROLOGICAL CHARACTERIZATION OF TRANSPORT THROUGH FRACTURED MEDIA}

\section{TASK DESCRIPTION}

This task is designed to identify a suite of reliable tools and merhodologies that can be used together to identify fast flow paths through fractured media. No one technology is expected to be sufficient for this purpose, so a suite of technologies was demonstrated at the Large Scale Aquifer Pumping and Stress Test site in FY94. This existing data set will be used to demonstrate the effectiveness of using multiple technologies to map, monitor, and predict fluid flow through the subsurface. The technologies used include conventional downhole sampling techniques and innovative non-intrusive techniques.

During FY95, interpretation of the existing geophysical data collected in FY94 will be performed, including the development and demonstration of interpretation techniques that correlate the geophysical data with the hydrologic data. Monitoring plumes using non-intrusive geophysical techniques in conjunction with borehole sampling techniques will result in better characterizations and monitoring of contaminant migration.

\section{TECHNOLOGY NEEDS}

The target problem addressed by this task is the difficulty of determining the transport rates and flow paths of contaminants from hazardous waste sites located in highly heterogeneous geologic areas. At many DOE sites with fracture systems (INEL, Oak Ridge, and Hanford, for example) current monitoring technologies does not adequately characterize the hydrologic structures affecting migration and transport of contaminants, nor do they adequately monitor the migration of contaminants through the subsurface. The causes of these deficiencies are two-fold. First, the transport of contaminants through fracture systems cannot be easily understood using transport modeling techniques based on porous media assumptions. Second, moni- toring solely with borehole sampling can miss significant features controlling transport in fractured or heterogeneous media.

\section{ACCOMPLISHMENTS}

During FY94, a preliminary infiltration test was performed at the Large-Scale Aquifer Pumping and Stress Test site at INEL. During this test, a large DC resistivity array was demonstrated and used in conjunction with borehole monitoring techniques. Initial data reduction activities have shown a correlation between the geophysical data, the hydrologic data, and the migration of water through the subsurface below and around the basin.

\section{BENEFITS}

The benefits of developing innovative monitoring technologies and using them in conjunction with traditional monitoring technologies are three-fold. First, this task provides a more efficient means of monitoring contaminant migration in highly heterogenous areas. Second, a better understanding of the complex geology that controls the hydrologic structure and hence migration paths and rates for contaminants is provided. Third, use of an integrated approach allows more effective placement of monitoring wells, thus limiting the number of wells drilled while at the same time increasing the overall understanding of the hydrologic and transport parameters controlling the migration of contaminants.

\section{COLLABORATION/TECHNOLOGY TRANSFER}

The initial Large-Scale Aquifer Pumping and Stress Test was funded predominantly by EM-40. EM-40 
is currently supporting portions of the final interpretation of the data from this test in conjunction with a separate TTP awarded to Lawrence Berkeley Laboratory (LBL). Private industry is currently involved as performers in FY94 and FY95. Numerous peer-reviewed publications and presentations at national technical meetings will be prepared to further publicize the results. Finally, discussion is currently underway to use the technologies demonstrated in FY94 and FY95 at other sites across the DOE Complex.

For further information, please contact:

M. Cathy Pfeifer

Principal Investigator

Idaho National Engineering Laboratory

P.O. Box 1625

Idaho Falls, ID 83415

(208) 526-1893

\section{S. Ken Merrill}

Technical Program Manager

Idaho National Engineering Laboratory

P.O. Box 1625

Idaho Falls, ID 83415

(208) 526-0797

\section{Dr. Caroline Purdy}

Program Manager, CMST-CP

U.S. Department of Energy

Cloverleaf Building

19901 Germantown Road

Germantown, MD 20874-1290

(301) $903-7672$
TTP Numbers: ID453001, SF141001

\section{BIBLIOGRAPHY OF KEY PUBLICATIONS}

Norrell, G.T., C.F. Knutson, J. Crocker, A.H. Wylie, Large-Scale Infiltration Test Site Characterization, EG\&G, EGG-ER-11304, Rev. 0, July, 1994.

Norrell, G.T., I. Porro, F.M. Dunnivant, J.M. Hubbell, M.C. Pfeifer, R.C. Starr, M. E. Newman, and C.W. Bishop, Conceptual Design of the LargeScale Infiltration Test, G\&G, EGG-ER-11363, Rev. 0, July 1994.

Pfeifer, M.C., Test Plan for the Direct Current (DC) Resistivity Array, EG\&G, EGG-ER-11365, Rev. 0, June 1994.

Porro, I., J.M. Hubbell, J.B. Sisson, C.W. Bishop, J.D. Burgess, E. Neher, and T.K. Honeycutt, Vadose Zone Monitoring Test Plan, EG\&G, EGGER-11369, Rev. 0, July 1994. 


\subsection{INTERNATIONAL ENVIRONMENTALASSESSMENT}

\section{TASK DESCRIPTION}

Nuclear fuel cycle activities of the former Soviet Union (FSU) have resulted in massive contamination of the environment in western Siberia. Pacific Northwest Laboratory is developing three-dimensional simulation models of the hydrogeology and potential contaminant migration in the West Siberian Basin. DOE uses such models to evaluate the potential for risk from contaminated U.S. sites, and to design mitigation strategies for them. Studies of the West Siberian Basin, which contains the largest amounts of surface and subsurface radioactive contaminants on earth, provide one of the best opportunities to verify and validate DOE models and modeling strategies using decades of data from fullscale experiments. The long-term goal is to determine future environmental and human impacts given the releases that have occurred to date in the West Siberian Basin and the waste management practices still in use there. Our objectives for FY94 were to document: (1) refinement and continued calibration of the regional hydrogeologic model of the West Siberian Basin, (2) the spatially registered, digital geologic and hydrologic databases derived from open-literature sources that implement the hydrogeologic conceptual model of the hydrogeology of Tomsk; and (3) the preliminary hydrogeologic conceptual model for Tomsk and its computer implementation.

\section{TECHNOLOGY NEEDS}

Validation of existing contaminant transport models may help site managers obtain approval from regulators for fewer samples, analyses, wells, and stronger cases for No Further Action (NFA) at many DOE sites.

\section{ACCOMPLISHMENTS}

Key issues for FY94 regional-model refinement and calibration were: (1) the use of isotropic material properties, (2) the low vertical resolution related to the lumping of all of the basinal facies into a single second layer, (3) the need to investigate whether the chronostratigraphic rock-type descriptions are consistent with known patterns of basinal deposition as well as other geologic and hydrologic cross-sections, and (4) whether an appropriate assignment of hydrologic properties can be developed that is consistent both with published geologic descriptions and with published hydrostratigraphic interpretations.

Sensitivity of a thirteen-layer hydrogeologic model of the West Siberian Basin was examined with four cases: three isotropic and one anisotropic. The resulting patterns of flow in the lower layers in the simulations is similar to that in the surface layers, which is in agreement with published behavior of the regional hydrogeologic system. The hydraulic heads from the anisotropic-case simulation are significantly different from the isotropic case results, although the general shapes of the head contours in the anisotropic case are similar to the isotropic cases. This results from the reduced vertical hydraulic conductivity, limiting the flux to these layers, and the larger horizontal conductivity, which requires less of a hydraulic gradient to drive this water horizontally within the layers. A finite element mesh was developed for the Tomsk area using an approach similar to that used in the development of the finite element mesh for the regional West Siberian Basin model. Equations and assumptions in the regional conceptual model also apply to the Tomsk area conceptual model. More detailed data on the geology of the Tomsk area were acquired through direct contacts and cooperation with the FSU scientists, and will be used in FY95 to develop the refined Tomsk local model. General results of the Russians' 
work are apparently similar to the behavior of our regional model in the Tomsk area in some of our sensitivity analyses, including the potential for upwelling ground water flow in the vicinity of the Tomsk injection areas.

\section{BENEFITS}

- Technical collaboration with former Soviet Union states and scientists on transport of large-scale ground water contamination.

- Validation of ground water transport models of U.S. scientists with decades of ground water sampling data.

\section{COLLABORATION/TECHNOLOGY TRANSFER}

Technical expertise from the United States is being brought to bear on transport of large-scale groundwater contamination.

For further information, please contact:

D. J. Bradley

Principal Investigator

Pacific Northwest Laboratory

P.O. Box 999, MS K8-41

Richland, WA 99352

(509) 372-4671

\section{Cheryl Thornhill}

Technical Program Manager

Pacific Northwest Laboratory

P.O. Box 999

Richland, WA 99352

(509) 375-2532
Dr. Caroline Purdy

Program Manager, CMST-CP

U.S. Department of Energy

Cloverleaf Building

19901 Germantown Road

Germantown, MD 20874-1290

(301) 903-7672

TTP Number: RL341009

BIBLIOGRAPHY OF KEY PUBLICATIONS

None at this time. 


\title{
CMST-CP Projects FOR THE
}

\author{
High-Level Waste Tank \\ REMEDIATION Focus Group
}




\section{CONTINUOUS IN SITU MONITORING OF GASEOUS COMPONENTS IN UNDERGROUND STORAGE TANKS USING PIEZOELECTRIC THIN FILM RESONATOR SENSORS}

\section{TASK DESCRIPTION}

This task is focusing on the development of fielddeployable gas sensors for use in the in situ monitoring of head space gases in underground storage tanks (USTs) and remediation sites located primarily at the Hanford facility. The gas sensor system is comprised on arrays of piezoelectric mass sensors and electronic readout instrumentation for the determination of the concentrations of several hazardous gases in the hostile environment of USTs (e.g., hydrogen, nitrous oxide, and ammonia). Using integrated circuit technology and specially synthesized surface coatings, small, low-cost sensor systems capable of long-term, low maintenance operation are under fabrication as field-deployable prototypes.

The gas sensors use bulk acoustic wave piezoelectric mass sensors coated with materials that selectively sorb the target gases. The sensors employ thin film resonators (TFRs) as transducers. The TFRs are constructed from thin piezoelectric aluminum nitride membranes shaped in $400-\mu \mathrm{m}$ squares that are supported by a silicon substrate. See Figure 2.1a.

These sensors can detect mass loading at extremely low levels (i.e., $2 \mathrm{ng} / \mathrm{cm}^{2}$ ) that are well below the mass loading for the adsorption of a single molecular layer of the target gases. The instrument is also being constructed from components that can with-

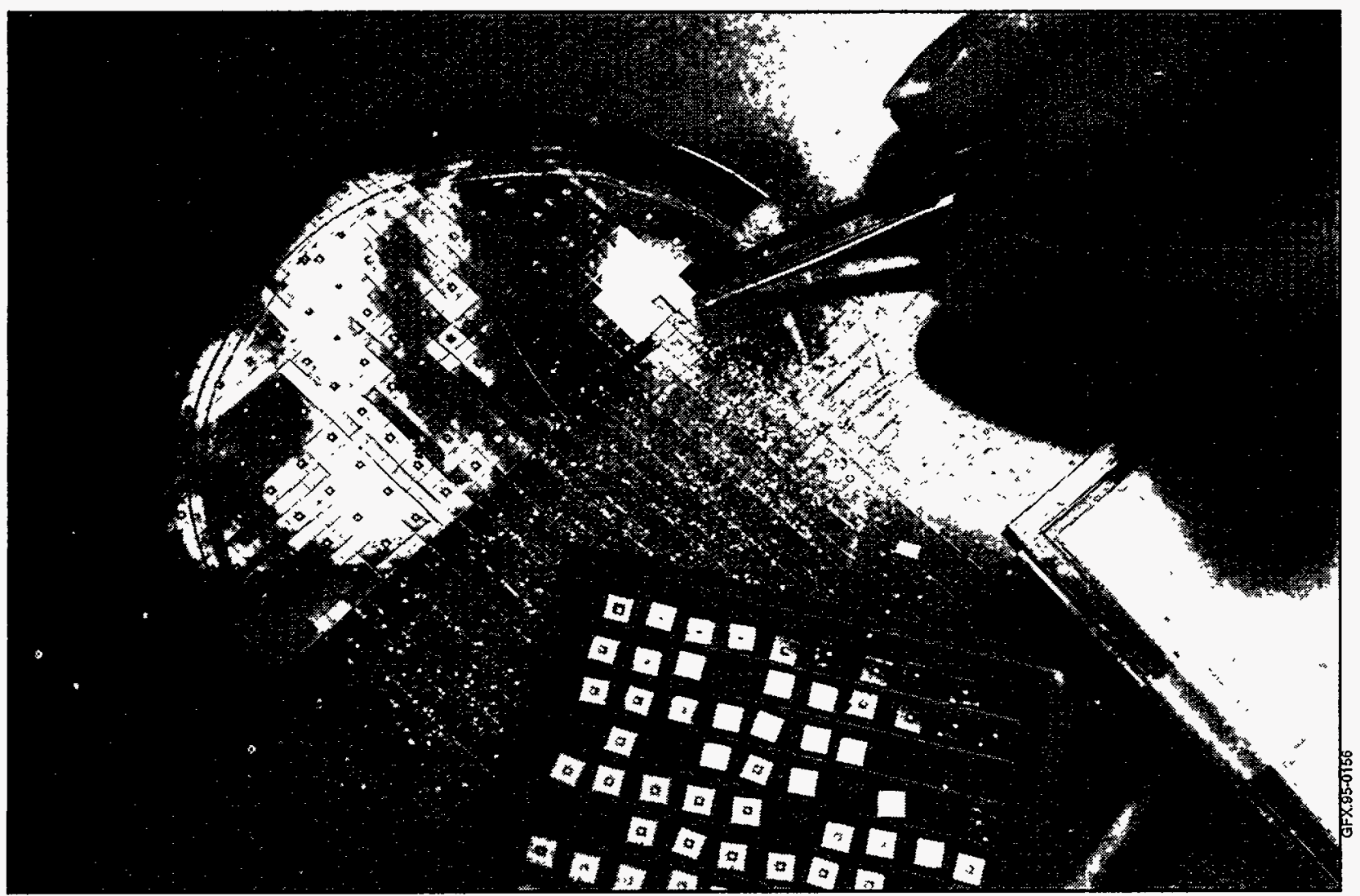

Figure 2.1a. A Wafer of TFRs After Processing and Prior to Packaging and Incorporation into an Array. 
stand the harsh chemical and radiological environment of USTs.

\section{TECHNOLOGY NEEDS}

The head spaces of USTs often contain explosive and toxic gases such as $\mathrm{H}_{2}, \mathrm{~N}_{2} \mathrm{O}, \mathrm{NH}_{3}$, and various hydrocarbons. These gases are released at the surface of high-level tank wastes, inducing a transient and potentially hazardous increase in local concentrations. The problem is amplified by the large number (177) and storage volumes of the USTs at the Hanford facility, with 25 of the tanks on the watch list. Thus, methods are needed to characterize the release and movement and monitor quantitatively the concentrations of these gases over extended periods of time at several locations in each tank. In view of the explosive potential of these head-space gases, it is also important that the sensors not pose a spark hazard. The monitoring need therefore requires the development of cost-effective gas sensors capable of long-term, unattended operation.

\section{ACCOMPLISHMENTS}

Prototype hydrogen sensors have been created by depositing a variety of doped and alloyed palladium films described in the literature to the surfaces of quartz crystal microbalances (QCMs). (Our general development procedure first tests coatings on QCMs and then on TFRs.) Linear responses over two orders of magnitude have been obtained, with a detection limit of a few parts-per-million. An example set of results is illustrated in Figure 2.1b. Importantly, the response of these coatings to $\mathrm{H}_{2}$ is the result of the dissociation and subsequent uptake of the analyte into the bulk of the coating, whereas the response to interferences is confined to a surface adsorption process. Thus, an analysis of the responses from an array of these sensors with varied coating thicknesses provides a basis to account quantitatively for the effects of interferences. Related approaches are being devised for $\mathrm{N}_{2} \mathrm{O}$ and $\mathrm{NH}_{3}$. A field-deployable sensor system is under development for operation in the hardware cabinets fixtured at the USTs of the Hanford facility. TFR-based arrays consisting of reference and indicator pairs, as depicted in Figure 2.1c, with partial compensation of non-specific effects such as temperature are in a second generation design stage. Electronic support circuitry has been successfully designed and implemented using surface mount components to facilitate maintenance. Designs for higher density TFR-based arrays are being implemented.

\section{BENEFITS}

Present technology, based on tests at the Hanford facility, only partially solves the monitoring needs at the USTs. Whitaker cells exhibit the requisite selectivity for $\mathrm{H}_{2}$ monitoring, but detection limits $(-100 \mathrm{ppm})$ and response times $(-2 \mathrm{~min})$ are unacceptable, precluding both an accurate assessment of $\mathrm{H}_{2}$ levels (15-20 ppm) during periods of low outgasing as well as the feedback rate $(-30 \mathrm{~s})$ necessary for a reliable assessment of the dynamics of outgasing. Similar limitations exist for the monitoring of $\mathrm{NH}_{3}$, where a photoacoustic cell has been coupled with an infrared spectrometer. Other more conventional approaches (e.g., miniaturized gas chromatographs) have prohibitively high equipment and operational costs. This task addresses these problems through the development, testing, and implementation of miniaturized, low-cost, fielddeployable sensors systems for real-time monitoring of hazardous components in UST head-space gases.

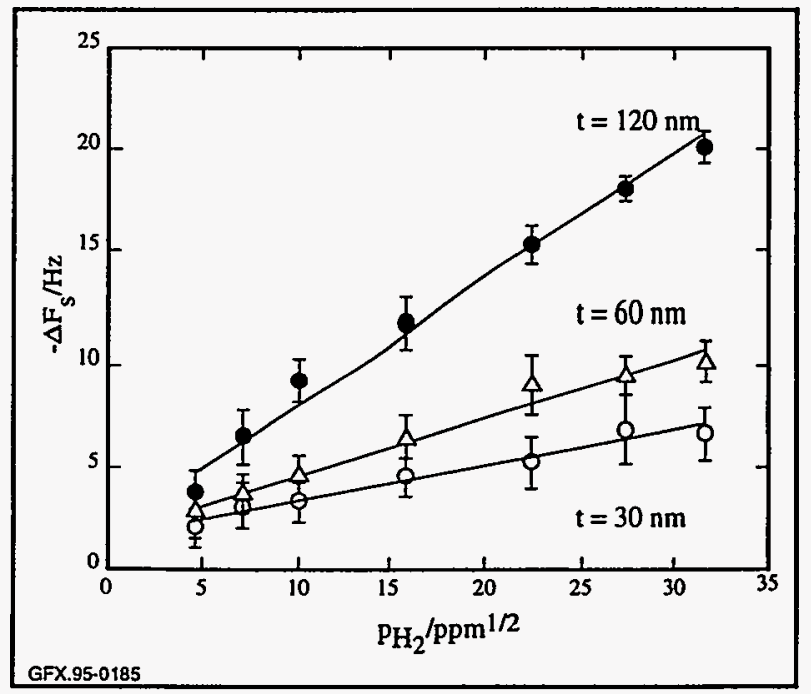

Figure 2.1b. Responses of QCM/PdNi to $\mathrm{H}_{2}$ as a Function of Film Thickness 


\section{COLLABORATION/TECHNOLOGY}

\section{TRANSFER}

Upon completion, the field-deployable gas sensor system will be useful for the characterization and long-term monitoring of hazardous and toxic gases in USTs. Collaborations, design, and performance specifications have been established and examined in view of the needs of the Hanford facility. The planning of a site visit and subsequent field tests is underway.

Commercialization of TFRs has been discussed with several corporations to find a partner for manufacturing and systems integration. An option for a license to patented TFR technology has been offered to one company for a portion of the environmental monitoring applications related to DOE needs. Discussions are continuing with other corporations for development of TFR sensors for commercial as well as other DOE-related areas.

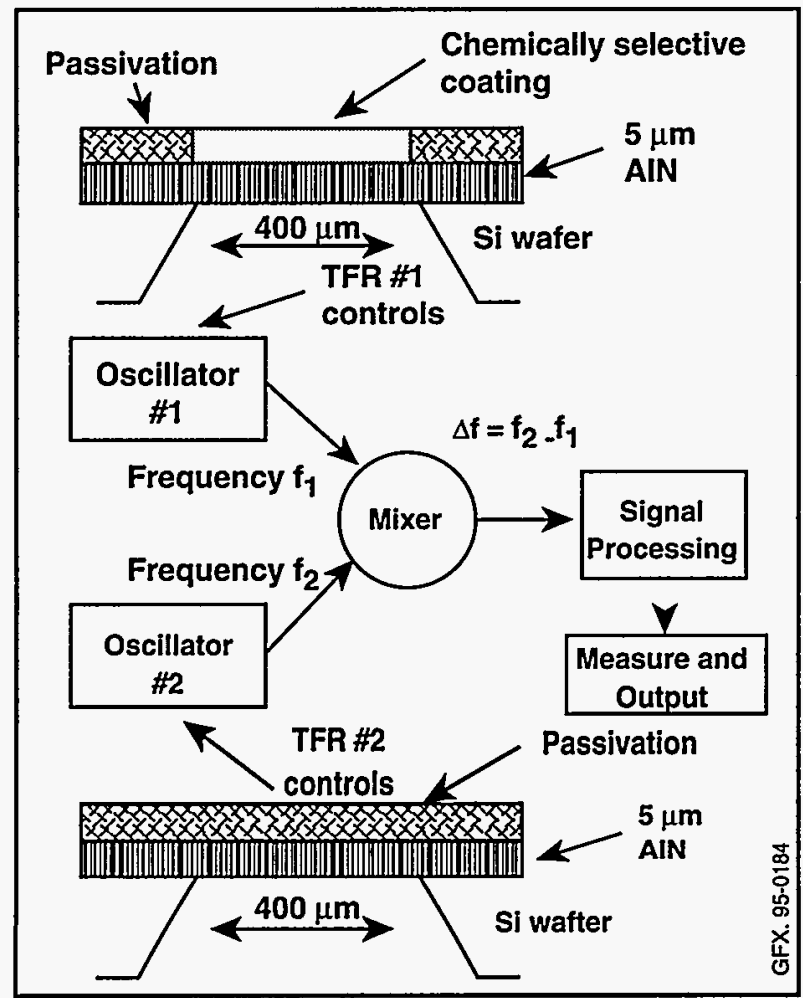

Figure 2.1c. Thin Field Resonator Sensors

(TFRs)
For further information, please contact:

Marc D. Porter

Principal Investigator

Ames Laboratory

109 Office and Laboratory Building

Iowa State University

Ames, IA 50011

(515) 294-6433

\section{Steve Webster}

Technical Program Officer

U.S. Department of Energy

Chicago Operations Office

9800 S. Cass Avenue

Argonne, IL 60439

(708) 252-7822

\section{Al Tardiff}

Project Manager, CMST-CP

U.S. Department of Energy

Cloverleaf Building

19901 Germantown Road

Germantown, MD 20874-1290

(301) $903-7670$

TTP Number: CH131004

\section{BIBLIOGRAPHY OF KEY PUBLICATIONS}

O'Toole, R.P., Burns, S.G., Bastiaans, G.J., Porter, M.D. Anal. Chem. 1992, 64 1289-1294. 


\subsection{ELECTRICAL RESISTANCE TOMOGRAPY FOR SUBSURFACE IMAGING}

\section{TASK DESCRIPTION}

The goals of this task are to: (1) develop and demonstrate a system for detecting and locating leaks in the single shell tanks at the Hanford Site, (2) develop a practical, fully three-dimensional inverse code for electrical resistance tomography (ERT), and (3) extend research and development for detection of non-aqueous phase liquids (NAPLs), by a small-scale ERT imaging experiment of a TCE or PCE release at the Oregon Graduate Institute LEAP tank facility.

\section{TECHNOLOGY NEEDS}

The ERT technology can be used for detecting leaks from the Hanford single-shell tanks. DOE has approximately 149 single-shell tanks that have been used to store high-level mixed wastes, many located at the Hanford site. It is known that 60 to 70 of these tanks are leaking and releasing their contents to the surrounding soil. Other tanks may be leaking, but the existing techniques for determining leakage prevents an accurate assessment. In line with the potential for danger such releases pose to site personnel and the longer term danger to the surrounding communities, environmental regulations require that even small volume releases from these tanks be reported. There is a clear need to be able to detect when a tank begins leaking so that corrective measures can be taken before damage is great. There is also a need to be able to isolate the leak location in the event that tank repairs are practical.

There are currently two methods for detecting leaks, and neither is useful for locating the precise location point. The simplest method is a careful inventory of tank contents. Unfortunately, the precision needed in level sensing is not simple with the nasty conditions in these tanks. Even level sensors are troublesome due to the large chunks of waste in some tanks. The other approach is to drill beneath the tank and install sen- sors. This method also presents problems since these sensors provide point measurements under the tank, and any leakage will be highly channeled due to the heterogeneous soil at Hanford and will likely be missed.

In situ remediation of contaminated sites requires at least two activities. First, it is necessary to characterize the relevant parameters of the site (e. g., geology, hydrology, geochemistry). Second, it is necessary to monitor whatever method is used to accomplish the remediation in order to control the process and evaluate the final results. Current technology for both tasks is often based on drilling and sampling, which is expensive, invasive, and often produces a very sparse data set. A technology is needed to provide highresolution information between boreholes. ERT is designed to fill in this missing information. A 2.5dimensional code has proven useful for many applications, especially for cross-borehole imaging where the subsurface is approximately two dimensional. However, much of the world cannot adequately be approximated by two dimensions. There is a clear need for accurate three-dimensional images of subsurface properties and processes. Such a capability would be very valuable in environmental restoration work as well as many other geophysical and geotechnical areas.

Much of the subsurface soil and ground water contamination that DOE is required to clean up is contaminated with NAPLs. Unfortunately, most of theseliquids are very difficult to detect without drilling a borehole and testing a soil or water sample. Because the subsurface is usually very heterogeneous, a lot of drilling is need for this approach to adequately map most contaminant plumes. A method is needed to look beneath the surface or perhaps between boreholes and map the three-dimensional extent of NAPL contaminants. This ability would make possible estimates of the contaminant mass, lateral extent of the plume, speed and direction of transport, and would greatly aid in designing remediation strategies. 


\section{ACCOMPLISHMENTS}

- Detecting leaks from the Hanford underground, single-shell tanks is a continuing task. At the DOE Hanford Site, a storage

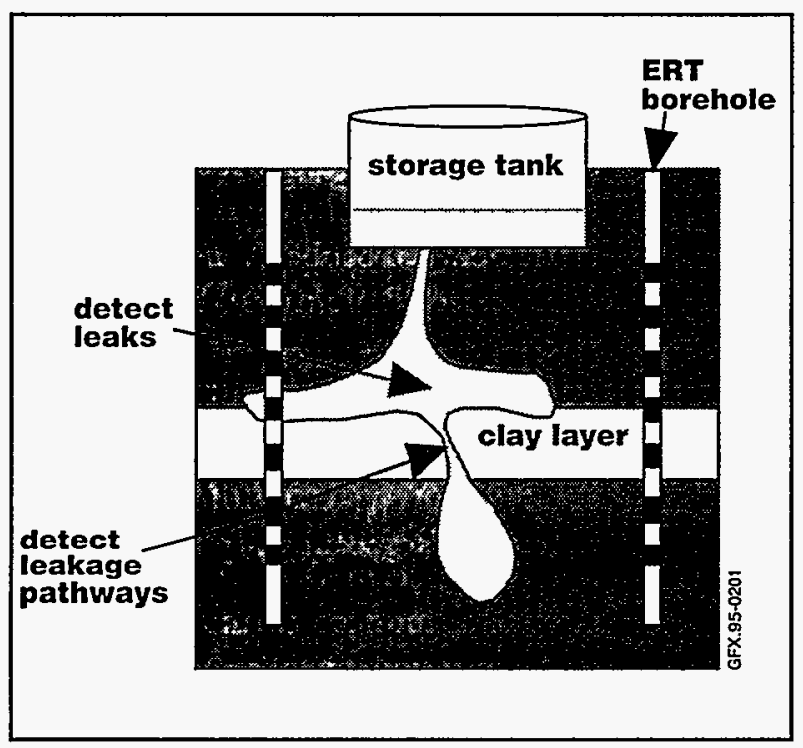

Figure 2.2a. Schematic Representation of Electrical Resistance Tomography to Delineate Leaks from an Underground Storage Tank.

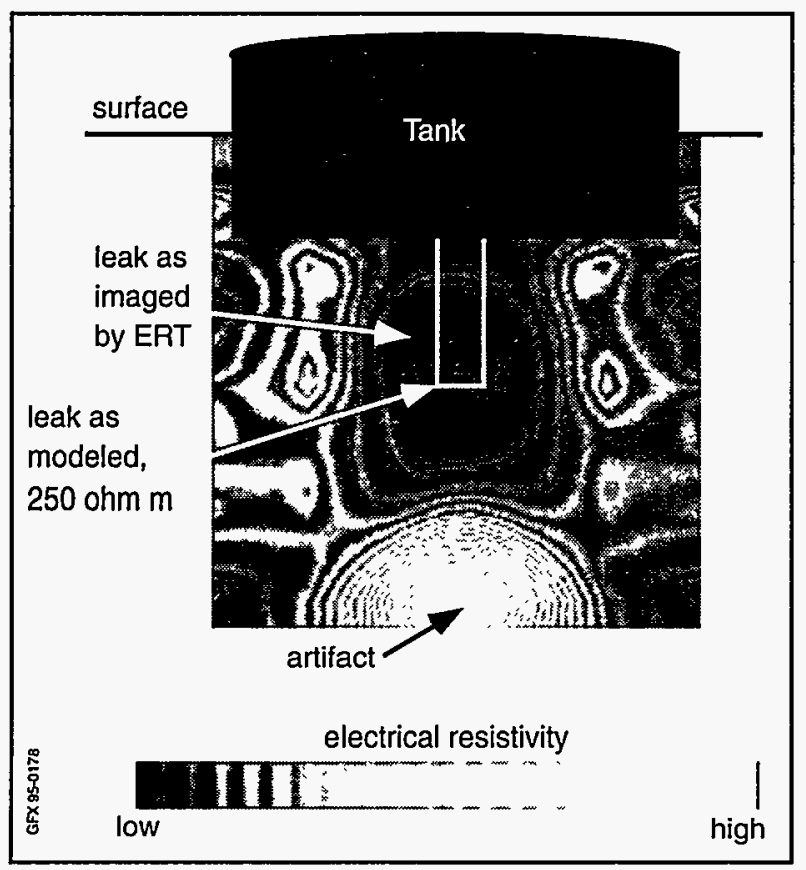

Figure 2.2b. Computer Simulation of Electrical Resistance Tomography Below a Steel Tank with a Conductive Plume of $250 \mathrm{ohm}-\mathrm{m}$ Beneath the Tank Center. tank test facility has been constructed that can be used to test schemes for detecting tank leaks. This facility has been used for two tests in FY94, which were designed to use electrical resistivity images under the tank to detect and locate leaks. The first test was for a 'bath-tub ring' leak where water was released from the tank along one side, and ERT images under the tank were successful in following the plume of water in the soil as a function of time and space down to a depth of 35 feet (the limit of our electrodes). The second test was for a leak from the tank bottom, where water was released from beneath the tank. The data for this test is now being processed.

- Development of a fully three-dimensional ERT code is underway. A test version of the three-dimensional inversion code has been written. It incorporates a new version of the forward solver, which is designed to be more accurate and faster than the previous solver. Initial tests were on synthetic data and some limited tests have been on field data. The performance remains very slowinversions of typical data sets require 4 to 8 days of CPU time on a Sun Sparc 5 workstation.

- Imaging NAPLs at the Oregon Graduate Institute (OGI) LEAP tank is a new task. We have negotiated with OGI for an experiment at the LEAP tank facility. The tank will be prepared for the experiment in early spring, the experiment will be conducted this summer, and the tank cleanup will be accomplished (and funded) in FY96. The experiment will consist of releasing a DNAPL (probably PCE) into a water-saturated sandy loam that has two low-permeability clay layers to impede downward movement. Before, during, and after the release, ERT images will be made of both resistivity and chargability. 


\section{COLLABORATION/TECHNOLOGY TRANSFER}

Collaboration is ongoing with RIMTech, Inc., a Denver-based geophysical service company, to transfer the basic ERT technology. That work began in FY94 and continued into FY95.

Collaboration is also ongoing with Prof. Douglas LaBrecque at the University of Arizona and with Prof. Andrew Binley at the University of Lancaster, England. Their contributions to the project are mainly computer code development.

Collaboration is ongoing with Westinghouse Hanford Co. (EM-30) in the development of tank leak detection technology. Collaboration is also ongoing with Rick Johnson at the Oregon Graduate Institute of Science and Technology in the NAPL experiment.

For further information, please contact:

\section{William Daily}

Principal Investigator

Lawrence Livermore National Laboratory

7000 East Avenue

P.O. Box 808, L-156

Livermore, CA 94550

(510) $422-8623$

\author{
Abe Ramirez \\ Principal Investigator \\ Lawrence Livermore National Laboratory \\ 7000 East Avenue \\ P.O. Box 808, L-206 \\ Livermore, CA 94550 \\ (510) 422-6909 \\ Jesse Yow \\ Technical Program Manger \\ Lawrence Livermore National Laboratory \\ 7000 East Avenue \\ P.O. Box 808, MS L-524 \\ Livermore, CA 94550 \\ (510) 422-3521 \\ Dr. Caroline Purdy \\ Program Manager, CMST-CP \\ U.S. Department of Energy \\ Cloverleaf Building \\ 19901 Germantown Road \\ Germantown, MD 20874-1290 \\ (301) $903-7672$
}

TTP Number: SF241002

BIBLIOGRAPHY OF KEY PUBLICATIONS

None at this time. 


\section{TASK DESCRIPTION}

Remote moisture measurement by electromagnetic induction has been successfully used in the wire-line logging industry for many years to measure water concentration and porosity in geologic formations. The objective for this task is to evaluate a similar electromagnetic induction method for monitoring moisture in the single-shell waste tanks at Hanford. Electromagnetic waves are transmitted into a waste material (typically a saturated salt solution containing 10 to 50 weight percent water) by placing a transmission coil at a selected location and exciting it with an alternating current. A receiver coil is placed at a nearby location. Monitoring the current applied to the transmitter and voltage developed in the receiver provides information about the electromagnetic properties of the material surrounding the two coils. The electromagnetic waves can penetrate into all materials to a depth controlled by their electrical conductivity, magnetic permeability, and the frequency of the current exciting the transmission coil. By selecting different frequencies, water concentrations, and the many other variables expected to occur in a waste tank, experiments will be performed to demonstrate how this technology can be applied in a waste tank to monitor moisture.

First, simulants must be verified electrically equivalent to the waste in the single-shell tanks. This is being accomplished by measuring the electrical properries of samples cored from a single-shell tank. The simulated waste presently in use will then be modified according to core sample measurements. A prototype measurement system has been developed and calibrated in the laboratory and tested inside the liquid observation well (LOW) of a waste tank. The moisture sensor, consisting of a transmitter and receiver coil, monitored the electrical conductivity (and hence the moisture) of the waste material surrounding the LOW out to a radius of about 60 inches and identified liquid level to within several millimeters.

\section{TECHNOLOGY NEEDS}

A major safety question exists for the high-level waste (HLW) tanks at Hanford. The safety question results from the fact that the thermal stability of tank waste containing ferrocyanide, or organics, in the presence of an oxidizer has been linked to the presence of sufficient water in the waste to quench any incipient explosive reaction. This makes it necessary to continuously monitor the HLW tanks for moisture to allow safe remediation activities to be executed. A safe water concentration is estimated to be 20 to 30 weight percent or greater. An active thermal neutron measurement technique deployed in an LOW is currently in use at Hanford to measure moisture. However, this method has an interrogation range of only a few centimeters. The electromagnetic method has a longer range, 60 inches or greater. If the electromagnetic method can provide even a relative measure of moisture, its measurements can be calibrated with an absolute measurement near the measurement point using the neutron probe. Combining the two methods could then yield absolute measurements at a distance up to several feet from the LOW. Such an advance in moisture measurement capability would provide a significant tank safety benefit.

\section{ACCOMPLISHMENTS}

- Experiments yielding insightful observations were performed to determine sensitivity of the EMI method to moisture variation, its ability to discriminate between moisture and other waste tank properties, and its depth of interrogation. Measurements at the test-tube and 500-milliliter beaker scale have shown that the EMI method can predict moisture content in saturated ionic slurries to within 5 percent by weight. Tests at the 100-liter scale demonstrated liquid level measurement accurate to within 1.0 millimeter. 
- An experiment was performed to determine electrical property equivalence between waste tank simulants and samples cored from a single-shell waste tank. The electrical conductivity of four samples cored from single-shell tank No. T-111, contained in four-ounce glass jars, was measured and found to be similar to that of non-radioactive simulant used in the laboratory. Core sample conducrivity measurements also established the calculated maximum distance electromagnetic (EM) waves can penetrate the waste material. The calculations, based on Maxwell's laws of electromagnetism and the core sample conductivity measurements, show that EM waves can penetrate up to 2 meters into the waste at a frequency of 10 $\mathrm{KHz}$.

- A measurement/deployment system was designed, assembled, tested, and then used to obtain EMI data from single-shell waste tank No. S-106. The in-tank EMI data included impedance measurements at 1millimeter intervals from tank bottom to top, at four different frequencies, and took only 45 seconds to acquire. Repeated tests in tank S-106 produced virtually identical impedance versus depth response curves. A calibration study to predict moisture from coil impedance is in progress. The study includes developing a calibration system to predict the moisture concentration in nonradioactive simulants from electrical impedance measurement.

- Although uncalibrated, interesting features can be seen in the EMI data from tank S106:

- The expected characteristic impedance change caused by the tank's top dome and bottom surface can be clearly identified.

- The liquid waste/air-space interface boundary can be easily distinguished from other fearures by a large impedance change, 90 degrees out of phase from that seen for metal objects, thus allowing liquid level detection to within \pm 1.0 millimeter.

- Data suggest wide variations in moisture near the waste surface then tapering to smaller variations toward the tank bottom. The shape of the impedance curve, as a function of depth, has many similarities to neutron and gamma-based sensor measurements in tank S-106.

- Differing moisture profiles as the depth of penetration changes with the frequency of induced current.

- In looking at recent EMI, neutron, and gamma data collected from tank S-106, similar trends among these tools were noticed. By using the information derived from the EMI data combined with existing neutron, gamma, and other physical property measurements, it is believed that real data fusion can be achieved, where more than just moisture information will be added to existing databases.

\section{BENEFITS}

In situ moisture measurement and liquid level management are major DOE concerns in HLW. The EMI measurement method is the only known technology that may interrogate appreciably beyond a few centimeters into the waste material and provide moisture-related data.

\section{COLLABORATION/TECHNOLOGY TRANSFER}

Westinghouse Hanford Company (WHC) is presently working toward adapting this technology to meet the needs of their waste tank monitoring program. Also, the well-logging and waste management industry is being informed of recent progress. Commercialization partner interest, based on 
progress to date, is presently being sought and will be continued as more information becomes available. The hardware developed for this work was a joint effort between PNL and Zetec Inc. in Issaqua, WA. Zetec has shown interest in commercializing the measurement system developed under this task.

For further information, please contact:

Ronald L. Hockey

Principal Investigator

Pacific Northwest Laboratory

P.O. Box 999, MS K5-25

Richland, WA 99352

(509) $375-2813 \cdot$ Fax 509-375-2856

\section{Cheryl Thornhill}

Technical Program Manager

Pacific Northwest Laboratory

P.O. Box 999

Richland, WA 99352

(509) 375-2532
Deborah E. Trader

Technical Program Officer

U.S. Department of Energy

Richland Operations Office

825 Jerdwin Avenue

P.O. Box 550

Richland, WA 99352

(509) 372-4035

\section{Al Tardiff}

Project Manager, CMST-CP

U.S. Department of Energy

Cloverleaf Building

19901 Germantown Road

Germantown, MD 20874-1290

(301) $903-7670$

TTP Number: RL341008

BIBLIOGRAPHY OF KEY PUBLICATIONS

None at this time. 


\subsection{IN-TANK INTERFACE DETECTION USING TIME DOMAIN REFLECTOMETRY}

\section{TASK DESCRIPTION}

This project is developing Time Domain Reflectometry (TDR) as a cost-effective means of monitoring liquids in waste tanks at Hanford and Savannah River. The TDR systems will be able to monitor levels in liquid-filled tanks as well as interstitial liquid in salt cake in tanks normally empty of liquid.

Present methods of liquid level detection have not been satisfactory in the waste tank environment. The TDR probe is unaffected by radiation, temperature, pressure, or liquid composition. The probe can function immersed in the liquid or possibly inside LOWs present in the Hanford tanks.

Commercial TDR equipment made available by the shut-down of K Reactor at Savannah River Site is being used for all tests. The equipment is computercontrolled with a large amount of usable software already available. Also of use is site experience with another installed TDR system used to monitor the benzene/water interface in a decanter on the Precipitate Hydrolysis Environmental Facility Reactor at the TNX facility.

Software development has integrated computer controlled microwave coaxial switches into the existing equipment. This allows the multiplexing of several probes to one system of TDR electronics.

\section{TECHNOLOGY NEEDS}

Accurate level detection inside waste tanks is of critical importance for environmental reasons. Of the 149 single-shell tanks at the Hanford site, at least half are assumed leakers with no sufficient level detection method being employed.

When a tank is found to be leaking, an interim stabilization is performed, in which as much liquid is removed (pumped out of the tank) as possible, leaving the more solid layers. Once a tank has been interim stabilized, there is no means of detecting if it is still leaking, since current level detection methods for the remaining liquid in the cake layer are not viable. Successful application of TDR level detection to this situation would be a significant accomplishment.

Tests with a laboratory twin lead probe in a LOW mock-up have shown that this configuration can detect liquid outside the LOW with surprising accuracy. See Figure 2.4a. This finding is very encouraging to

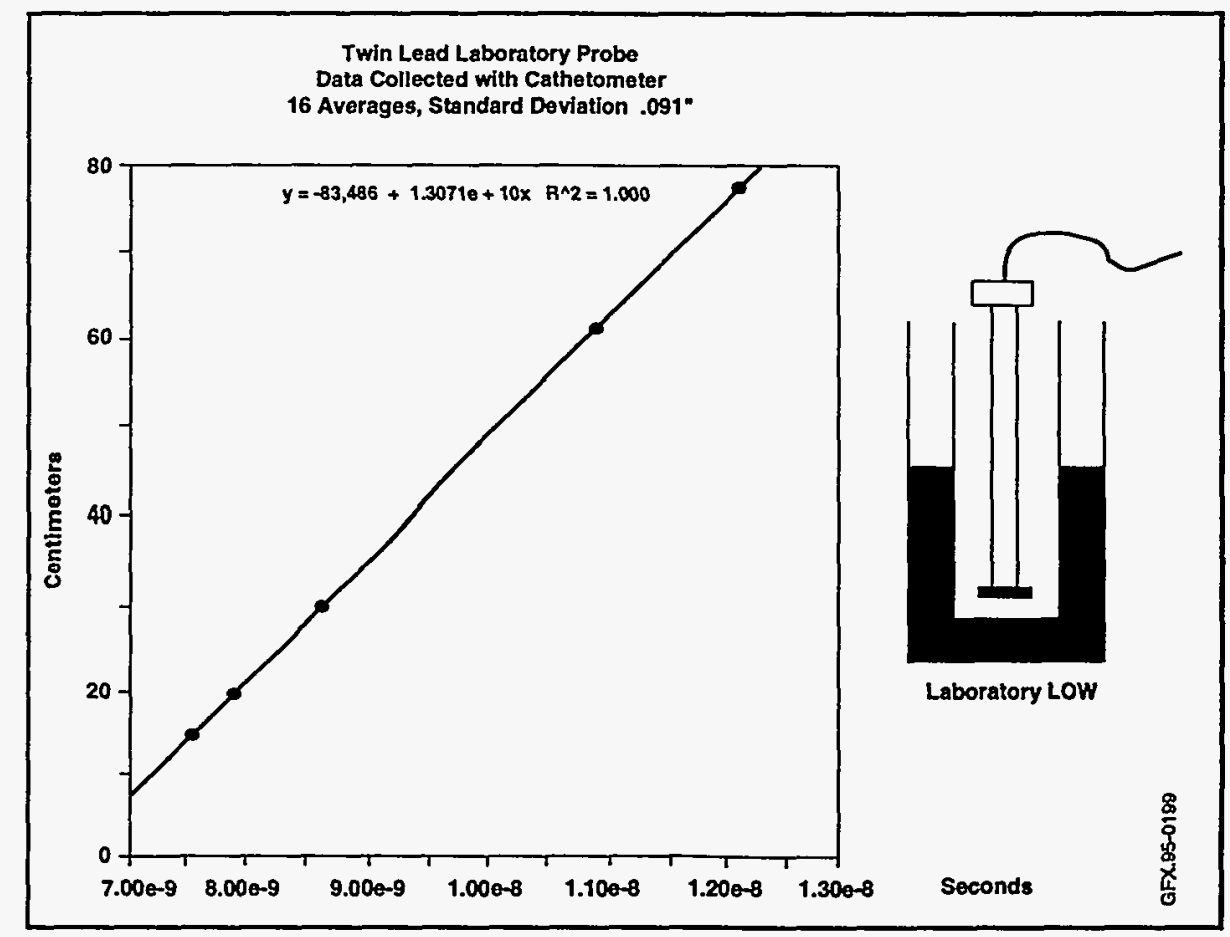

Figure 2.4a. Twin Lead Laboratory Probe Data Collected with Cathetometer. 
the possibility that interstitial water in salt cake can be monitored in the Hanford tanks using their LOWs. See Figure 2.4b.

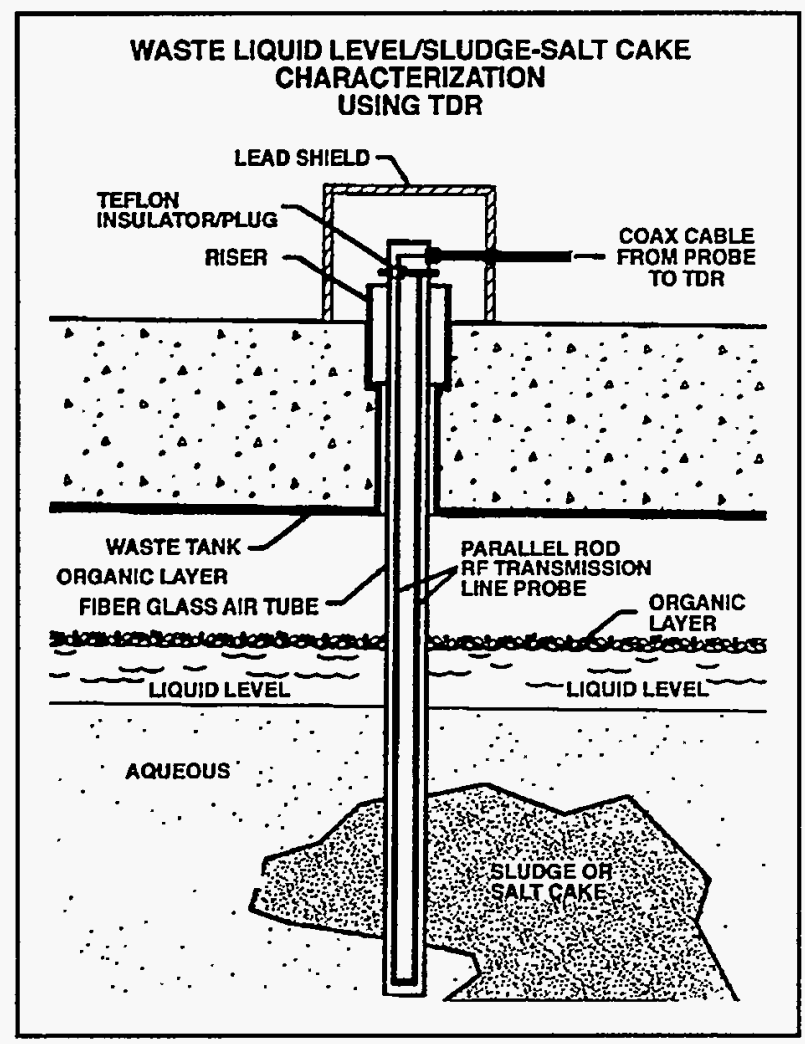

Figure 2.4b. Waste Liquid Level/Sludge-Salt Cake Characterization Using Time Domain Reflectometry.

TDR may also be able to detect the moisture content of salt cake.

Tests will be performed with waste simulants with different moisture contents in a Hanford waste tank mockup. Tests with neutron and electromagnetic moisture measurement devices will also be performed under the same conditions by Hanford personnel so the results can be compared directly.

\section{ACCOMPLISHMENTS}

- During FY94, several probe configurations were designed and tested. These included both coaxial and twin lead probes with calibration discontinuities.
- An improved constant impedance connector was also fabricated. A microwave coaxial relay was integrated into the system along with the controlling software permitting multiplexing up to six probes to a single TDR electronics system.

- The Savannah River TNX single probe system was upgraded using the improved connector design with two additional probes for a system total of three. Two organic/aqueous decanters and one organic hold tank are continuously monitored. The decanter probes give organic thickness based on aqueous information that was not previously available. The data are fed automatically to the facility process control computers. The TDR information is the controlling factor in the process. The probe tests determined that a twin lead probe was best suited for use in Hanford single-shell waste tanks.

\section{BENEFITS}

The present method used to monitor interstitial water and salt cake moisture requires a neutron source/detector be lowered into the LOW. This method is expensive, time-consuming, and noncontinuous. If TDR is used on the Hanford tanks, several million dollars could be saved.

\section{COLLABORATION/TECHNOLOGY TRANSFER}

This technology will be directly applicable to all existing high level radioactive waste tanks as well as many other commercial waste/chemical storage tanks. It will also be useful for liquid level monitoring in pressure/vacuum vessels. This information will be transferred via open literature publications. In terms of commercialization, Hyperlabs, Inc., of Beaverton, $O R$, is interested in using probes developed at Savannah River along with their TDR electronics to form a complete instrument package. 
For further information, please contact:

Hilton R. Tilley, Sr.

Principal Investigator

Westinghouse Savannah River Company

P.O. Box 616

Building 723-A

Aiken, SC 29802

(803) 725-1876

John L. Steele

Technical Program Manager

Westinghouse Savannah River Company

P.O. Box 616

Aiken, SC 29802

(803) 725-1830

\section{Al Tardiff}

Project Manager, CMST-CP

U.S. Department of Energy

Cloverleaf Building

19901 Germantown Road

Germantown, MD 20874-1290

(301) $903-7670$

\section{BIBLIOGRAPHY OF KEY PUBLICATIONS}

None at this time. 


\subsection{ACOUSTIC CHARACTERIZATION OF WASTES IN DOUBLE-SHELL UNDERGROUND STORAGE TANKS}

\section{TASK DESCRIPTION}

This project is adapting commercially available acoustic devices to be used to locate and characterize wastes and submerged objects in high-level waste USTs. Two sensors are being developed to comprise a monitoring system: an echo sounder for locating interfaces and tank obstructions, and a density monitor for reporting changes in mixed fluid density during waste mobilization procedures. Transducers produced for commercial and sport fishing use are being modified to tolerate the high $\mathrm{pH}$, high temperature, and radiologically hot environment in double-shelled underground storage tanks (DSTs) at the Hanford site. A signal source for making the sonar measurement has been obtained commercially and is currently being modified to meet the smaller scale and more attenuative environment than the design for sea water conditions. The density monitor is being developed using the adapted transducers with standard laboratory signal sources and data acquisition equipment. A density monitor and echo rangers have been delivered to the Hanford site and will be mounted on a mixer pump to be used in DST-AN-10 later in FY95. Preliminary evaluation of the sensors to measure sludge layer depth, dispersion of the sludge under stirring, changes in supernatant density, effective cleaning radius, and location of in-tank structures is scheduled to occur in the third quarter of FY95. The prototype monitoring system will be used by Hanford with Ames Laboratory support during the development period. A more automated monitoring system based on FY95 results is scheduled to be evaluated during the final test/demonstration period planned to occur in DST-AZ-101 in April of 1996.

\section{TECHNOLOGY NEEDS}

Information about material properties in USTs is currently provided by intrusive methods such as core sampling, buoyancy-based density measurements, level tapes, and video cameras. None of these methods are effective in determining the distribution of waste types and submerged objects beneath the surface of the waste. In the planned effort to pump the waste out of DSTs, vitrify it for permanent disposal, and then transfer SST waste to the DSTs for interim storage, process monitoring will be very important. Critical data will include, but will not be limited to, radius of cleaning from the mixer/transfer pump, locations of submerged objects, and density of waste mixtures. The absence of such data could compromise adequately designing a pump, predicting the effectiveness of transfer through lines without plugging, determining how completely a tank has been cleaned, and determining if obstructions or debris in the tank will interfere with pumping. An acoustic method, such as is being addressed in the current work, shows considerable promise of meeting these data needs.

\section{ACCOMPLISHMENTS}

The ability to detect an interface between simulant sludge and water has been demonstrated at distances from one to three meters directly, and to approximately ten meters indirectly. Submerged objects have similarly been detected. The simulants used to create interfaces have small acoustic impedance mismatches compared to what is expected for in-tank wastes, which indicates that probability of successful application of the interface detector is high. The direct density, phase shift, and sound speed data, which allow calculation of density 
changes with the density monitor, indicate that intank density changes will be observable. Sensors developed in collaboration with a manufacturer have been deployed in an actual waste tank for over a year without failure. These sensors are the only acoustic sensors designed and field tested for tolerance to actual conditions in the high level waste UST environment. A test of the echo ranging and density monitoring instruments in a DST has been scheduled for early March 1995. Previous deployment of similar instruments in DST-SY-101 succeeded in demonstrating the survivability of the sensor, and the response of the density monitors to changes in tank density during pumping, but the echo rangers were not operated until after considerable tank mixing, and were not useful in interface detection.

\section{BENEFITS}

This technology will directly facilitate the remediation effort in USTs throughout the United States. The acoustic sensors promise to be applicable to any fluid-filled tanks, and as more systems are operational in actual tanks, additional development of the technique will allow the technology to be fine-tuned for use in a range of waste types. These systems will, in addition to benefiting the remediation process by monitoring mixing and trans$\mathrm{fer}$, provide designers with information to aid in designing the most effective transfer pumps. The sensors are installed as part of the mixer/transfer pump and are operated remotely, which minimizes worker exposure for obtaining monitoring data. Another benefit is that the remote control of the technology could be extended to be operated through a central control station, for example via ethernet control of IEEE instruments. This could decrease the cost of monitoring by reducing the number of data acquisition control centers, which are currently expected to be one per tank.

\section{COLLABORATION/TECHNOLOGY TRANSFER}

Airmar Technology, Raytheon, and Westinghouse Hanford Company have collaborated extensively with Ames Laboratory and Iowa State University on the development of this technology. Airmar is the manufacturer that has supplied the off-the-shelf sensors and worked with lowa State researchers to develop housings and choose an appropriate array of piezoelectric elements for use in this application. This company is a small business, but produces a large share of the transducers currently used in hobby and commercial fishing for navigation and fish-finding. Airmar has expressed interest in manufacturing and marketing the finished device, and has the resources needed to handle the job. Raytheon manufactures the pulser used to drive the echoranging transducers. Engineers at Raytheon have been very cooperative in helping modify the pulsers to be used in the tank environment and by providing engineering drawings and consultations. Raytheon is currently not interested in marketing the device, but is interested in supporting the work as it has in the past. Westinghouse Hanford Company has cooperated in installing and providing engineering support for tests of the instruments in actual tanks. We estimate they have supplied on the order of 0.5 person-years of support in this effort and have paid for the majority of the installation and safety assessment costs. Current planned tests will initially benefit the development of the instruments and, in addition, will place instruments in tanks that will be used operationally to their full capability as soon as feasible. 
For further information, please contact:

\section{Amanda Clark}

Principal Investigator

Ames Laboratory \& The Center for NDE Iowa State University

284 Applied Science Complex II

Room 251B

Ames, IA 50011

(515) 294-3344 or 7338

James Corones

Technical Program Manager

Ames Laboratory

Iowa State University

329 Wilhelm Hall

Ames, IA 50011

(515) 294-9636

\section{Al Tardiff}

Project Manager, CMST-CP

U.S. Department of Energy

Cloverleaf Building

19901 Germantown Road

Germantown, MD 20874-1290

(301) $903-7670$

\section{BIBLIOGRAPHY OF KEY PUBLICATIONS}

M.A. Clark, D.M. Martin, "Acoustic Properties of Underground Storage Tank Simulant Wastes", Review of Progress in Quantitative Nondestructive Evaluation, vol. 13, p. 1075, eds. D.O Thompson and D. E Chimenti, Plenum Press, New York, 1994. 


\section{6 \\ IMAGING THROUGH OBSCURATIONS DURING SLUICING OPERATIONS}

\section{TASK DESCRIPTION}

The purpose of this project is to evaluate candidate methods for viewing through obscurations, such as fog and water droplets, that can occur during waste tank remediation efforts. Candidate methods will be evaluated for their applicability for use during waste tank remediation efforts. A test chamber will be fabricated in which the size and salt concentration of the fog/water droplets can be varied in order to test several candidate methods for imaging through an environment that could occur during a sluicing operation. The results of this task will provide a basis for specifying and developing a system to meet the imaging needs of waste remediators.

\section{TECHNOLOGY NEEDS}

Waste remediators have identified that surveillance of waste remediation operations and periodic inspections of stored waste are required under very demanding and difficult viewing environments. In many cases, obscurations such as dust or water vapor are generated as part of the remediation acrivity and methods for viewing or imaging beyond the normal visual spectrum are needed. Workspace images guide the movement of remediation equipment, creating a need for rapidly updated, near realtime imaging capability. At present, because of the closed environment in which the remediation effort is conducted, a substantial amount of time is needed to clear the atmosphere, so that the effect of the remediation effort can be determined. During this time, labor costs continue and equipment is being exposed to the hazardous environment. In addition, the safery of the operation could be jeopardized because of the lack of viewing the remediation operation in near real time.

\section{ACCOMPLISHMENTS}

In FY94, potential technologies for viewing through obscurants were reviewed. These technologies included conventional video with special lighting schemes, infrared sensors, acoustic sensors, laser range-finding, and millimeter wave imaging. Selected methods were tested in a tube filled with water vapor and water/salt vapor particulates to simulate the atmosphere of a waste tank during sluicing operation. Measurements demonstrated that millimeter waves were only slightly attenuated under these simulated conditions and that imaging was possible using millimeter waves. In FY95, a millimeter wave imaging system will be developed and demonstrated in a non-radioactive environment. FY95 activities will provide basis to continue into the development of a full-scale radioactive hardened system for use by tank operations. See Figure 2.6a.

\section{BENEFITS}

Development of a millimeter wave imaging system to view the waste retrieval operations during reme-

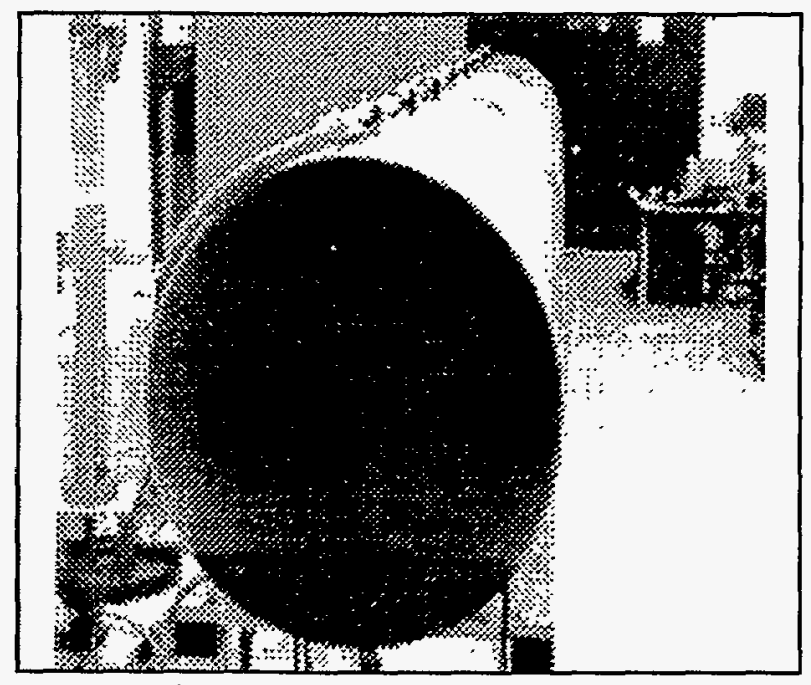

Figure 2.6a. Test Chamber. 
diation. Workspace images could guide the movement of remediation equipment. The millimeter wave imaging system is a solution to the obscurement problem.

\section{COLLABORATION/TECHNOLOGY}

\section{TRANSFER}

The imaging technologies will be available for other DOE and DoD sites that require imaging systems for imaging through obscurations. In addition, this system will be used throughout the waste tank farm at the Hanford Site and throughout the DOE Complex.

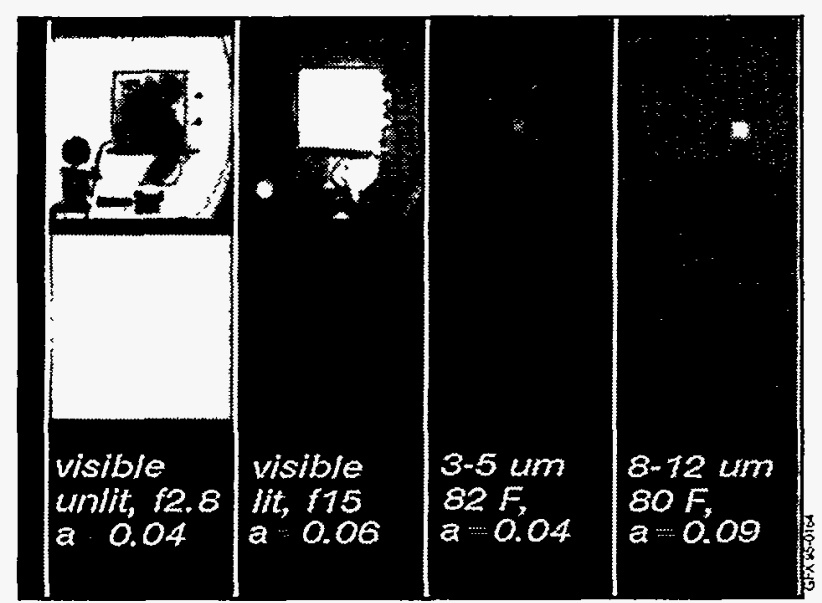

Figure 2.6b. Optical System Tests.
For further information, please contact:

\section{Douglas McMakin}

Principal Investigator

Pacific Northwest Laboratory

P.O. Box 999, MS K2-31

Richland, WA 99352

(509) 375-2206

\section{Cheryl Thornhill}

Technical Program Manager

Pacific Northwest Laboratory

P.O. Box 999

Richland, WA 99352

(509) 375-2532

\section{Deborah E. Trader}

Technical Program Officer

U.S. Department of Energy

Richland Operations Office

825 Jadwin Avenue

P.O. Box 550

Richland, WA 99352

(509) 372-4035

\section{Al Tardiff}

Project Manager, CMST-CP

U.S. Department of Energy

Cloverleaf Building

19901 Germantown Road

Germantown, MD 20874-1290

(301) $903-7670$

TTP Number: RL341005

\section{BIBLIOGRAPHY OF KEY PUBLICATIONS}

Peters, T.J. Imaging Through Obscurations for Sluicing Operations in the Waste Storage Tanks, Pacific Northwest Laboratory, Richland, WA. 


\subsection{MOISTURE SENSOR IN CONE PENETROMETER FOR IN-TANK CHARACTERIZATION}

\section{TASK DESCRIPTION}

The objective of this task is to develop, fabricate, install, and acceptance-test a moisture sensor for use on an in-tank cone penetrometer. See Figure 2.7. The cone penetrometer is a device that deploys an instrumented rod into the waste. The rod collects numerous physical and chemical properties of the waste while being deployed. Once the rod is deployed, the moisture sensor will be lowered down its center, and percent moisture and liquid level measurements of the waste will be taken.

\section{TECHNOLOGY NEEDS}

There are many needs for the monitoring of percent moisture and liquid level in high-level waste tanks. Moisture content is required to determine if unsafe conditions are present in tanks that contain explosive gases such as $\mathrm{FeCN}$ and hydrogen. If a certain percent- age of moisture exists, it is impossible for the gas to ignite and burn. Liquid level is also a much-needed measurement in order to monitor whether a tank is leaking or losing liquids by other means. Retrieval, pretreatment, and characterization are all waste operations needing moisture content data for various reasons.

The contract for the cone penetrometer was placed in September 1994 with Applied Research Associates (ARA). The cone penetrometer will be fabricated with off-the-shelf sensors that are applicable to characterization's needs. The contract for the moisture sensor development was placed in May 1994 with Science Applications International Corporation (SAIC). SAIC will be required to design and install the moisture sensor on the ARA cone penetrometer vehicle when the truck is being fabricated. It is critical the two systems are integrated throughout their design to ensure proper functional requirements are achieved.

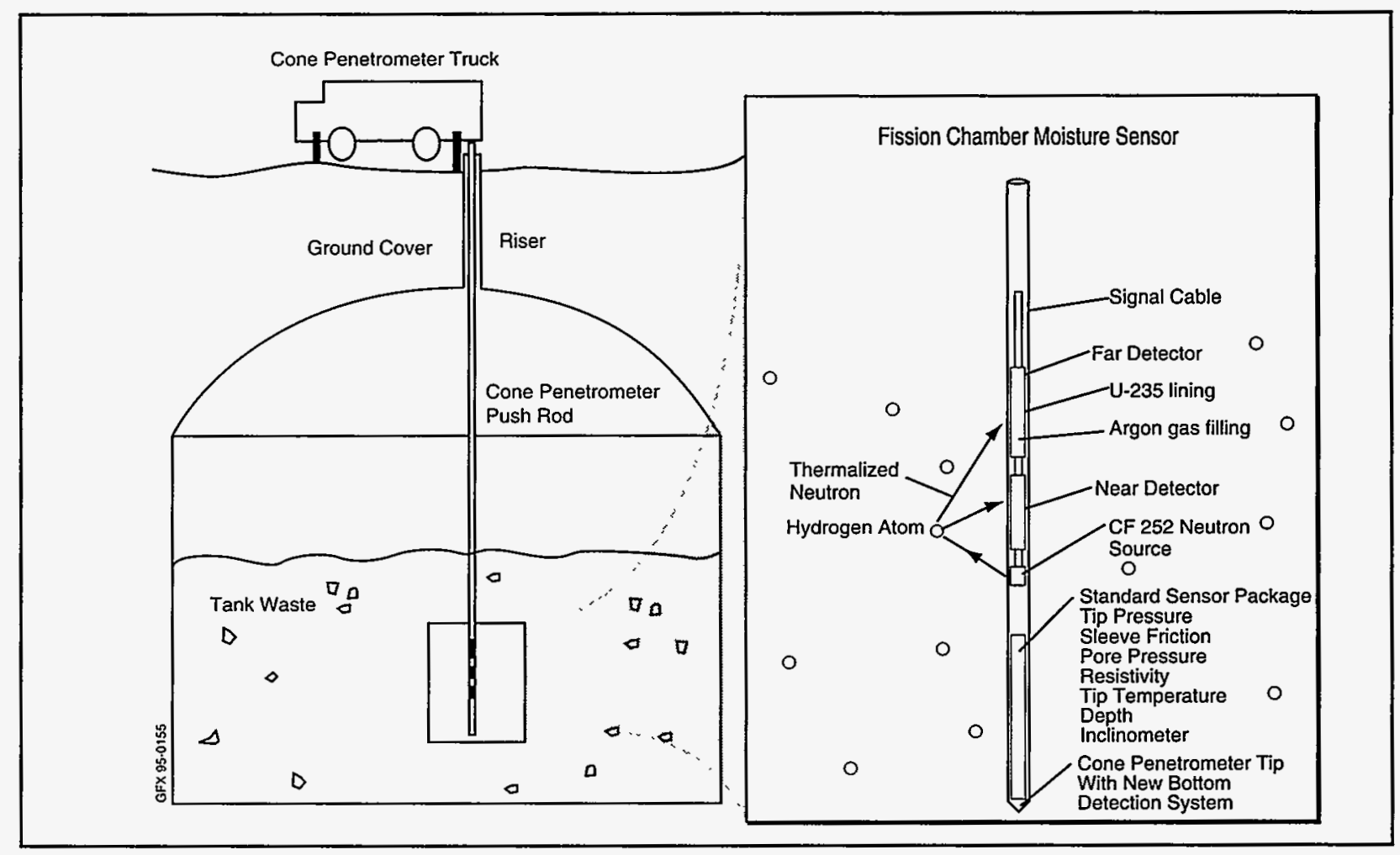

Figure 2.7. Fission Chamber Moisture Sensor. 


\section{ACCOMPLISHMENTS}

Phase I testing of a fission chamber detector determined the following:

- Good distinction between 0,13,22, 26,30, 46 , and 100 percent water simulants was achieved.

- Tests exposing the sensor to up to $3000 \mathrm{R} /$ hr showed no effect on its accuracy.

- Locating the source in the middle of the sensor resulted in more accurate measurements.

- Using two detectors and one source resulted in data indicating the effects from neutron-absorbing elements within the waste could be eliminated.

- Liquid level tests indicated better than expected results were achieved when using the fission chamber detector for liquid level measurements.

Phase II testing is currently underway and will include the following:

- Side-by-side tests of fission chamber, $\mathrm{BF}_{3}$ and Boron 10 lined detectors. The detectors will be tested for effects of temperature, gamma, and simulated poisons that represent the tank conditions.

- Simulated LOW tests on all three detectors.

- Near-Far configuration tests to optimize the response in varying moisture contents and contamination levels.

- Computer modeling for a cross-check on the tests.

\section{BENEFITS}

If developed successfully, this moisture sensor will be able to accurately read liquid level and moisture content whenever the cone penetrometer is deployed. It will be a faster method of measuring liquid level since the $\mathrm{LOW} \mathrm{BF}_{3}$ method requires a permanent LOW be installed. The cone penetrom- eter rod will be quickly and easily deployed. Although numerous moisture measuring devices are currently under development, none are presently being used in the waste tanks. This moisture sensor will be the first method to accurately determine water content in situ in the waste tanks.

\section{COLLABORATION/TECHNOLOGY TRANSFER}

It is acknowledged that the fission chamber detector for the cone penetrometer may have technology transfer potential; however, no contacts have been made to date.

For further information, please contact:

Nick Boechler

Principal Investigator

Westinghouse Hanford Company

P.O. Box 1970

Richland, WA 99352

(509) 373-3041

\section{Ted Noble}

U.S. Department of Energy

Richland Operations Office

825 Jadwin Avenue

P.O. Box 550

Richland, WA 99352

(509) 372-0917

\section{Al Tardiff}

Project Manager, CMST-CP

U.S. Department of Energy

Cloverleaf Building

19901 Germantown Road

Germantown, MD 20874-1290

(301) $903-7670$

TTP Number: RL441001

\section{BIBLIOGRAPHY OF KEY PUBLICATIONS}

None at this time. 


\section{TASK DESCRIPTION}

This project consists of two different subtasks that are developing technologies for separate environmental needs. Subtask 1 (Photoacoustic Spectroscopy of Tank Sludges) is developing chemical analysis methods for the sludge cores taken from the underground storage tanks at Hanford and transferring the technology to Hanford. Subtask 2 (Transient Infrared Spectroscopy of Polymer Encapsulation Waste Process Streams) is producing an on-line real-time process stream monitor for the polymer encapsulation of lowlevel nitrate salt radioactive waste.

The Hanford waste-tank sludges are difficult to analyze by most methods without substantial sample preparation because of their physical characteristics, and their radioactivity makes sample preparation hazardous. Subrask 1 applies Fourier transform infrared photoacoustic spectroscopy (FTIR-PAS) to the quantitative measurement of chemical components of the sludges, as shown in Figure 2.8a. The FTIR-PAS merhod provides rapid analysis of normally difficult materials, such as the sludges, with minimal sample preparation. Quantitative methods have already been developed for a limited range of components in a few sludge surrogates. The project is now expanding the application to a wider range of components, a wider range of surrogates, and actual sludges. The technology is being transferred both by training sessions for Hanford personnel, which have already started, and by demonstration analyses scheduled for this fiscal year that will be done on real sludges at Hanford by Ames Laboratory staff.

Polymer encapsulation of low-level wastes is a promising waste immobilization technology being developed at Brookhaven National Laboratory, Rocky Flats Plant, and Hanford. Subtask 2 is using transient infrared spectroscopy (TIRS) as the basis for an online, real-time composition monitor of the molten waste stream produced by the encapsulation process. TIRS provides a quantitative analysis of the process stream in only a few seconds without directly contacting the stream, as shown in Figure 2.8b. The TIRS monitor has already been successfully demonstrated on-site under controlled conditions using waste salt surrogates. The monitoring system is now being made more robust, so that it remains accurate when processing conditions change. More on-site demonstrations,

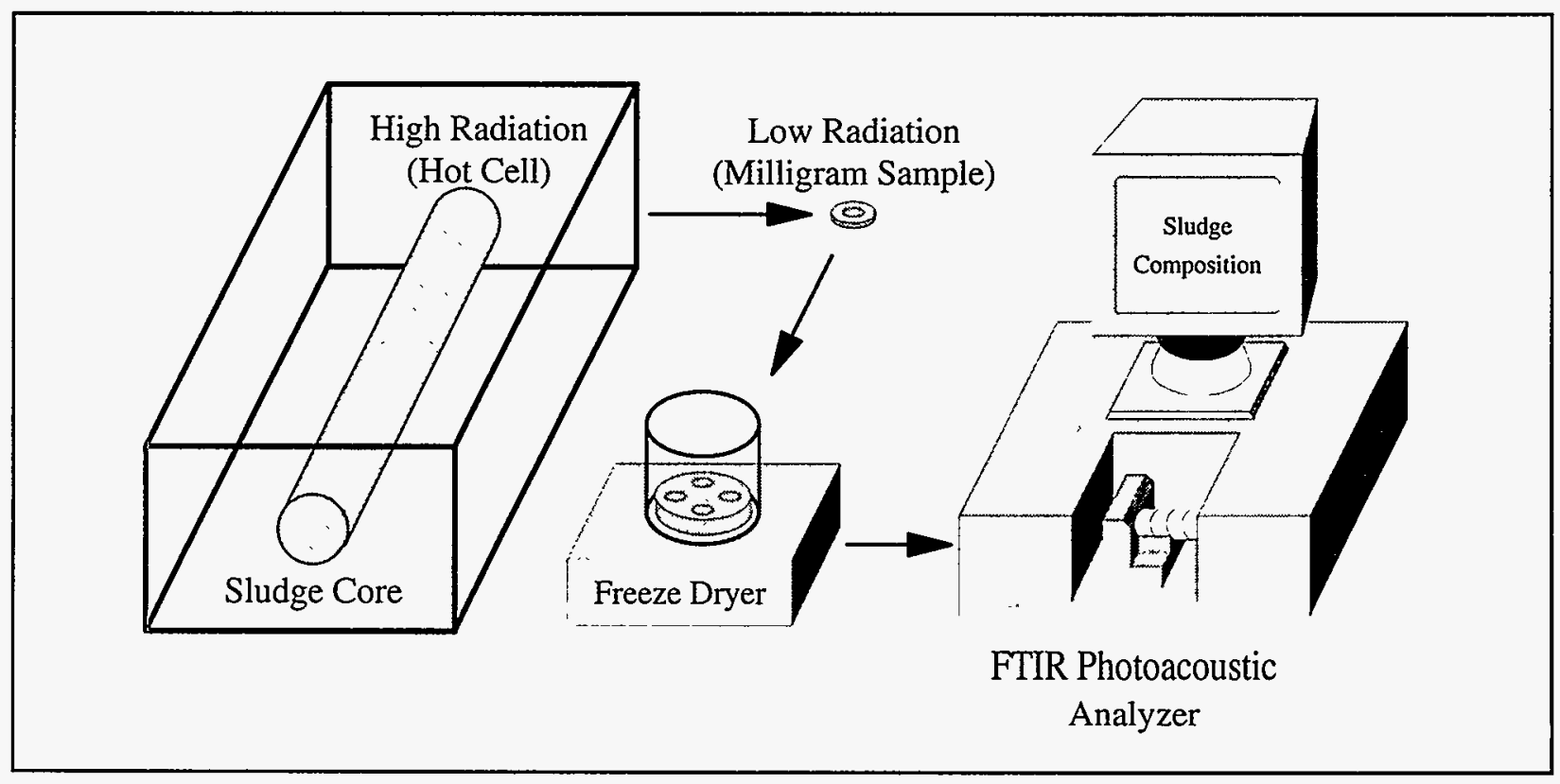

Figure 2.8a. Fourier Transform Infrared (FTIR) Spectrometer. 


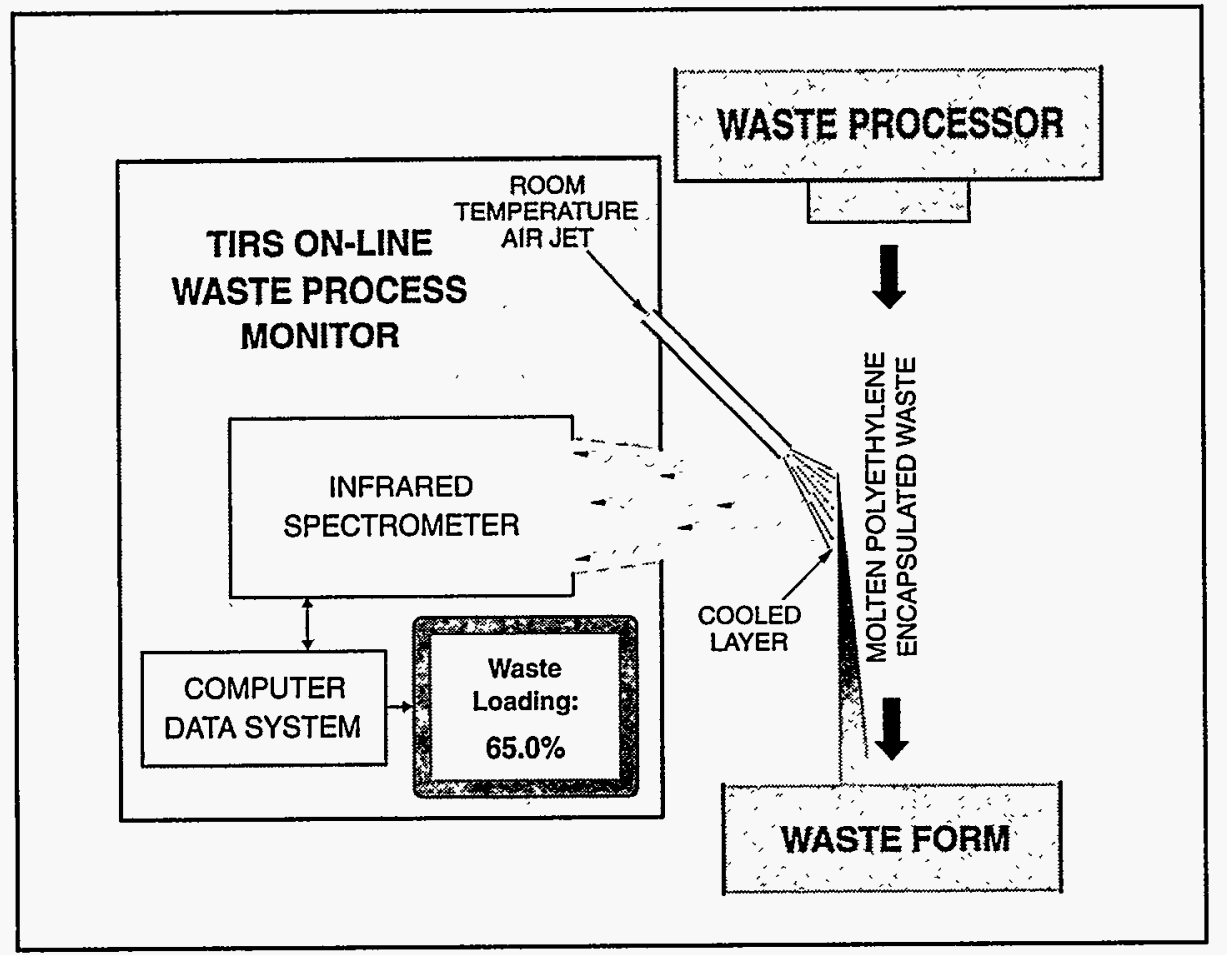

Figure 2.8b. Schematic of the TIRS Unit on a Waste Encapsulation Line. those technologies used to draw samples from the storage tanks.

DOE has an inventory of 250 million kilograms of low-level nitrate salt waste, and Rocky Flats Plant alone produces $1,000,000$ kilograms annually. Low-level radioactive salt waste is currently immobilized by cementation, but cementbased waste cannot contain more than 20 percent (by weight) salt and still meet the Toxicity Characteristic Leaching Procedure test. The polyethylene encapsulation of low-level waste is a promising alternative, which produces a waste form that can contain up to

including ones involving low-level salt waste, are planned for this fiscal year, as are tests on applying the monitor to low-level wastes other than salts.

\section{TECHNOLOGY NEEDS}

The 177 underground storage tanks at Hanford contain 60 percent of DOE's tank waste. The sludges and solids from these tanks present a challenging analysis problem. The Tri-Party Agreement established a schedule for analyzing materials from the tanks, and has thereby created needs for both a very rapid method to semi-quantitatively map components in sludge cores drawn from the tanks and a moderately rapid, fully quantitative analysis of samples drawn from the cores. FTIR-PAS is uniquely capable of meeting these needs. It can analyze milligram-sized samples of sludge with no sample preparation other than drying. It can be done very rapidly to provide a semi-quantitative map, or with more extensive calibration, to provide an accurately quantitative analysis. No additional technology unique to FTIR-PAS need be developed, but application of FTIR-PAS is dependent on
70 percent (by weight) waste. Reliably maintaining proper encapsulation at such high waste loadings requires monitoring the process in real-time. TIRS is the only technology available that can monitor the process stream in real-time. It will provide data that will guide the waste process operators in their control of the encapsulation, document the processed waste composition for certification purposes, and provide a record of the processed waste should questions or problems later arise. No other technologies need be developed specifically for applying the TIRS monitor, but of course it is dependent on continued development of the encapsulation technology.

\section{ACCOMPLISHMENTS}

Subtask 1: Photoacoustic Spectroscopy of Tank Sludges

- Training sessions to facilitate technology transfer held for Hanford personnel in May and August 1994.

- Rapid qualitative identification of components using FTIR-PAS spectrum library. 
- Quantitative measurement of sludge components (e.g., nitrate to an accuracy of 0.5 percent by weight).

Subtask 2: Transient Infrared Spectroscopy of Polymer Encapsulation Waste Process Streams

- Successful pilot-scale demonstration on sodium nitrate waste surrogate during the Polyethylene Encapsulation Process Production-Scale Technology Demonstration in September, 1994, at Brookhaven.

- Successful laboratory-scale demonstration on sodium nitrate at Rocky Flats Plant in May, 1994.

- Quantitative measurement of sodium nitrate loading in molten process streams to an accuracy of 0.7 percent by weight.

\section{BENEFITS}

The physical characteristics of tank sludges make them difficult to analyze without substantial sample preparation, which is time-consuming, costly, and exposes workers to radiation hazards. FTIR-PAS in Subtask 1 requires very little sample preparation and therefore mitigates these problems. The minimum FTIR-PAS sample size of less than one milligram greatly reduces the radiation hazard. Only drying is required after a sample is taken, which greatly reduces the worker time required. Worker time per sample analyzed is less than an hour, with a sample turnaround time of less than a day. No secondary waste is created.

The polyethylene encapsulation of low-level radioactive waste produces high-quality waste forms for longterm storage. The very high waste loading $(70$ percent by weight) possible offers substantial cost savings, but the waste loading must be monitored to ensure the waste is properly processed. TIRS is the only technology available that can provide on-line, real-time monitoring of the molten processed-waste stream composition. It does this automatically and without contacting the waste stream, so there is no secondary waste and little worker time required. The TIRS analysis will guide the process operators so that a highquality waste form is maintained, provide documentation of the waste composition to aid in its certification, and provide an archival record of the processed waste should questions or problems with the stored waste arise later.

\section{COLLABORATION/TECHNOLOGY TRANSFER}

The FTIR-PAS technology as applied to tank sludge is actively being transferred to Westinghouse Hanford Company. Two training sessions for Hanford personnel have already been held. During the current fiscal year, Ames Laboratory staff will work at Westinghouse Hanford to set up an FTIR-PAS system and to carry out analyses on waste-tank core samples with the system. The FTIR spectrometer technology is readily available commercially from numerous companies. The leading commercial source of photoacoustic technology is MTEC Photoacoustics, Inc., a company spun off from Ames Laboratory. An MTEC photoacoustic detector was selected in 1985 for an R\&D 100 Award (then called IR 100). A close, informal relationship is maintained between MTEC Photoacoustics and the Ames Laboratory project staff.

The TIRS technology was invented by the principal investigator and is patented by Iowa State University. The Ames Laboratory project staff have provided demonstrations of the technology at both Brookhaven and Rocky Flats. The principal component in a TIRS monitor is an infrared spectrometer. The project staff can provide TIRS systems built from commercial spectrometers to user sites. Project staff have also demonstrated TIRS monitors on the process and pilot lines of several manufacturers. TIRS received a 1992 R\&D 100 Award. 
For further information, please contact:

John McClelland

Principal Investigator

Ames Laboratory

Iowa State University

B27 Spedding Hall

Ames, IA 50011-3020

(515) 294-7948

James Corones

Technical Program Manager

Ames Laboratory

Iowa State University

329 Wilhelm Hall

Ames, IA 50011-3020

(515) 294-9636

\section{Al Tardiff}

Project Manager, CMST-CP

U.S. Department of Energy

Cloverleaf Building

19901 Germantown Road

Germantown, MD 20874-1290

(301) $903-7670$

\section{BIBLIOGRAPHY OF KEY PUBLICATIONS}

R.W. Jones, S.Ochiai, and J.F. McClelland, "OnSite Infrared Analyses for Complex Systems", Proceedings of the Information Exchange Meeting on Characterization, Sensors, and Monitoring Technologies, U.S. DOE Environmental Restoration and Waste Management Technology Development Program, Conference 920791, Dallas, TX; July 1516, 1992.

S.L. Wright, R.W. Jones, J.F. McClelland, and P.D. Kalb, "Preliminary Tests of an Infrared Process Monitor for Polyethylene Encapsulation of Radioactive Waste", Stabilization and Solidification of Hazardous, Radioactive and Mixed Waste, ASTM STP 1240, T. M. Gilliam and C. C. Wiles, Eds.; American Society for Testing and Materials, Philadelphia, PA; in press.

R.W. Jones and J.F. McClelland, "On-Line Analysis of Solids and Viscous Liquids by Transient Infrared Spectroscopy", Process Control Quality, 4, 253-260, 1993. 


\title{
CMST-CP PROJeCtS FOR THE
}

\author{
Mixed Waste \\ Characterization, \\ Treatment, and Disposal \\ FocUs AREA
}

\section{Section 3.0}




\section{TASK DESCRIPTION}

The objective of this task is the development and application of various advanced diagnostic methods to characterize the plasma properties, the melt properties, and the downstream emissions from a plasma torch facility designed to vitrify mixed waste. Correlation of the measured properties, with the operating parameters of the torch is being sought to improve, optimize, and control the overall operation of the plasma treatment process. As part of this program, diagnostic methods are being developed and evaluated for characterization, monitoring, and control of treatment processes in general. Field measurements and development of modern control methods are part of the program. Table 3.1a. summarizes the principal subtasks.

\section{TECHNOLOGY NEEDS}

Better and improved monitoring and control methods are needed to optimize the thermal treatment processes, in particular the plasma torch treatment system.

\section{ACCOMPLISHMENTS}

The overall progress of the DIAL program has been demonstrated by the activities of the field operations program. The field program is designed for the rapid demonstration and implementation of modern field-ready diagnostic methods for characterization, monitoring, and control purposes.

DIAL's mobile instrument laboratory was employed during the weeks of July 25-29 and September 1216,1994 , to support a series of measurements at the Clemson University Environmental Systems Engineering Vitrification Laboratory. At Clemson, exploratory measurements on the Stir Melter and
EnVitCo melters focused on determination of the melt temperature, the melt discharge temperature, thermal images of the melt discharge, off-gas compounds, the heavy metals in the molten glass, and the off-gas local flow velocity and velocity profile exiting the melters.

\begin{tabular}{|c|c|}
\hline TASK: SUBTASK & DESCRIPTION \\
\hline Task 1: Subtask 1 & Plasma Torch Operation \\
\hline Task 1: Subtask 2 & Plasma Torch/Process Control \\
\hline Task 1: Subtask 3 & $\begin{array}{l}\text { Diagnostics - Plasma, Melt, } \\
\text { and Off-Gas Emission } \\
\text { Characterization }\end{array}$ \\
\hline Task 1: Subtask 3.1 & Emission Spectra \\
\hline Task 1: Subtask 3.2 & Laser Doppler Velocimetry \\
\hline Task 1: Subtask 3.3 & $\begin{array}{l}\text { Coherent Anti-Stokes Raman } \\
\text { Spectroscopy }\end{array}$ \\
\hline Task 1: Subtask 3.4 & $\begin{array}{l}\text { Multiwavelength Emission/ } \\
\text { Adsorption System }\end{array}$ \\
\hline Task 1: Subtask 3.5 & Pyrometer Systems \\
\hline Task 1: Subtask 3.6 & $\begin{array}{l}\text { Fourier Transform Infrared } \\
\text { Spectroscopy }\end{array}$ \\
\hline Task 1: Subtask 3.7 & Laser Scattering \\
\hline Task 1: Subtask 3.8 & Multicolor Imaging \\
\hline Task 1: Subtask 3.9 & $\begin{array}{l}\text { Laser Optogalvanic } \\
\text { Spectroscopy }\end{array}$ \\
\hline Task 1: Subtask 3.10 & $\begin{array}{l}\text { Extinction Based Cross } \\
\text { Correlation System }\end{array}$ \\
\hline Task 1: Subtask 3.11 & Gas Analysis/GC \\
\hline Task 1: Subtask 3.12 & $\begin{array}{l}\text { Laser-induced Breakdown } \\
\text { Spectroscopy }\end{array}$ \\
\hline Task 1: Subtask 3.13 & $\begin{array}{l}\text { Ultrasonics and Laser } \\
\text { Ultrasonics }\end{array}$ \\
\hline Task 1: Subtask 4 & Torch Operations/Correlations \\
\hline Task 1: Subtask 5 & Modeling \\
\hline Task 1: Subtask 6 & Field Operations \\
\hline Task 1: Subtask 7 & Special Projects \\
\hline Task 1: Subtask 8 & Diagnostics/National Effort \\
\hline Task 1: Subtask 9 & Industrial Affiliate/Marketing \\
\hline Task 2 & Continuous Emission Moni \\
\hline
\end{tabular}

Table 3.1a. DIAL Contract Tasks. 
DIAL's mobile instrument laboratory was also employed during the week of October 17-21 to support a series of tests at the Western Energy Technology Office (WETO) operated by MSE in Butte, MT. The diagnostic measurements on the Plasma Arc Centrifugal Treatment System represent the first attempt to apply a number of modern diagnostic methods to a large-scale plasma torch facility. Measurements were carried out at a number of locations along the treatment system. Interface discussions were held earlier with representatives of WETO and Clemson to identify the measurement locations, interface requirements, and other specifications.

Table 3.1b. details the test measurements made and the instrumentation and techniques used at WETO/ MSE.

The primary objectives of the measurements in Table $3.1 \mathrm{~b}$ and the Clemson measurements were to: (1) characterize the gas stream at the measurement locations, (2) demonstrate the capability of the measurement technique, (3) provide useful facility data, and (4) enable planning for future tests.

\section{BENEFITS}

Support ongoing test facilities and provide improved characterization, monitoring, and control instrumentation systems. Provide diagnostic field measurements and demonstrations.

\section{COLLABORATION/TECHNOLOGY TRANSFER .}

Cooperative research and development (R\&D) efforts, with an emphasis on mixed waste treatment, are underway with the following participants:

- Westinghouse Savannah River Center Technical Center, Aiken, SC and Clemson University, Clemson, $\mathrm{SC}$

- Argonne National Laboratory-West, Idaho National Engineering Laboratory, Idaho Falls, ID

- Catholic University, Washington, DC

- Western Environmental Technology Office, Butte, MT

\begin{tabular}{|ll|}
\hline MEASUREMENT(S) & INSTRUMENT(S) \\
\hline Melt Discharge temperature & Multicolor Pyrometer Systems \\
\hline Temperature images of the melt discharge & Multipurpose Imaging System \\
\hline Pour Flow images of the melter & Mulitpurpose Imaging System \\
\hline Hot gas $\mathrm{CO}, \mathrm{CO}_{2}$ measurements & Fourier Transform Infrared Spectroscopy \\
\hline Off-gas heavy metal detection & Laser-induced Breakdown Spectroscopy \\
\hline Downstream off-gas $\mathrm{HCl}$, and/or organics & $\begin{array}{l}\text { Fourier Transform Infrared Spectroscopy } \\
\text { (Extractive) }\end{array}$ \\
\hline Velocity profile at reactor output & Laser Doppler Velocimeter \\
\hline
\end{tabular}

Table 3.1b. DIAL Measurements at WETO/MSE, October 1994. 
For further information, please contact:

W. Steve Shepard

Principal Investigator

Diagnostic Instrumentation and

Analysis Laboratory

Post Office Drawer MM

Mississippi State, MS 39762-5932

(601) 325-2105

\section{Al Tardiff}

Project Manager, CMST-CP

U.S. Department of Energy

Cloverleaf Building

19901 Germantown Road

Germantown, MD 20874-1290

(301) $903-7670$

\section{BIBLIOGRAPHY OF KEY PUBLICATIONS}

Lengel, R., J. Linder, D.L. Monts, O.P. Norton, J.P. Singh, C.F. Su, P.R. Jang, W. Okhuysen, R.L. Cook, D. Bennert, J.C. Whitehouse, "Application of Advanced Diagnostic Techniques to the Study of Mixed Waste Vitrification," submitted to Proceedings of Waste Management '95 Symposium, Tucson, AZ, February 1995.

Jang, P.R., R.K. Lengel, D.L. Monts, R.L. Cook, W.S.Shepard, "Pyrometry Studies of a Mixed Waste Vitrification Plasma Arc Centrifugal Treatment System," submitted to Proceedings of Third Biennial Mixed Waste Symposium, Baltimore, MD, August 1995.

Singh, J.P., T. Phillip, C.F. Su, F.Y. Yueh, "Study of Laser-Induced Breakdown Spectroscopy of Vitrified Glass Sample," Proceedings of I\&EC Special Symposium, American Chemical Sociery, Atlanta, GA, September 1994. 


\subsection{SUPPORT FOR RCRA METAL AND AIR STREAM CHARACTERIZATION}

\section{TASK DESCRIPTION}

This project is comprised of two separate tasks: MSE's function in Task 1 is to select a test bed and verify field analyses performed by field detection technologies that can identify and quantify Resource Conservation and Recovery Act (RCRA) metals contained in soils. In Task 2, MSE will provide assistance to DIAL with sampling and analysis work on several thermal waste processing technologies. Of particular importance is the ability to obtain baseline data for the implementation of Fourier Transform Infrared Spectroscopy (FTIR), Laser Induced Breakdown Spectroscopy (LIBS), and Laser OptogalvanicSpectroscopy (LOGS).

\section{TECHNOLOGY NEEDS}

TASK 1: Current methods for determining heavy metals concentration in soils are both costly and time consuming. The development of this technology should enable field analyses to be performed immediately on-site, with a sensitivity that meets RCRA limitations.

TASK 2: MSE's task at WETO regarding DIAL is to provide assistance with test implementation, test analysis, and operational coordination. MSE will coordinate appropriate National Environmental Policy Act (NEPA) documentation if required for a particular DIAL analysis scheme or apparatus. MSE will coordinate administrative and technical reporting.

\section{TECHNOLOGY DESCRIPTION}

TASK 1: Conceptual description may include, but is not limited to, the following:

The technology must be field-based, nondestructive, and require minimal sample preparation. The technology must be portable, hand held, or maneuverable over hazardous terrain.
The technology must be able to identify RCRA metals such as $\mathrm{As}, \mathrm{Pb}, \mathrm{Cd}, \mathrm{Ag}, \mathrm{Cr}, \mathrm{Se}$, and other metals such as $\mathrm{Zn}, \mathrm{Cu}, \mathrm{Fe}$, and $\mathrm{Mn}$.

TASK2: The FTIR system is a monitoring device that has the ability to detect organic molecules and breakdown products that may be precursors to dioxin formation. The LIBS and LOGS are sampling systems that measure toxic metals in the thermal treatment offgas stream.

\section{Test Bed Description}

TASK 1: Description of a rest bed to be used in this project may include but is not limited to the following:

- The test bed may be either an abandoned mine or mill tailings pile or soil contaminated with heavy metals.

- The test bed will have As, $\mathrm{Pb}, \mathrm{Cd}, \mathrm{Ag}, \mathrm{Cr}, \mathrm{Se}$, and other metals such as $\mathrm{Zn}, \mathrm{Cu}, \mathrm{Fe}$, and $\mathrm{Mn}$ at detectablelevels. (Note: More than one site may be used.)

- A test bed will be sectioned in quadrants in order to get a number of comparable data.

- Each quadrant will be sampled and data analysis performed to develop a baseline. These analyses will be standard laboratory procedures.

TASK 2: The test bed to be used in this project is the Plasma Centrifugal Furnace (PCF) at WETO and its associated off-gas system.

\section{ACCOMPLISHMENTS}

Funding for this project is expected in the near future. Early accomplishments for this project are as follows:

A list of possible field test beds has been developed for Task 1. MSE has identified six distinct matrices of interest: mineral processing tailings from the Cham- 
pion Mine, mineral processing tailings from the Bullion Mine, waste rock from the Bullion Mine, pyrometallurgical slag from the Bullion Mine, mineral processing tailings from the Cataract Mine, and soil from the Mill Creek Townsite.

Samples from these test beds have been sent to Los Alamos National Laboratory for preliminary testing by Laser-Induced Breakdown Spectroscopy (LIBS). Primary analyses of interest are $\mathrm{As}, \mathrm{Pb}, \mathrm{Cd}, \mathrm{Cu}$ and $\mathrm{Zn}$. In addition, $\mathrm{Ag}, \mathrm{Cr}, \mathrm{Fe}$, and $\mathrm{Mn}$ are of interest due to regulatory drivers.

\section{BENEFITS}

TASK 1: DOE along with other federal agencies and private industry, is faced with massive soil characterization problems at numerous contaminated sites. It is anticipated that millions of dollars will be required for laboratory analyses to accurately depict the constituents of the contamination. DOE is attempting to meet the objective of cost-effective field analyses by preparing a test bed and demonstrating field detection technologies. The screening and evaluation will identify technologies that solve the characterization problem in a timely and inexpensive manner.

TASK 2: The FTIR system has the potential of providing a real-time ability to detect organic molecules and breakdown products that may be precursors to dioxin formation. The LIBS and LOGS systems have the potential of providing real-time measurement of toxic metals in the thermal treatment off-gas stream.

\section{COLLABORATION/TECHNOLOGY}

\section{TRANSFER}

TASK 1: Although the purpose of these demonstrations is to identify field analytical technologies that can identify RCRA heavy metals in contaminated sites, follow-up work may result under a separate project resulting in modifications to one or several technologies tested to overcome physical and mechanical deficiencies identified during the demonstration.

Potential users of the technologies are widespread across the DOE Complex and in the nation. Because the need is extensive, the technologies would be readily transferable to private entities that must evaluate the extent of RCRA metals at contaminated sites outside DOE. Some candidates for field detection technologies are Superfund sites, existing mining operations, and terminated mining operations.

Developments from the evaluations will result in dissemination of technical and economic information via presentations and/or publications at national meetings, conferences, workshops, seminars, etc.

Potential technologies will be selected from OTD projects and respondents to a Commerce Business Daily (CBD) announcement. The selection process and issuance of the CBD announcement will be jointly conducted by MSE and the CMST-CP's technical support team at Ames Laboratory. MSE is collaborating with Los Alamos National Laboratory concerning the LIBS detection technology.

\section{For further information, please contact:}

\author{
Martin Foote \\ Principal Investigator \\ MSE, Inc. \\ P.O. Box 4078 \\ Butte, MT 59702 \\ (406) 494-7431
}

\section{Melvin Shupe}

DOE Technical Program Officer:

Western Environmental Technology Office

P.O. Box 3462

Butte, MT 59702

(406) 494-7205
Al Tardiff
Project Manager, CMST-CP
U.S. Department of Energy
Cloverleaf Building
19901 Germantown Road
Germantown, MD 20874-1290
(301) $903-7670$ 
TTP Number: PE153001

BibliOgRAPHY OF KEY PUBLICATIONS

None at this time. 


\section{CONTINUOUS EMISSION MONITOR FOR THERMAL TREATMENT SYSTEMS}

\section{TASK DESCRIPTION}

This project addresses the need mandated by the Clean Air Act of 1990 to monitor air toxics. The objective is to develop a Fourier transform infrared (FTIR) spectrometer, combined with a heated long-path cell, as a continuous emission monitor (CEM) for thermal treatment systems. See Figure 3.3a. The instrumentation will continuously monitor organic and selected inorganic stack emissions. The technology is applicable to incinerators, other thermal treatment processes, process monitoring, and ambient air monitoring.

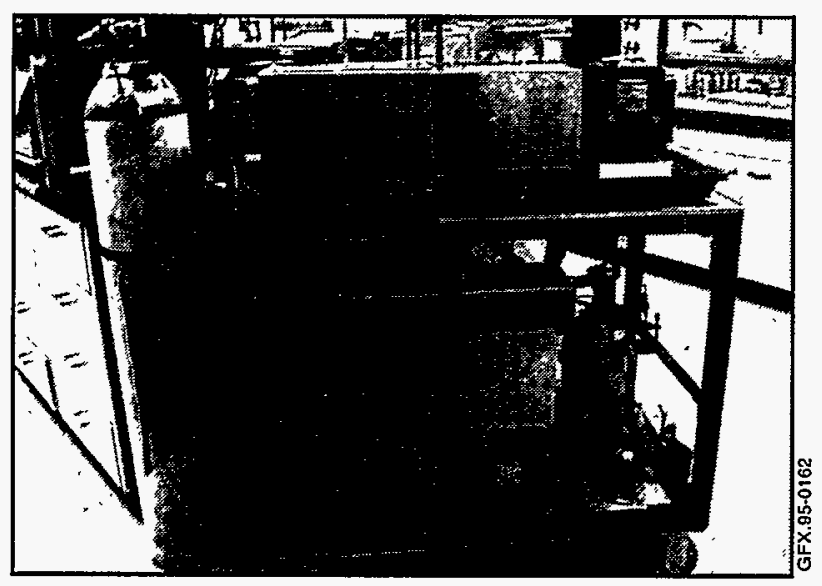

Figure 3.3a. Prototype FTIR ContinuousEmission Monitor Used During the Field Test at the K-25 Site.

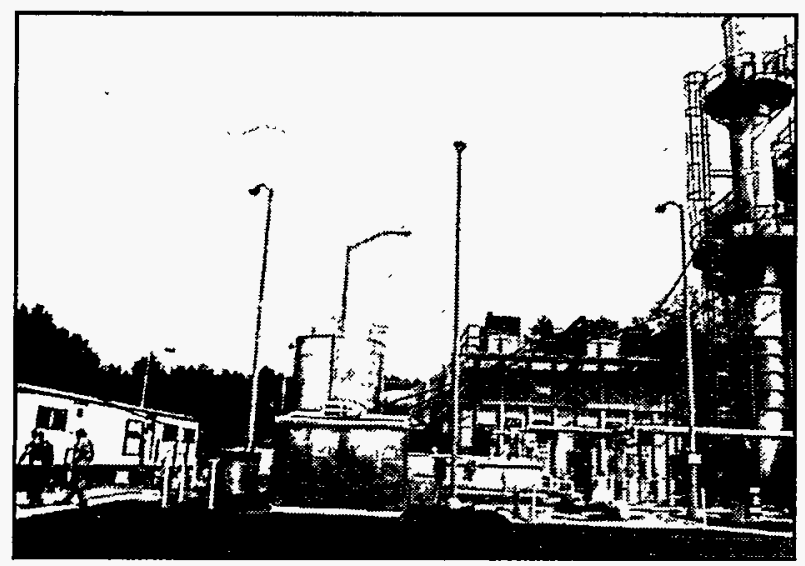

Figure 3.3b. The Toxic Substances Control Act Incinerator at the K-25 Site in Oak Ridge, TN.
The primary benefit of an on-stream monitor for stack effluent is the near real-time determination of performance. On-stream analysis of the stack effluent would satisfy the requirements of the Clean Air Act of 1990 and address public concern about incinerator safety. Another benefit is the elimination of the need for expensive monitoring techniques currently used to characterize the effluent, such as a volatile organic sampling train (VOST) followed by GC/MS laboratory analysis. This method is required under current procedures and provides a one-time analysis. See Figure 3.3b.

A complete package including advanced instrumentation that is compliant with regulatory standards and commercially available is essential. To achieve these goals, the project has progressed in three areas. The first area is technical development of instrument optimization, automation software, sampling, and advanced data analysis. The second area is obtaining EPA regulatory approval. The third area is commercialization of the instrument. At the completion of this project, all data will be EPA-compliant and the instrument packaged as a complete unit.

Instrument development has progressed from commercially available instrumentation through a "breadboard" unit with interchangeable parts, to a small cabinet unit that contains all the hardware for sampling and can easily be rolled to different locations. A complete sampling system has been designed and integrated with the FTIR spectrometer. The sampling system is automated and interactive with the instrument through the "TEAM" software package that runs in a Microsoft Windows environment. Infrared cell and transfer optics design have been greatly simplified. The entire system, including the spectrometer, has been moved on a forklift and requires no optical alignment.

Analysis software has also progressed. Initial data analysis consisted of single classical and partial least squares (PLS) methods. Parallel processing of individual methods has been implemented. Data analysis is currently being enhanced with time and frequency domain 
methods that mathematically, using peak width, separate components with overlapping bands. This combined approach will enhance the ability to detect substances that have overlapping absorbances and allow for the digital filtering of system noise.

Obtaining regulatory compliance has focused on working with the EPA. We contributed to an EPA protocol for continuous emission monitoring using FTIR technology. We were requested by the EPA to prepare and submit a procedure to them for validation. EPA procedures are not required; however, when they are followed and quality control is within the specified limits, the EPA guarantees acceptance of the data. The procedure was submitted in September 1994 and validation is now underway. We anticipate that data generated with this system will be EPA compliant in 1995.

A CRADA to commercialize the system was completed in October 1994 with Clean Air Engineering (CAE) and Martin Marietta Energy Systems (MMES), operators of the DOE Toxic Substances Control Act (TSCA) incinerator at the K-25 Site in Oak Ridge, Tennessee. The CRADA, in combination with the EPA acceptance of the data, will make the system commercially viable and facilitate acceptance in the community. We are also chairing the American Standard Testing Methods (ASTM) task committee to develop an FTIR continuous-emission monitoring method for FTIR methods.

During FY95, the alpha unit will be constructed and tested under the CRADA. There will be at least two field tests of the new system. There will be a long-term test at the K-25 TSCA incinerator and a short-term test at the Bureau of Mines vitrification facility at Albany, Oregon. Work will continue on advanced data analysis algorithms and the validation of the EPA procedure will continue. The spectrum illustrated at the top is that of stack gas containing no methane. The middle spectrum shows the presence of methane in the stack sample. The standard FTIR spectrum of methane is shown in the bottom spectrum.

\section{TECHNOLOGY NEEDS}

Title 3 of the Clean Air Act requires monitoring of air toxics from incinerators, stacks, and fugirive emissions. This technology is applicable for these requirements and will result in EPA acceptance for FTIR monitoring data. The method can be extended to cover thermal treatment, stack, and ambient air monitoring. Continuous monitoring will directly address issues of environmental safety, and the technology can be used to identify and quantify organic chemicals in the air. There is significant public concern about incineration and a continuous emission monitor helps address those concerns.

\section{ACCOMPLISHMENTS}

A laboratory incinerator has been constructed and integrated to an FTIR system. The operating conditions can be deliberately and reproducibly changed to simulate off-set conditions of an incinerator. Two freld tests were completed using the FTIR Continuous Emission Monitor at the $\mathrm{K}-25$ site. The combination of field testing and laboratory testing have demonstrated the accuracy and precision of the system. The EPA procedure has been completed and EPA approval is anticipated in 1995. Once the procedure is approved, the system can be used to demonstrate compliance.

\section{COLLABORATION/TECHNOLOGY TRANSFER}

A CRADA has been approved with CAE and MMES. The first CRADA field test was in January 1995. 
For further information, please contact:

Jack Demirgian

Principal Investigator

Argonne National Laboratory

9700 S. Cass Avenue

Argonne, IL 60439-4835

(708) 252-6807

James Helt

Technical Program Manager

Argonne National Laboratory

9700 S. Cass Avenue

Argonne, IL 60439-4835

(708) 252-7335

\section{Al Tardiff}

Project Manager, CMST-CP

U. S. Department of Energy

Cloverleaf Building

19901 Germantown Road

Germantown, MD 20874-1290

(301) $903-7670$

\section{BIBLIOGRAPHY OF KEY PUBLICATIONS}

None at this time. 


\subsection{METAL EMISSIONS MONITOR FOR DOE MIXED WASTE THERMAL TREATMENT}

\section{TASK DESCRIPTION}

This project is developing an instrument using Laser-Spark-Spectroscopy (LASS) as a continuous monitor to measure metal emissions from the offgas of thermal treatment units. Major tasks include performing laboratory proof-of-concept evaluation, designing and fabricating a series of prototype field instruments, and demonstrating these instruments at a DOE waste treatment field experiment, at an EPA test site, and at a DOE waste treatment site. Results of prototype measurements are being analyzed, evaluated, and compared to standard EPA measurements.

\section{TECHNOLOGY NEEDS}

Current effluent measurement techniques are based on extractive samples followed by chemical analyses. In addition to being expensive and subject to human error, these methods provide no real-time data for operational feedback. Also, results generally take two to four weeks from the time of sampling. LASS provides the capability to measure continuously, in situ, and in real time. LASS also offers the capability to measure metals embedded in either particles, fine aerosols, or vapors in emissions from thermal treatment units, while many of the other advanced monitors under development can only measure vapor-phase species.

\section{ACCOMPLISHMENTS}

- Instrument performance specifications (detection limits, species of interest, etc.) have been defined for effluents typical of DOE waste treatment processes.

- Laboratory proof-of-concept experiments have been conducted to demonstrate the feasibility of a continuous metals monitor based on the laser spark technology.
- An automated data-acquisition system has been developed that allows user specification and control of data collection parameters.

- The minimum detectable concentration has been determined using LASS for each of the 11 metals regulated under the Clean Air Act.

- A prototype portable continuous metal emissions monitor based on LASS has been designed and fabricated.

- The prototype metal emissions monitor and data-acquisition system have been demonstrated and evaluated in laboratory experiments.

- The prototype metal emissions monitor system has been demonstrated at a DOE mixed waste treatment experimental facility, the Clemson University Joule Melter Project.

\section{BENEFITS}

Advances in control and monitoring of metal emissions will benefit DOE-EM operations in several areas. For thermal treatment units, such a monitor will simplify permitting and daily operations, ease public opposition, and improve system efficiency. This monitor will also serve as an important tool to evaluate emissions from new thermal treatment technologies. Since this is a long-term development effort, it is difficult to estimate the potential cost savings. However, current EPA methods to measure metal emissions are very costly (upwards of $\$ 8,000$ per stack per triplicate sample). The lack of continuous emissions measurements also makes ensured compliance more costly due to tighter operational restrictions. All of these costs would be reduced, if not eliminated, with the introduction of this instrument. 


\section{COLLABORATION/TECHNOLOGY TRANSFER}

In this project, Sandia is collaborating with ADA Technologies Inc., a small $R \& D$ company with experience in stack-gas monitoring and field instrumentation. Sandia also is working with an instrument manufacturer is interested in commercializing the laser spark technology.

For further information, please contact:

Bill Flower

Principal Investigator

Exploratory Systems Department

Sandia National Laboratory

P.O. Box 969, MS-9103

Livermore, CA 94551-0969

(510) 294-2046

\section{George Allen}

Technical Program Manager

Sandia National Laboratory

P.O. Box 969

Livermore, CA 94551-0969

(505) 844-9769

\section{Dennis Olona}

Technical Program Officer

U.S. Department of Energy

Albuquerque Operations Office

P.O. Box 5400

Albuquerque, NM 87185-5400

(505) $845-4296$

\section{Dr. Caroline Purdy}

Program Manager, CMST-CP

U.S. Department of Energy

Cloverleaf Building

19901 Germantown Road

Germantown, MD 20874-1290

(301) $903-7672$

\section{TTP Number: AL333501}

\section{BIBLIOGRAPHY OF KEY PUBLICATIONS}

W.L. Flower, L.W. Peng, N.B. French, H.A. Johnsen, and D.K. Ottesen, A Laser-Based Technique for Continuously Monitoring Metal Emissions from Thermal Waste Treatment Units, 1994 Proceedings for the International Incineration Conference, Houston, TX, University of California Irvine Office of Environment, Health \& Safety.

W.L. Flower, L.W. Peng, M.P. Bonin, H.A. Johnsen, R.F. Renzi, D.K. Ottesen, L.V. Westbrook, and N.B. French, A Technique to Continuously Monitor Metal Aerosol Emissions from Incinerators and Industrial Process Vents, 1993 Proceedings for the International Incineration Conference, Knoxville, TN, University of California Irvine Office of Environment, Health \& Safety.

W.L. Flower, L.W. Peng, M.P. Bonin, H.A. Johnsen, R.F. Renzi, D.K. Ottesen, L.V. Westbrook, and N.B. French, A Laser-Based Technique to Continuously Monitor Metal Aerosol Emissions, EPRI/ EPA Workshop on Trace Elements Transformations in Coal-Fired Power Systems, Scottsdale, AZ, Elsevier Publishing, Fuel Processing Technology, Volume 39, p 277-284, April, 1993. 


\section{CMST-CP PROJECTS}

FOR THE

\section{DECONTAMINATION AND DECOMMISSIONING Focus AREA}

\section{Section 4.0}




\subsection{ASSOCIATED PARTICLE IMAGING DEVELOPMENT}

\section{TASK DESCRIPTION}

The Associated Particle Imaging (API) system is an active, non-intrusive, single-sided, fast-neutronbased interrogation system that will examine contaminated surfaces, display the locations, shapes, and sizes of their contents in three-dimensional image format, and identify their elemental compositions.

The general principles on which the API method is based are illustrated in Figure 4.1a. A Sealed Tube Neutron Generator (STNG), not shown in the figure, produces $14 \mathrm{MeV}$ neutrons. The neutrons leave the collision site in a direction antiparallel to the particles, as shown in the figure. The particle hits a two-dimensional position-sensitive detector and starts the clock (labelled "TAC"). At the same time, the neutron heads off toward the region to be interrogated. If the neutron interacts with target material in the interrogation region, and if a gamma ray is produced and subsequently detected within a preset period of time, then the clock is stopped upon detection of the gamma ray. The particle's location on the two-dimensional detector gives the neutron direction of flight. The elapsed time between clock "start" and "stop" provides information that tells how far the neutron travelled before hitting the target. These pieces of information ultimately give the $x, y, z$ location of the neutron-target interaction. Furthermore, the energy of the gamma ray is characteristic of the material that was hit. Thus, the gamma spectrum allows one to identify the elemental composition of the material in the target region as a function of position.

API's real power lies in its ability to gain simultaneous elemental and positional information. This is illustrated in Table 4.1, The two columns on the left list the elemental information pertinent to salt and water. The next two columns give information about each of these elements if only a "lump sum" of salt and water data is considered. However, if one is able to separate the salt from the water, as we have done in the boxes of Figure 2, one can significantly enhance the signalto-noise ratio. This is evidenced by comparison of the third and fifth columns of the table. In terms of non-destructive evaluation (NDE) measurements, this means that our confidence level is higher than it would be without the ability to spatially isolate the

Figure 4.1a. API. 
data aggregates. The system to be used for Deconsurements will use these technologies to interrogate contaminated surfaces and volumes. tamination and Decommissioning (D\&D) mea-

\section{BENEFITS}

Descriptions of $D \& D$ problems repeatedly include the need for three-dimensional, elemental information about solid structures and the interiors of enclosed volumes at candidate DOE sites. These data, which are needed to

\begin{tabular}{|l|l|c|c|c|c|}
\hline \multirow{2}{*}{$\begin{array}{c}\text { Energy } \\
\text { (Mev) }\end{array}$} & \multirow{2}{*}{ Element } & & \multicolumn{2}{|c|}{ Without Spatial Gate } & \multicolumn{2}{|c|}{ With Spatial Gate } \\
\cline { 3 - 6 } & & S/N Ratio & $\%$ Error & S/N Ratio & $\%$ Error \\
\hline 1.78 & Salt & .15 & $17 \%$ & .43 & $9 \%$ \\
2.15 & Salt & .12 & $16 \%$ & .58 & $5 \%$ \\
3.68 & Water & .15 & $7 \%$ & 1.30 & $7 \%$ \\
6.13 & Water & .44 & $42 \%$ & .76 & $15 \%$ \\
\hline
\end{tabular}

Table 4.1 API has the Ability to Gain Simultaneous Elemental and Positional Information.

\section{TECHNOLOGY NEEDS}

API addresses the need for nondestructive evaluation of contaminated surfaces and volumes by nonintrusive methods. The planned API measurements will demonstrate the utility of the technique to assist in some of the measurements that will be required to accomplish cleanup tasks at DOE sites as part of the $D \& D$. The first measurements, designed to show proof of concept, will produce elemental analyses and selected images of contaminants in concrete floors at a DOE site to be identified. Based on these results, API systems and experiments will be designed for future $D \& D$ measurements where three-dimensional information about such enclosed volumes as cascade pipes in gaseous diffusion pipes is a prime $D \& D$ requirement.

\section{ACCOMPLISHMENTS}

Technologies developed with the laboratory API system are being incorporated into systems for $D \& D$ measurements. devise the most effective internal decontamination techniques, can be supplied only by nonintrusive interrogation measurements, such as computerized tomography (CT), real-time radiography ( $R T R$ ), and API. For many $\mathrm{D} \& \mathrm{D}$ applications, the geometries are fixed and very complex, so that neither CT nor RTR can be applied. CT requires that the sample be rotated, while both CT and RTR require that the sample be placed between the source and the detector. In addition, neither provides elemental information. This places API, with its ability to make single-sided measurements, at a significant advantage over the others.

\section{COLLABORATION/TECHNOLOGY}

\section{TRANSFER}

The strategy for technology transfer is to introduce API to the $D \& D$ community and demonstrate its utility for selected applications. The API technology has been described to Paducah Gaseous Diffusion Plant personnel as a technique for displaying suspended geometries in the cascades. The special neutron generator is also drawing interest from the petroleum industry, since it will have the potential of providing more information of the subsurface via borehole logging than is currently available. Atlas Wireline, a company based in Houston, TX has expressed such an interest in the downhole design of the STNG tube. 
For further information, please contact:

Dr. J. Paul Hurley

Principal Investigator

Special Technologies Laboratory

5520 Ekwill Street, Suite B

Santa Barbara, CA 93111

(805) 681-2472

\section{Richard Lynn}

Technical Program Manager

Special Technologies Laboratory

5520 Ekwill Street, Suite B

Santa Barbara, CA 93111

(805) 681-2401

\section{Katie McWilliam}

Technical Program Officer

U.S. Department of Energy

Nevada Operations Office

P.O. Box 98518

Las Vegas, NV 89193-8518

(702) 295-1031

Dr. Caroline Purdy

Program Manager, CMST-CP

U.S. Department of Energy

Cloverleaf Building

19901 Germantown Road

Germantown, MD 20874-1290

(301) $903-7672$
BIBLIOGRAPHY OF KEY PUBLICATIONS

None at this time. 


\subsection{DEFINING REQUIREMENTS FOR EVALUATION AND TESTING OF RADIOLOGICAL SENSOR TECHNOLOGIES}

\section{TASK DESCRIPTION}

This comprises two tasks: (1) to establish performance guidelines for, and monitor the progress of, selected OTD radiological programs in characterization, monitoring, and sensor technologies, and (2) to examine the current and near-future radiological sensor technology to identify those radiological sensors and sensor systems that will be most effective for measurements in D\&D acrivities.

Task 1: A document for each program will be prepared composed in association with the appropriate principal investigator, and will include a detailed set of performance specifications that will be used to review proposals for new and extant projects. Each will be examined for both technical and management content. New experimental plans will be evaluated for overall technical merit by matching proposed capabilities with regulatory requirements to estimate the probability of success for those projects. Similar proposals will be screened to ensure complementariness and prevent duplication.

For the existing programs, low-profile, on-site visits will be made to selected laboratories to increase the accuracy of the technical assessments. Evaluation criteria for each of the programs will be established to provide standards against which the performances of the individual projects can be compared. The sensors and their related instrumentation will be evaluated for performance expectation, while the data processing algorithms will be examined for technical merit and applicability.

The proposed experimental plans, which will include schedules, milestones, cost estimates, and ultimate objectives in addition to the performance specifications, will be reviewed for reality and consistency. These criteria will then be used to determine if the measured values meet the regulatory requirements, the projected milestones have been reached, the data is both reasonable and realistic, and the system is performing as proposed and anticipated.
Task 2: Reductions and cessations of activities at nuclear weapon production facilities have generated a need for D\&D activities at those facilities. Selections of the appropriate sensors and sensor systems will depend strongly on the measurements to be made and robotic platforms under development. The program will use data acquired in the initial tasks to monitor the progress of the radiological sensor technology development as it applies to evolving $\mathrm{D} \& \mathrm{D}$ requirements.

Results of the measurements at the various sites will be monitored to evaluate the effectiveness of the sensors in meeting those requirements. Deficiencies will be noted and analyzed to determine if new and different sensors and/or techniques may be required, with the results communicated to EM-50 and the appropriate laboratories for their actions.

Because the $D \& D$ program will be dynamic, its requirements will change frequently, and the technologies will have to respond correspondingly. This program will assist EM-50 in monitoring the progress of the design, development, and availability of new and innovative sensors and sensor systems. It will also assist in testing and evaluating them for reliability and specificity to D\&D problems. Beginning with visits to the appropriate D\&D sites, the measurements to be made and the sensor systems to be used will be reviewed, communications between the robotics and sensor system programs will be monitored to ensure coordinated development, and sensor development will be monitored to evaluate their utility in future $D \& D$ measurements.

\section{TECHNOLOGY NEEDS}

Task 1: The establishment of standards of quality for OTD programs will provide principal investigators, DOE customers, and DOE program reviewers with guidelines that can be used to evaluate existing and future OTD proposals for quality and relevance. 
Task 2: Identifying the $\mathrm{D} \& \mathrm{D}$ measurements to be made, the platform and sensor problems associated with those measurements, and monitoring the appropriate sensor and platform technologies to ensure mutual compatibility will maximize the specificity of each to D\&D measurements.

\section{ACCOMPLISHMENTS}

Proposals have been reviewed and selected sites visited to evaluate their use in future $\mathrm{D} \& \mathrm{D}$ applications. Programs and proposals will continue to be monitored and evaluated to ensure coordinated development.

\section{BENEFITS}

Task 1: The enhanced quality of the EM-50 programs will provide DOE with improved guidelines for evaluating existing and future $R \& D$ proposals.

Task 2: The enhanced quality of the radiological sensors to be used for D\&D measurements will provide DOE with better cleanup capabilities at reduced cost.

\section{COLLABORATION/TECHNOLOGY TRANSFER}

Not applicable for either task.

\section{For further information, please contact:}

Dr. J. Paul Hurley

Principal Investigator

Special Technologies Laboratory

5520 Ekwill Street, Suite B

Santa Barbara, CA 93111

(805) 681-2472.

Richard Lynn

Technical Program Manager

Special Technologies Laboratory

5520 Ekwill Street, Suite B

Santa Barbara, CA 93111

(805) 681-2401

\section{Katie McWilliam}

Technical Program Officer

U.S. Department of Energy

Nevada Operations Office

P.O. Box 98518

Las Vegas, NV 89193-8518

(702) 295-1031

\section{Dr. Caroline Purdy}

Program Manager, CMST-CP

U.S. Department of Energy

Cloverleaf Building

19901 Germantown Road

Germantown, MD 20874-1290

(301) $903-7672$

TTP Number: NV031002, NV053001

BIBLIOGRAPHY OF KEY PUBLICATIONS

None at this time. 


\subsection{A ROBUST RADIATION DETECTOR FOR RAPID WASTE CHARACTERIZATION}

\section{TASK DESCRIPTION}

This project aims to develop a robust, miniaturesized, room-temperature, and real-time radiation detector with good spectroscopic capabilities and the ability to simultaneously detect and discriminate alpha, beta, and gamma radiation. It will be especially suitable for characterizing waste materials including mixed radionuclides. The use of chemical vapor deposited (CVD) diamond thin-film as a windowless front-part of the detector makes the device capable of withstanding harsh environments, such as high-pressure difference, high temperature, dust and particulate impacts, high-moisture content, even water and oil in direct contact, and ultimately, chemically aggressive gases and liquids. While the detector's front-part is sensitive to alpha and low-energy beta radiation, gamma (and high energy beta) detections are accomplished within the rear part of the device. The rear part consists of one or several layers of $\mathrm{CdZnTe}(\mathrm{CZT})$. The diamond and CZT detector units will be bonded together using a special diamond brazing technique developed by Grumman Aerospace Corporation.

\section{TECHNOLOGY NEEDS}

This project directly addresses needs for: (a) a portable, real-time alpha-gamma sensor for use in the robotics program, (b) field equipment for rapid characterization of radionuclides in soil, ground water, waste containers, and process effluents, and (c) a sensor for assay of transuranics (TRU) under high gamma dose rates. Depending on the harshenvironment test results, this detector may also be applied to ground water and cone-penetrometer testing, as a support to $D \& D$ under a wide range of solution conditions, and for in situ measurements of TRU and fission products in chemically hazardous environments. It is directly responsive to several D\&D needs: non-destructive assay (NDA) and in situ measurements of uranium in enclosed volumes such as pipes, ducts, and process equipment, in situ/real-time measurements of TRU and fission products, and in situ characterization for wet and/ or underwater concrete. The detector being developed is also applicable to the needs for NDA and in situ characterization of excavated buried waste, soil, rock, and debris.

\section{TECHNOLOGICAL BACKGROUND}

As radiation detector material, CVD diamond of fers an excellent alternative to natural and synthetic diamond. It is inexpensive, and its quality is reproducible. At present, free-standing diamond films, four inches in size and $1 \mathrm{~mm}$ in thickness, are available commercially.

Stringent selection criteria for detector material include, among others, high bulk resistivities in excess of $1 . \mathrm{E}+10 \mathrm{Ohm}-\mathrm{cm}$ and the absence of subbandgap photoconductivities. While both are pertinent to low leakage current and low detector noise, the latter may ultimately result in a solarblind detector suitable for field use. So far, only diamond films grown by the microwave plasma-enhanced CVD (PECVD) technique have been shown to satisfy these quality criteria. By applying postgrowth processing techniques, bulk resistivities higher than natural diamond can be achieved.

Using a few microns of gold-coating as electrode, alpha energy resolutions on the order of less than five percent have been demonstrated. This can be further improved if the diamond detector is made windowless. Currently, windowless alpha particle detectors based on silicon are available commercially (PIP/Canberra and ULTRA/EG\&G Ortec). In those detectors, the front electrode coating is replaced by a heavily doped semiconductor of the same material. Such a technique is also applicable to CVD diamond. For this purpose, p-type semiconducting diamond will be made by doping with boron. 
Cadmium-Zinc-Telluride (CZT) has been identified recently as being ultimately superior to Cadmium-Telluride with respect to gamma-detection properties. Good spectroscopic capabilities have been demonstrated for CZT detectors of up to 30 $\mathrm{mm}$ thickness without showing the detrimental effects of polarization at room temperatures. This results in a much higher gamma detection efficiency as compared to $\mathrm{CdTe}$, which is usually usable to a maximum thickness of only a few millimeters. More recent findings indicate that, while polarization in $\mathrm{CdTe}$ shows up at room, or even higher temperatures, the threshold lies at around $250^{\circ} \mathrm{K}$ for CZT, thus rendering the latter a better material for room temperature applications.

\section{ACCOMPLISHMENTS}

Success has been achieved in using electrically conducting rubber as ohmic contact material for routine, expeditious resistivity measurements of (free-standing) diamond wafers. Extremely high resistivities, ranging from 1 . E+10 to 1 . E+15 Ohm$\mathrm{cm}$, have been measured using a homemade device (R-Box).

Photoconductivity measurement: Under strong room illumination the leakage-current increased from $30 \mathrm{pA}$ (dark-current) to $2 \mathrm{nA}$ (photocurrent) at $400 \mathrm{~V}$ across the film-thickness $(<0.1 \mathrm{~mm})$. Such a small leakage current is very promising with regard to the expected solarblindness of the detector.

Polarization effect: The higher the resistivity, the stronger the polarization. The observed effect vanishes under strong illumination, at the cost of increased leakage current (from $30 \mathrm{pA}$ to $2 \mathrm{nA}$ at 400 Volt voltage bias).

\section{BENEFITS}

The success of this project will satisfy diverse DOE requirements, as cited above. The benefit will be maximum if the expected solarblindness can be established. Owing to the detector's suitability for field and in situ applications, a large amount of time, money, and manpower will be saved as compared to the elaborate, presently employed technique of taking samples and carrying out laboratory measurements.

\section{COLLABORATION/TECHNOLOGY TRANSFER}

This collaborative project is making use of Grumman's CVD diamond reactor (which originates from a former, no longer funded, BNLGrumman collaborative project), and also of its expertise in diamond-growing and brazing of diamond to other materials. Grumman owns a PECVD diamond reactor. The project will also benefit from a collaboration with Grumman's group specializing in CdTe material and the company's potential for nuclear detector commercialization.

The project is taking advantage of an existing BNLNew Jersey Institute of Technology (NJIT) collaboration in photoluminescence and radiation damage in microelectronics, while making use of a BNLowned laser and CCD camera installed at NJIT for that purpose. BNL expertise in laser and spectroscopy techniques and NJIT expertise in marerials characterization are being transferred/exchanged. 
For further information, please contact:

\section{Eng-Kie Souw}

Brookhaven National Laboratory

P.O. Box 5000

Upton, NY 11973-5000

(516) $282-5407$

\section{Eena-Mai Franz}

Brookhaven National Laboratory

P.O. Box 5000

Upton, NY 11973-5000

(516) $282-7103$

Dr. Caroline Purdy

Program Manager

U.S. Department of Energy

Cloverleaf Building

19901 Germantown Road

Germantown, MD 20874-1290

(301) $903-7672$

\section{BIBLIOGRAPHY OF KEY PUBLICATIONS}

None at this time. 


\subsection{DEVELOPMENT OF A PORTABLE HEAVY METAL DETECTOR USING X-RAY, K-EDGE ANALYSIS}

\section{TASK DESCRIPTION}

The objective of this project is to develop improved methods for detection and quantification of heavy metals, such as $\mathrm{Hg}, \mathrm{Pb}, \mathrm{U}$, and $\mathrm{Pu}$ located inside containers and equipment. An $\mathrm{X}$-ray transmission measurement of the $k$-shell absorption edge of these materials will be implemented in this task. The sensitivity of this technique for detecting different elements in the presence of different matrix materials is being determined. To enhance the sensitivity, improvements in X-ray sources and detectors are being investigated. Components are being selected with the goal of producing a compact portable system. This technique will be tested in the field at DOE sites.

\section{TECHNOLOGY NEEDS}

Cleanup of many DOE facilities requires dismantling equipment that was used to process hazardous materials such as uranium, plutonium, and mercury. Using existing techniques, such as passive neutron and gamma measurements, and neutron activation analysis, it is difficult and time-consuming to detect and quantify these hazardous materials when they are contained within heavy equipment. The gaseous diffusion plant at the K-25 Site at Oak Ridge contains over 100 acres of heavy equipment used for processing uranium. The Fernald Site has over 40,000 cubic feet of transite panels containing uranium, thorium, and RCRA hazardous metals. Rapid in situ analysis of these types of materials for hazardous elements is needed.

\section{ACCOMPLISHMENTS}

Initial tests using non-optimized equipment indicate the ability to detect an 80 micron thick layer of uranium located behind $4 \mathrm{~cm}$ of steel. This is already at the level of sensitivity achieved using conventional NDA techniques.

\section{BENEFITS}

A fast in situ method for quantifying the presence of uranium, plutonium, and RCRA-listed heavy metals inside closed containers would greatly enhance the safety and efficiency of $D \& D$ efforts. In particular, it is important to monitor the removal of uranium from gaseous diffusion plant equipment by chemical flushing. Not having to dispose of these materials as high-level waste would yield significant savings. Accurate determination of the level of hazardous metals present would enhance the safety of dismantling operations.

\section{COLLABORATION/TECHNOLOGY TRANSFER}

This project is currently being carried out at lowa State University. As part of the initial investigations, surveys will be made of existing commercial equipment that could be applied to this technique. Based on these results, it is anticipated that collaboration with industry will follow to optimize equipment to meet the needs of the application. 
For further information, please contact:

Joe Gray

None at this time.

Terry Jensen

Center for NDE

Iowa State University

Ames, IA 50011

(515) 294-9745

(515) 294-6788

\section{Jim Corones}

Technical Program Manager

Ames Laboratory

329 Wilhelm Hall

Iowa State University

Ames, IA 50011

(515) 294-9636

Steve Webster

Technical Program Officer U.S. Department of Energy Chicago Operations Office 9800 S. Cass Avenue

Argonne, IL 60439

(708) 252-2822

\section{Dr. Caroline Purdy}

Program Manager, CMST-CP

U.S. Department of Energy

Cloverleaf Building

19901 Germantown Road

Germantown, MD 20874-1290

(301) 903-7672 


\section{CMST-CP PRojeCts FOR THE}

\section{LANDFILL STABILIZATION Focus AREA}

Section 5.0 


\subsection{REMOTELY PILOTED VEHICLES AND MINIATURIZED SENSORS}

\section{TASK DESCRIPTION}

Remote sensing techniques such as aerial photography, multispectral scanning, and airborne geophysics are of unquestioned value for hazardous waste site characterization, facility monitoring, and cleanup verification. When planning remediation activities, however, remote sensing is often dismissed as too expensive unless the site is large enough to justify mobilization and data processing costs. The purpose of this project is to demonstrate that for small sites a radio-controlled airplane or helicopter can be used to collect high-quality data quickly and cheaply. See Figure 5.1a.
For example, when new buildings or roads are constructed at an active disposal area, the facility manager's existing aerial phorographs become outof-date, which hinders future planning. By using a small, radio-controlled airplane equipped with an ordinary $35 \mathrm{~mm}$ camera, a new aerial photograph can be taken of the site, eliminating the cost and inconvenience of hiring a helicopter or fixed-wing aircraft. At minimal cost, a whole series of aerial photographs could be taken to document activities at the burial ground.

Efforts are not limited to photography. A new generation of lightweight, low-power sensors is be-

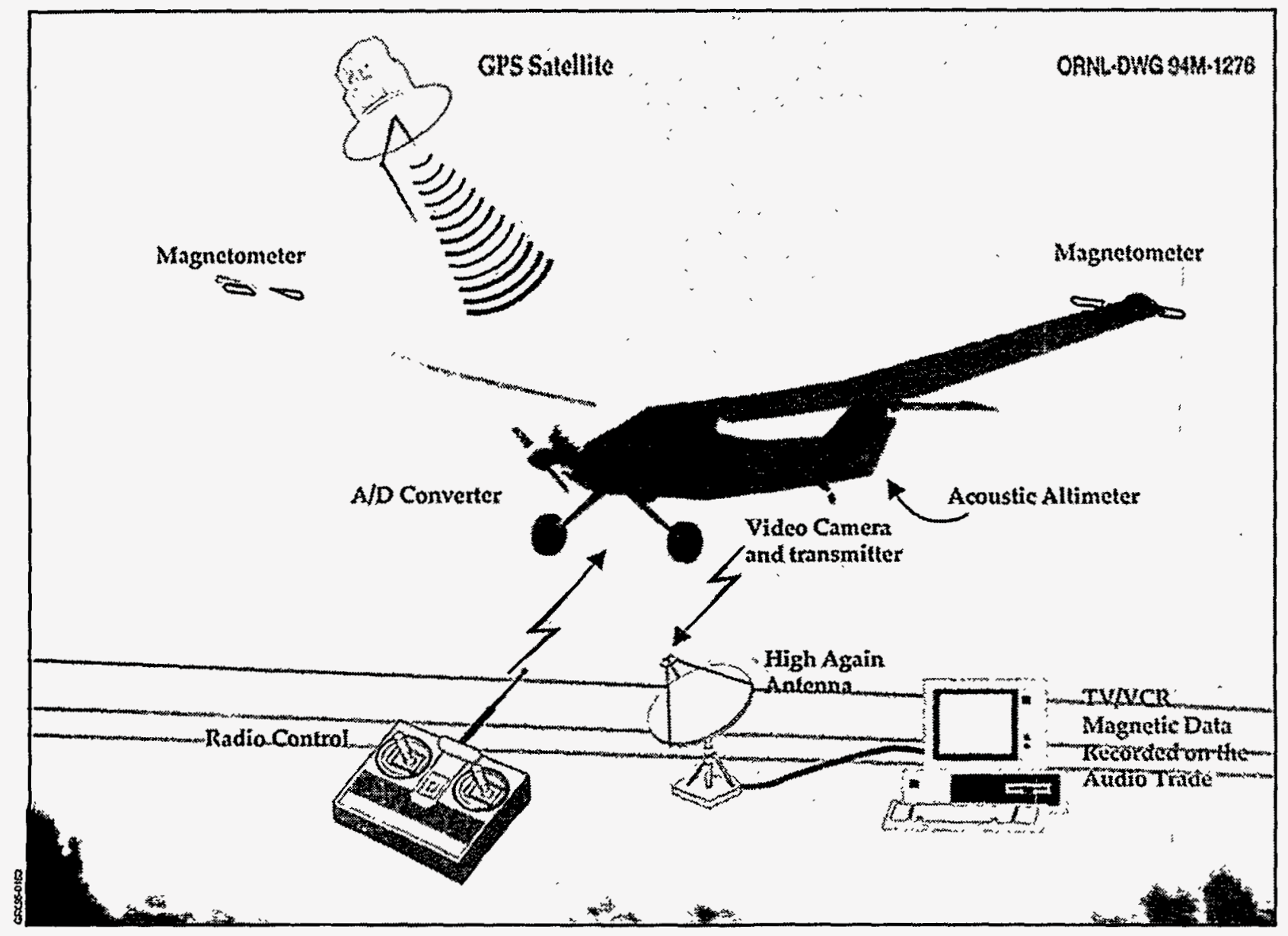

Figure 5.1a. A Model Airplane: the Droop Snoop. 
ing developed by OTD. These new sensors offer exciting new applications for airborne miniature platforms.

\section{TECHNOLOGY NEEDS}

The idea of using remotely piloted vehicles for aerial photography and remote sensing is not new. But many of the current aerial platforms, most of which were developed for military applications, are complicated to operate and expensive to maintain. Consequently these are of little use in environmental restoration.

Ordinary, readily-available model airplanes and helicopters are being adapted. These aircraft cost less than a thousand dollars, can be flown by any radio-control hobbyist, and can carry a 5-10 pound sensor payload.

\section{ACCOMPLISHMENTS}

Figure 5.1b shows an aerial photograph taken in 1990 of a $1000 \times 1000$ foot section in Solid Waste Storage Area 6, an active burial ground on the Oak Ridge Reservation. Since then, a new building has

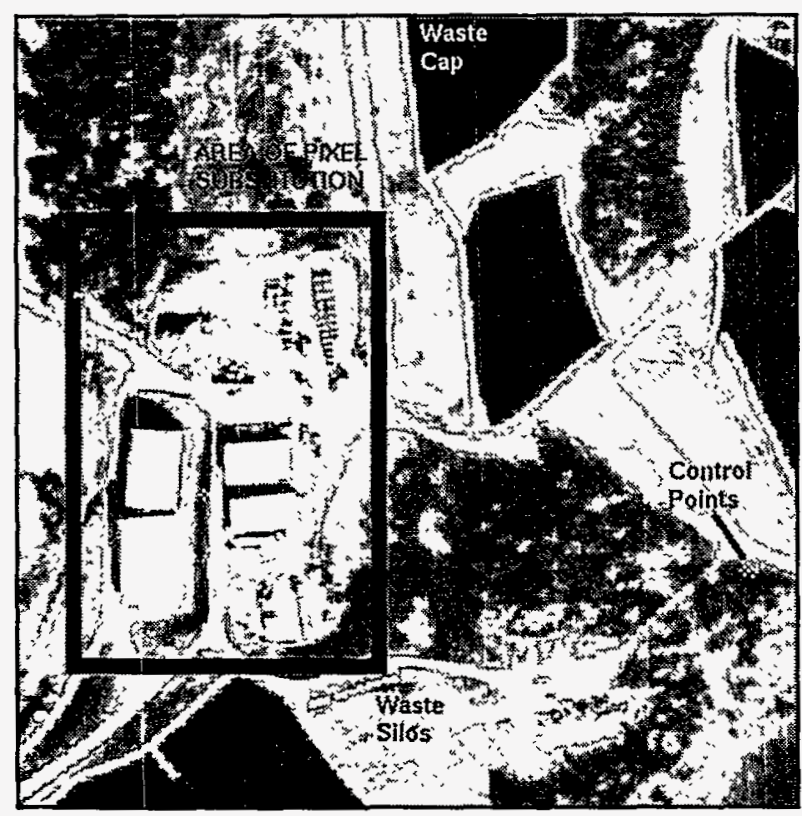

5.1b. Aerial Photograph of Solid Waste Storage Area 6 on the Oak Ridge Reservation. been constructed, so this photograph is out of date. Using the "Droop Snoop," a model airplane designed and built by Jim Walker of Brigham Young University, the boxed area was photographed. This newer image was then rectified and substituted into the digital version of the original aerial photograph. The results are seen in Figure 5.1c.

Current efforts are focused on equipping a model plane with a miniature three-component magnetometer similar to those currently used by geophysicists in land-based surveys to look for buried drums and waste trenches. Radiation sensors and very low frequency monitors, are examples of other sensors that may be added in the future.

\section{COLLABORATION/TECHNOLOGY TRANSFER}

Considerable interest in this project has been expressed by Environmental Restoration workers and model aircraft manufacturers. Collaboration with researchers at the U.S. Geological Survey and at Georgia Institute of Technology is currently underway. As the geophysical applications are developed, inquiries from consulting companies and manufacturers of geophysical equipment are expected.

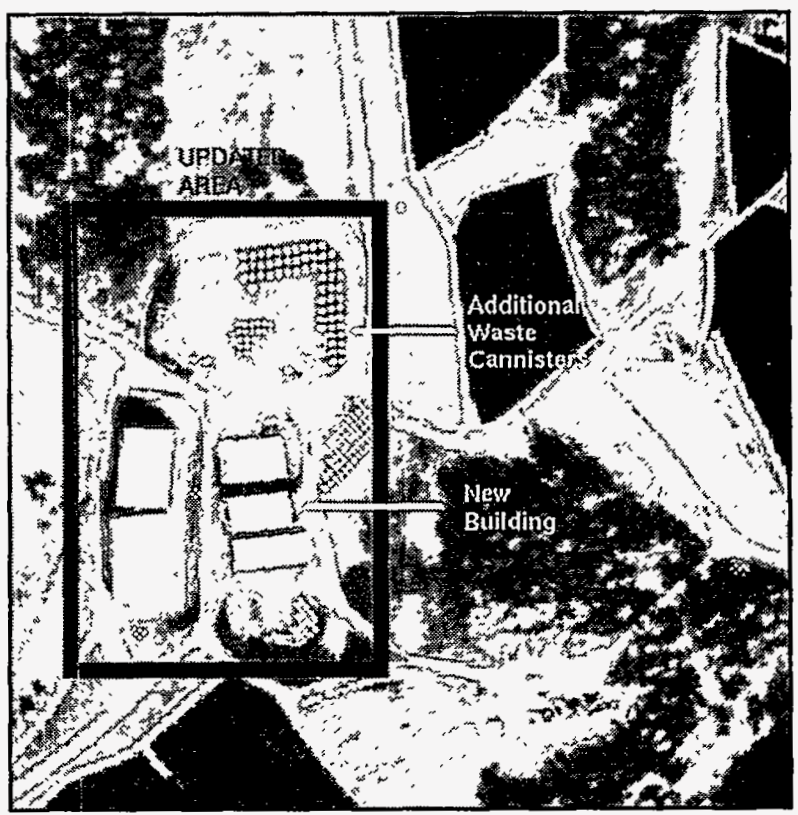

5.1c. A Picture Taken from Droop Snoop. 
For further information, please contact:

Jonathan E. Nyquist

Principal Investigator

Oak Ridge National Laboratory

P.O. Box 2008

Oak Ridge, TN 37831-6317

(615) 574-4646

\section{Jan Pruitt}

Technical Program Officer

Oak Ridge National Laboratory

P.O. Box 2008

Oak Ridge, TN 37831-6317

(615) 574-4457

\section{Dr. Caroline Purdy}

Program Manager, CMST-CP

U.S. Department of Energy

Cloverleaf Building

19901 Germantown Road

Germantown, MD 20874-1290

(301) 903-7672

\section{BIBLIOGRAPHY OF KEY PUBLICATIONS}

None at this time.

(1) 


\section{TASK DESCRIPTION}

The focus of this project is the coordinared development and evaluation of existing sensor systems and new remote sensing technologies for environmental restoration and waste management efforts. The objective is to provide a methodology forapplying current multispectral and nextgeneration hyperspectral remore sensing techniques to surface characterization studies. Multispectral and hyperspectral aircraft data will be acquired over various DOE sites. Targets that are representative of local needs will be specified by sire personnel. Field data will be corrected for solar, atmospheric, and instrument effects from selected aircraft data. The resulting apparent reflectance data sets are useful for identifying surface materials and detecting changes in surface characteristics. Techniques for analyzing multispectral and hyperspectral data will be developed, tested, and modified as necessary. A subtask to this work includes the development of an algorithm for improved image registration, and development of an image browse system to use to rapidly select suitable data for analysis.

\section{TECHNOLOGY NEEDS}

At many DOE sites, there is a need for non-invasive, in situ characterization of contaminants and resulting alteration of surface materials. The list of contaminants found on DOE sires includes a variety of organic and inorganic compounds such as lubricants, fuels, solvents, and DNAPLs. Multispectral and hyperspectral sensors will be evaluated for their usefulness for detecting and identifying contaminants exposed on the surface. Other needs include the delineation of burial sites, detection of vegetation stress caused by contamination, monitoring of site operations and remedial activities, and detection of geologic structures affecting water transport processes.

Given that airborne remote sensing imagery can be difficult to integrate with Geographic Information System (GIS) databases, another task is to address the need for developing algorithms to more robustly correct image distortions caused by viewing and target geometry, and aircraft roll, pitch, and yaw.

\section{ACCOMPLISHMENTS}

Spectral data of stressed greenhouse plants were collected at EPCOT Center, Florida. The objectives were to provide preliminary data and experience to plan a program to develop techniques to identify plant stresses with electro-optical remote sensing systems. Reflectance and transmittance spectra were acquired, as well as plant photosynthesis efficiency data, and thermal imagery. Collaborators included EPCOT Center scientists, John DiBenederto with Special Technologies Laboratories Laser-Induced Fluorescence Imager, and Bob Satterwhite from the U.S. Army Corps of Engineers Topographic Engineering Center. Of interest to $\mathrm{DOE}$ is the ability to detect and differentiate natural and man-induced contaminant-related stresses in plants.

Regarding reflectance data acquired at the greenhouses, changes in spectra were noted for all vegetation stresses. While some stresses produced distinctive changes in spectral reflectance, generally spectral changes were not indicative of any one stress. However, given certain spectral changes, some causes of vegetation stress can be ruled out. In order to detect subtle changes in reflectance spectra, a high instrument signal-to-noise ratio is imperative. It is also useful to look at changes in spectra over a wide wavelength region (e.g., $400-700 \mathrm{~nm}$, or 1000-2400 $\mathrm{nm})$.

Analysis of LANL multispectral data collected in FY93 is continuing. Significant results include the delineation of a disturbed area thought to be a material disposal site at TA-8. Work was also done on improving our groundbased radiometry capability for field measurements. An upgrade package was ordered for the GER field spectrometer. A newstate-of-the-art field spectrometer (FieldSpec) was obtained from Analytical Spectral Devices. The instrument covers the same spectral range as the GER but acquires a spectrum in 100 milliseconds as opposed to four minutes. 
The Oak Ridge Reservation Multispectral Scanner mission was carried out in FY94. Good weather enabled an earlier completion than scheduled. Data analysis of waste areas is ongoing.

A new software package (Specpr) was obtained from the U. S. Geological Survey. This package enables matching remotely sensored contaminant spectra using the position, size, and shape of absorption features. This capability will greatly enhance the interpretation of multi-and hyper-spectral data.

An algorithm was also developed to correct for cross-track illumination variations due to atmospheric scattering or sun-sensor viewing geometry. This algorithm will help normalize remotely sensed imaging collected during various missions with different atmospheric conditions. This capability will aid in the multi-temporal analysis of imagery (i.e., change detection analysis).

\section{BENEFITS}

Airborne remote sensing of DOE sites provides:

- Spatially complete coverage over large areas, allowing for detection of unknown environmental anomalies, even in areas of restricted access.

- Repetitive coverage so that temporal changes can be monitored and analyzed.

- A geospatial data layer that can be combined with other types of data within GIS for more comprehensive analyses across several scientific disciplines.

- Information from areas with unsafe or difficult access.

\section{COLLABORATION/TECHNOLOGY}

\section{TRANSFER}

Technologies developed for commercialization will likely involve techniques for calibrating and analyzing multispectral and hyperspectral remote sensing data. Transfers of techniques developed and research results will be accomplished through discus- sions and meetings with DOE site personnel, as well as presentations at various national meetings.

Several image processing vendors have expressed interest in incorporating the multiquadric registration algorithm into their software. A cooperative technology transfer effort will follow the publication of an article in a technical journal.

\section{For further information, please contact:}

Lee Balick

Principal Investigator

Remote Sensing Laboratory - EG\&G/EM

P.O. Box 1912

Las Vegas, NV 89125

(702) $295-8603$

\section{Katie McWilliam}

Technical Program Officer

U.S. Department of Energy

Nevada Operations Office

P.O. Box 98518

Las Vegas, NV 89193-8518

(702) 295-1031

\section{Dr. Leo Rogers}

Technical Program Manager

Remote Sensing Laboratory - EG\&G/EM

P.O. Box 1912 M/S RSL-19

Las Vegas, NV 89128

(702) 295-8726

Dr. Caroline Purdy

Program Manager, CMST-CP

U.S. Department of Energy

Cloverleaf Building

19901 Germantown Road

Germantown, MD 20874-1290

(301) $903-7672$

TTP Number: NV001102

BibliograPHY OF Key PUBlications

None at this time. 


\subsection{LASER-INDUCED FLUORESCENCE IMAGING FOR SURFACE URANIUM}

\section{TASK DESCRIPTION}

Laser-induced fluorescence (LIF) is an oprical technique that exploits the detection of fluorescent compounds irradiated with laser light or filtered conventional light sources. The scope of this TTP includes a variety of techniques to exploit LIF in several environmental applications, including aerial remote sensing, handheld portable survey tools for surface uranium contamination, and hyperspectral portable technology for the detection of plant stress over intermediate distances (to be used at Walt Disney's EPCOT Center in a cooperative effort). This task has required the development of hardware, software, and analysis methods for groundbased and airborne laser-induced fluorescence imaging (LIFI) systems. LIFI applications include the detection of contaminants such as uranium (as uranyl oxides), and VOCs (polyaromatics, fuels, and vegetational stress as an indicator of surface and subsurface contamination).

This year's scope of work includes: (1) completion and fielding of the portable uranium survey tool at DOE sites for facility walls, floors, equipment, and surface soils, (2) integration of the airborne LIFI system into a helicopter geometry, and (3) a cooperative effort with scientists from EPCOT Center to determine the viability of using plant stress as contaminant and plant vitality indicators.

The uranium survey tool will be fielded at Oak Ridge Gaseous Diffusion Facility in cooperation with EM-40 personnel (ORGDF- Roy Sheely$P O C)$. The survey tool will return to Santa Barbara, $\mathrm{CA}$ after an extended field exercise to be fitted with additional sensors before the second deployment.

The airborne LIFI system was configured last year for the DOE Convair 580T aircraft. The system will be reconfigured for helicopter usage. Deployment will now be possible in a variety of platforms including the U-60 class (Blackhawk, seahawk, pavehawk), Chinooks, and $\mathrm{SH}-3$ s. A technology transfer will most likely result in FY95 from hard- ware developed in the airborne project. A disk array interface card was developed in FY94 to facilitate high-speed, high-volume digital data transfer from the multi-tap digital camera to the 13 Gbyte storage array. The third task involves a series of cooperative efforts with EPCOT to investigate contaminant plant stress signatures and methods of detection. The Land Pavillion at EPCOT is a World Showcase for the R\&D of technologies for agricultural application. This subtask included a Technology Exchange Symposium held at EPCOT on February 23-24, 1995. Scientists from universities, industry, DOE, and other agencies were invited to present some of their work and discuss the state of plant stress research. A summary will result that will outline the present areas of research and technology advances required to specify furure remote sensing systems. In addition to working directly with EPCOT plant physiologists during FY95, a graduate student at Rochester Institute of Technology has been sponsored to investigate the radiometric specifications of LIF airborne measurements under real world conditions.

\section{TECHNOLOGY NEEDS}

Laser-induced fluorescence addresses the need for rapid survey tools for monitoring sites remotely, identifying contaminant "hot spots," and assisting in the cleanup activities and monitoring progress. Future efforts may include verification of site cleanup, if regulatory sensitivity can be achieved and verified through field tests. Development of an airborne survey tool for fluorescence and reflectance signature detection will continue. The system promises area coverage of sites that are spread out geographically, such as uranium firing sites, or sites that have poor access, such as clay cap areas. The system is being reconfigured for helicopter use. Conversion of the system, previously mounted in the Convair $580 \mathrm{~T}$ to pallet mounted containers in the helicopter, will provide a rapid deployment feature to a variety of platforms. 


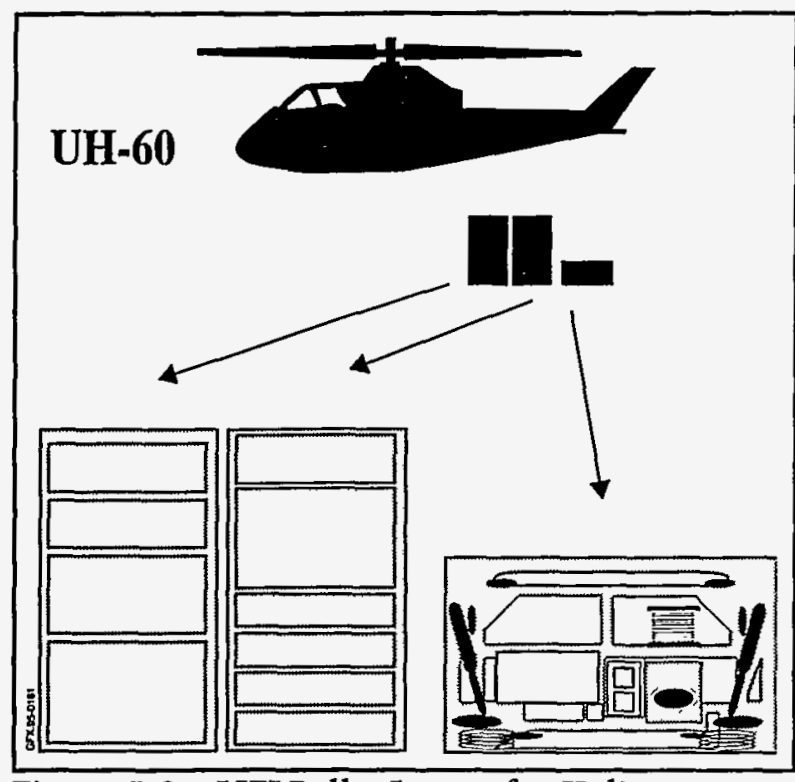

Figure 5.3a. LIFI Pallet Layout for Helicopter Deployment.

The concept of plant stress detection is an active area of research at a number of federal agencies, as well as many universities. The EPCOT Symposia brought researchers together from many institutions in an effort to better understand and scope the applicability of LIF as a remote sensing tool.

\section{ACCOMPLISHMENTS}

During FY93 field tests at Oak Ridge Gaseous Diffusion Facility (K-25), it became clear that LIF images from uranyl compounds could be a great help to the D\&D efforts at the site. FY94 activities focused on transforming the $1,000 \mathrm{lb}$ laser pallet assembly (used in outdoor LIF field tests in FY93) into a portable laser survey tool that employed a handheld transmitter/receiver and provided realtime display. The uranium survey tool will be delivered to EM-40 personnel this year for evaluation as a D\&D tool. EM-40 sponsored the packaging and initial deployment costs. The device will be used primarily as a rapid survey tool for $D \& D$ activities in the buildings where extensive salvaging of components has occurred over many years. Figure $5.3 \mathrm{~b}$ shows an arrist's rendition of the uranium tool. The laser power supply, laser head, computer, and batteries are located in a 19 inch rack/crate. The laser is connected to the transmitter optics through a fiber optic. The camera signals are processed and redisplayed as false color composites at the view screen. Raw data is recorded on $8 \mathrm{~mm}$ tape. The detection algorithm developed last year requires that the fast shutter (MCPII) be controlled to collect delayed phosphorescence, as well as ambient illuminated frames from room illumination. These will be used as the background for visual reference. Frames from the luminescence of uranyl oxides are superimposed on the ambient illuminated frames to create a false color overlay of contamination over the gray-scale image of the room. The system has been successfully tested in the laboratory.

In FY94, the airborne system was successfully integrated into the DOE Convair 580T aircraft. After two weeks of flight tests, the Convair was removed from the DOE fleet due to budget considerations. The helicopter-based system will afford a smaller system that will be modular. Camera modifications, including a higher sensitivity $\mathrm{CCD}$ detector, will improve system sensitivity. As a result of the extensive component development in FY94, the digital interface from the camera to the disk array storage device is now a candidate for technology transfer to a disk manufacturer.

\section{BENEFITS}

Fluorescence techniques have the ability to detect signatures that are not observable by traditional

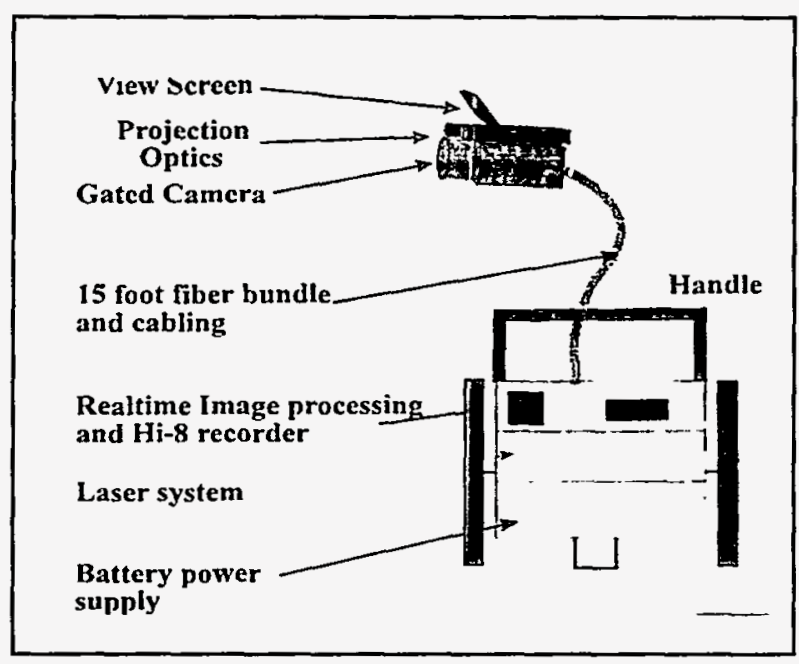

Figure 5.3b. Hand-Held LIFI Instrument. 
remote sensing methods. The high spatial resolution of intensified CCD cameras and the timeresolved phosphorescence emission characteristic of the uranyl ion allow one to obtain a digital picture of the extent of surface contamination. This allows mitigation efforts to be focused on specific areas, which speeds the survey and lowers overall costs. The real-time image processing of the data into a false color composite on gray scale background allows the operator to quickly distinguish the uranium signature. Since the data is recorded on video tape, it can be reviewed for planning and review of $D \& D$ activities. The fusion of radiation data and position sensor information will greatly enhance the tool.

Participation with EPCOT Center in plant studies affords the opportunity to collaborate with world class plant physiologists to study the effects of plant pathogens and contamination. A variety of sensors will be used and compared to evaluate the concept of plant stress. EPCOT center will act as a focal point for collaboration across agency boundaries and act as a site for continued collaboration. The eventual development of robotics systems in other DOE/EPCOT collaborations will provide platforms for testing the concept of LIF on sites of agricultural interests.

The advantages of airborne systems for remote sensing are well documented. Fluorescence techniques have the ability to detect signatures that are not observable by traditional remote sensing methods. Airborne operations allow one to survey large areas in a cost-effective manner. Many DOE areas are located in remote areas, with practical access obtained only from the air. An aerial view allows identification of subtle changes and patterns that are not apparent from ground-based operations. High resolution imaging techniques under development allow one to obtain a picture of the extent and location of surface contamination. This allows mitigation efforts to be concentrated on specific local areas.

\section{COLLABORATION/TECHNOLOGY TRANSFER}

The laser-induced fluorescence project has often used the leverage of collaboration to control costs, especially in joint agency field exercises. Efforts with EPCOT scientists have involved scientists from the DOE Remote Sensing Lab, DOE Special Technologies Laboratory, Army Topographic Engineering Lab (Army Corps of Engineers), and Rochester Institute of Technology. FY93 field tests were performed in collaboration with the abovementioned federal agencies, members of EM-50 and EM- 40 at the Oak Ridge reservation, and EM50 personnel at Savannah River. FY95 field tests at the Oak Ridge Gassious Diffusion Facility will be completed in collaboration with EM-40 at K-25 (Roy Sheely-POC).

FY95 technology transfer activities include the pursuit of an agreement with SYSTEMWARE, a disk manufacturer in Westlake Village, CA. A proposal was submitted through the Nevada field office for a joint effort to bring the disk interface card to the commercial market. SYSTEMWARE's market survey has confirmed that the activity is in the company's best interest.

\section{For further information, please contact:}

Dr. John DiBenedetto

Principal Investigator

Special Technologies Laboratory

5520 Ekwill Street, Suite B

Santa Barbara, CA 93111

(805) 681-2307

Dr. Leo Rogers

Technical Program Manager

Remote Sensing Laboratory - EG\&G/EM

P.O. Box 1912, M/S RSL-19

Las Vegas, NV 89125

(702) 295-8726 
Katie McWilliam

Technical Program Officer

DOE Field Contact

DOE/NVO

2765 South Highland

Las Vegas, NV 89109

(702) 295-1031

Dr. Caroline Purdy

Program Manager, CMST-CP

U.S. Department of Energy

Cloverleaf Building

19901 Germantown Road

Germantown, MD 20874-1290

(301) $903-7672$
TTP Number: NV053002

\section{BIBLIOGRAPHY OF KEY PUBLICATIONS}

None at this time. 


\section{RABBIT VALLEY GEOPHYSICS PERFORMANCE EVALUATION RANGE}

\section{TASK DESCRIPTION}

The DOE Grand Junction Projects Office (GJPO) provides a facility for $\mathrm{DOE}$, other government agencies, and the private sector to evaluate and document the utility of specific geophysical measurement techniques for detecting and defining cultural and natural targets in the environment. This facility is the Rabbit Valley Geophysics Performance Evaluation Range (GPER). This facility has test cells in the high-desert terrain of Rabbit Valley, 30 miles west of Grand Junction, CO, and test cells and calibration models at the DOE-GJPO facility in Grand Junction.

\section{TECHNOLOGY NEEDS}

The GPER provides facilities to evaluate the performance of instrumentation systems and geophysical measurement methods used in site characterization and assessment. It provides a means of comparing the performance of the various methods and instruments, and permits standardization of performance to a common baseline. Once these systems are evaluated on an equal basis, the best demonstrated technologies can be selected for use in the characterization activities.

\section{ACCOMPLISHMENTS}

Construction of nine new cell areas at the GPER resulted in the emplacement of approximately 150 discrete targets selected for their physical and electrical properties. These targets and their geophysical environment provide numerous performance evaluation parameters ranging from "very easy to detect" to "a challenge to the most advanced systems." Table 5.4 lists the targets and the geophysical methods they are expected to evaluate. Target shapes and materials were selected to respond to different geophysical methods in different ways and to facilitate computer modeling of measurement system responses. For example, spheres of steel, copper, clay, glass, and plastic provide variations in conductivity and dielectric constant for evaluation of magnetic and electromagnetic systems. Identical spheres buried at different depths and spacings provide a means of determining system sensitivity and spatial resolution.

\section{BENEFITS}

The Rabbit Valley GPER provides DOE with a standardized testing range for geophysical sensor systems evaluations. The GPER is also "user friendly." Access to GPER requires no security clearance or special permission, and user support is available when requested. Data from previous surveys is archived and available for review and used by all who agree to share their data.

\section{COLLABORATION/TECHNOLOGY TRANSFER}

During FY94, users from government agencies, private industry, and academia conducted various surveys at the Rabbit Valley GPER. The use of this facility and the user support provided are a form of leverage funding to users. GJPO use of the site for a Project Support Research and Development project has resulted in the development of an improved Time-Domain Electromagnetic profiling method that is expected to find broad application in landfill assessment, site characterization, and plume tracking/mapping. 


\section{For further information, please contact:}

\section{James W. Allen}

Principal Investigator

RUST Geotech, Inc.

P.O. Box 14000

Grand Junction, CO 81502

(303) 248-6715

\section{Daniel V. Varhus}

Technical Program Officer

U.S. Department of Energy

Grand Junction Projects Office

P.O. Box 2567

Grand Junction, CO 81502-2567

(303) 248-7768

\section{Eric Lightner}

Projects Manager, CMST-CP

U.S. Department of Energy

Cloverleaf Building

19901 Germantown Road

Germantown, MD 20874-1290

(301) $903-7672$

\begin{tabular}{|c|c|c|c|c|c|c|c|c|}
\hline \multirow[b]{2}{*}{ Material and Shape of Target } & \multicolumn{8}{|c|}{ Geophysical Survey Method To Be Evaluated } \\
\hline & $\mathrm{MAG}^{\mathrm{a}}$ & IEM $^{\mathrm{b}}$ & FDEM ${ }^{c}$ & TDEM $^{\mathrm{d}}$ & $\mathrm{R} / \mathrm{Pe}$ & GPR' & SEIS 9 & GRAV \\
\hline 1/4-m, 1/2-m, and 1-m Steel Spheres & y & $\mathrm{y}$ & $\mathrm{y}$ & $y$ & $\mathrm{y}$ & $\mathrm{y}$ & y & $y$ \\
\hline $1-m$ by $1-m$ by $1-\mathrm{cm}$ Steel Sheets & y & $\mathrm{y}$ & y & y & y & y & y & $\mathrm{y}$ \\
\hline 10-cm by $2-\mathrm{m}$ Steel Cylinders & y & $y$ & $y$ & $y$ & $y$ & y & & y \\
\hline 15-cm-Diameter Steel Pipes & y & $\mathrm{y}$ & y & y & y & y & & \\
\hline 1/4-m Copper Spheres & & y & $y$ & y & $\mathrm{y}$ & $y$ & & \\
\hline $1-\mathrm{m}$ by $1-\mathrm{m}$ by $1-\mathrm{cm}$ Aluminum Sheets & & y & y & y & y & y & y & \\
\hline 1/4-m Glass Spheres & & & & & & y & & \\
\hline 1/4-m Clay Spheres & & & & & & $\mathrm{y}$ & & \\
\hline 1/4-m Plastic Spheres & & & & & & $\underline{y}$ & & \\
\hline Clay Bed & & $y$ & y & y & y & $y$ & $y$ & \\
\hline Sand Bed & & $y$ & y & y & y & y & y & \\
\hline Wood & & y & $y$ & $\mathrm{y}$ & y & $\mathrm{y}$ & $y$ & \\
\hline Bladder of Vegtable Oil & & y & $y$ & $\mathrm{y}$ & y & $y$ & y & y \\
\hline Plastic Pipes & & & & & & y & & \\
\hline Wires & & $y$ & $y$ & & $\mathrm{y}$ & $\mathrm{y}$ & & \\
\hline Mixed Construction Trash & $y$ & $y$ & $y$ & & $y$ & $y$ & $y$ & $y$ \\
\hline $\begin{array}{l}\text { "Magnetics } \\
\text { 'inductive electromagnetics } \\
\text { "Frequency-domain electromagnetics }\end{array}$ & & $\begin{array}{l}\text { ne-dom } \\
\text { sistivity } \\
\text { sund-pe }\end{array}$ & $\begin{array}{l}\text { ain electr } \\
\text { /induced } \\
\text { enetrating }\end{array}$ & $\begin{array}{l}\text { magneti } \\
\text { olarizati } \\
\text { radar }\end{array}$ & & $\begin{array}{l}\text { eismic } \\
\text { iravity }\end{array}$ & & \\
\hline
\end{tabular}

Table 5.4. Static Cell Targets in Rabbit Valley GPER. 
TTP Number: AL932003

\section{BIBLIOGRAPHY OF KEY PUBLICATIONS}

Rabbit Valley Geophysics Performance Evaluation Range, Geophysical Background and As-Built Target Characteristics, prepared by RUST Geotech, Inc. for U.S. Department of Energy, Grand Junction Projects Office under DOE Contract No. DEAC04-86ID12584, September 1994.

INITIAL REPORT: U.S. Department of Energy Geophysical Test Beds and Range Design Specifications for the Grand Junction Projects Office Rabbit Valley Geophysics Performance Evaluation Range, prepared by RUST Geotech, Inc. for U.S. Department of Energy, Grand Junction Projects Office under DOE Contract No. DE-AC04-86ID12584, October 1993. 


\subsection{THREE-DIMENSIONAL/THREE-COMPONENT SEISMIC SURVEYS FOR SITE CHARACTERIZATION}

\section{TASK DESCRIPTION}

This task is conducting an investigation of the nearsurface earth in a uniform three-dimensional manner with the acquisition, processing, and interpretation of three-dimensional, three-component (3D/3C) seismic dara. A 3D/3C seismic survey records data in three dimensions ( $\mathrm{x}$ and $\mathrm{y}$ along the ground surface and depth $z$ ) and in three-components (one vertical and two orthogonal horizontal directions). See Figure 5.5a.

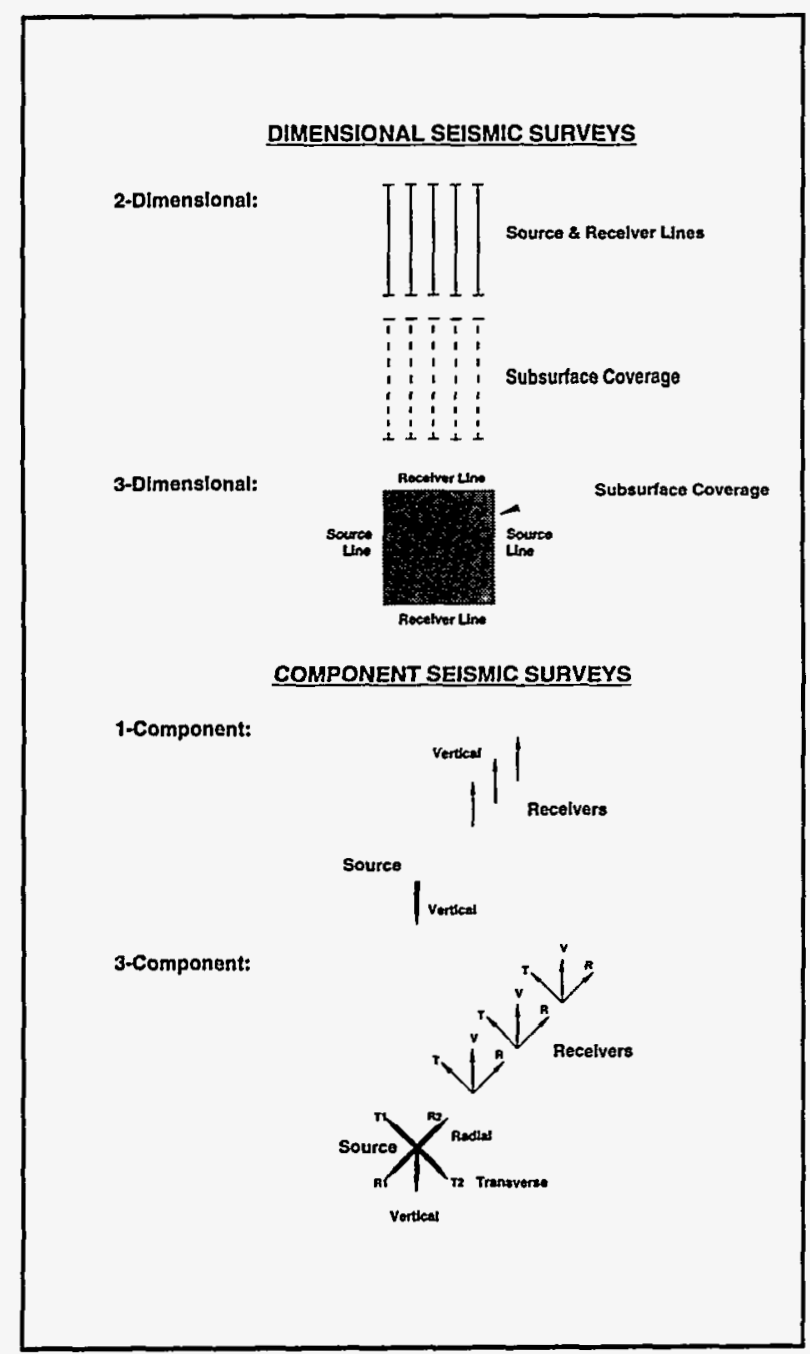

Figure 5.5a. Types of Seismic Surveys.
Beginning in FY94 and continuing into FY95, data will be acquired with available instrumentation; processed with existing, adapted, and/or developed computer software; and interpreted with a combination of existing and developed methodologies. A full-scale demonstration in FY96 will allow commercialization of the technology. A Core Planning Group, consisting of RUST Geotech Inc., the United States Geological Survey (USGS), the Colorado School of Mines (CSM), and Bay Geophysical Associates, Inc., is involved in all activities of this task.

\section{TECHNOLOGY NEEDS}

The $3 \mathrm{D} / 3 \mathrm{C}$ seismic technology is applicable to the Landfill, Plumes, and Tanks Focus Areas. The technology addresses the overall need to expedite site characterization with nonintrusive methods at three general depths of investigation - shallow, intermediate, and deep - with inherent approximation of boundaries. The shallow need is primarily concerned with the definition/delineation of rrench and pit boundaries, location of buried contaminants, and imaging of shallow geologic structures. The intermediate need, while also concerned with those elements in the shallow regime, concentrates more on hydrogeologic framework and subsurface geologic/physical properties measurements. The deep need is basically an extension of the intermediate with more emphasis on regional characteristics.

The Technology Needs Assessment details sitespecific needs. In addition to DOE field sites, DoD, $\mathrm{EPA}$, and other government entities require technologies to conduct the best available characterization to supply data for input into Records of Decision. 


\section{ACCOMPLISHMENTS}

The field site selected for the initial demonstrations is south of the Old Burial Ground (OBG) in the FArea Effluent Line (creek) at the DOE SRS, and was chosen in collaboration with DOE/EM-40 personnel at SRS. The primary problem addressed at this site with the $3 \mathrm{D} / 3 \mathrm{C}$ seismic technology was the definition and/or description of structural and textural features that can serve as preferential pathways for contaminant migration.

Two-dimensional (2D) and 3D seismic characteristic surveys were conducted using sledgehammer and vibrator sources in both one component (1C) and three components in FY94. The USGS, with assistance from RUST Geotech and SRS EM-40 personnel, conducted compressional-and shear-wave sonic logging, a $3 \mathrm{C}$ vertical seismic profiling survey, and $2 \mathrm{D} / 3 \mathrm{C}$ surface seismic surveys with a vibrator source.

Figures $5.5 \mathrm{~b}$ and $5.5 \mathrm{c}$ show two sets of shear-wave seismic data acquired along the same line (northsouth oriented line C) in orthogonal directions. Figure 5.5 b presents vertically polarized shear-wave (SV) data acquired with both the source and receivers oriented parallel to the line (north-south), while Figure $5.5 \mathrm{c}$ shows horizontally polarized shear-wave $(\mathrm{SH})$ data collected with the source and receivers oriented perpendicular to the line (east-west). Continuous seismic reflections are present within the SV data (especially at times less than 100 milliseconds) and essentially absent in the SH data. Therefore, the continuity of the seismic wave transmission is dependent upon the direction of polarization and

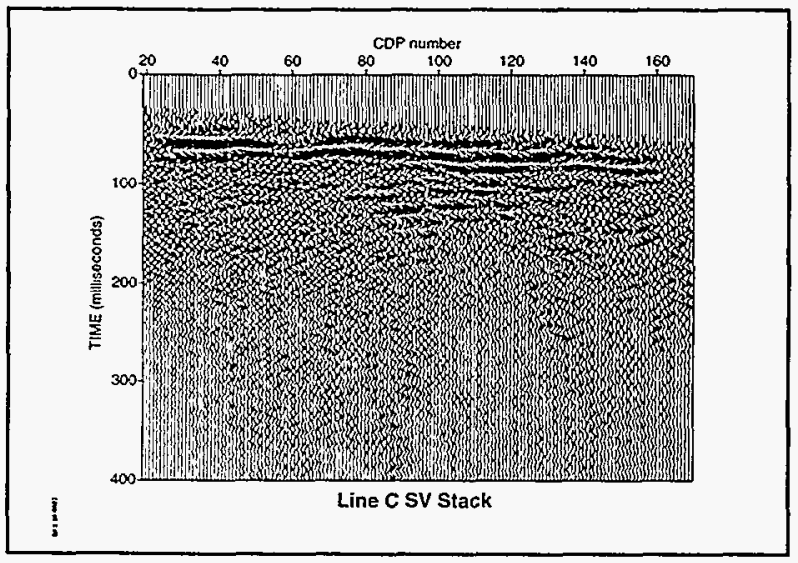

Figure 5.5b. Vertically Polarized Shear-Wave Seismic Data. is interpreted as an indication of subsurface anisotropy. Anisotropy is defined as variations of a physical property depending on the direction in which it is measured (e.g., polarization direction) and may be correlatable to preferential contaminant flow direction. Typical causes of anisotropy include aligned cracks, parallel fractures, periodic layering, and preferred orientation of grains. FY95 activities will develop software and interpretation methods to determine the actual direction of preferential seismic wave transmission in addition to other characteristics related to the structure and texture of the subsurface.

\section{BENEFITS}

The $2 \mathrm{D} / 1 \mathrm{C}$ and $3 \mathrm{D} / 1 \mathrm{C}$ data will serve as baseline comparisons for the $3 \mathrm{D} / 3 \mathrm{C}$ data and will permit a direct indication of the improvement in characterization between the two types of data. The 3D/3C technology has three primary benefits over the baseline 2D/1C and 3D/1C technology: (1) improved characterization and operation, (2) reduced health and environmental risks, and (3) reduced costs. A 3D/3C seismic survey will allow a uniform $3 \mathrm{D}$ investigation of an area, thus minimizing the possibility that the area will need to be resurveyed because of less-than-optimum placement of $2 \mathrm{D}$ survey profiles. This technology minimizes the number of times an area must be accessed for surveying and maximizes the amount of information possible.

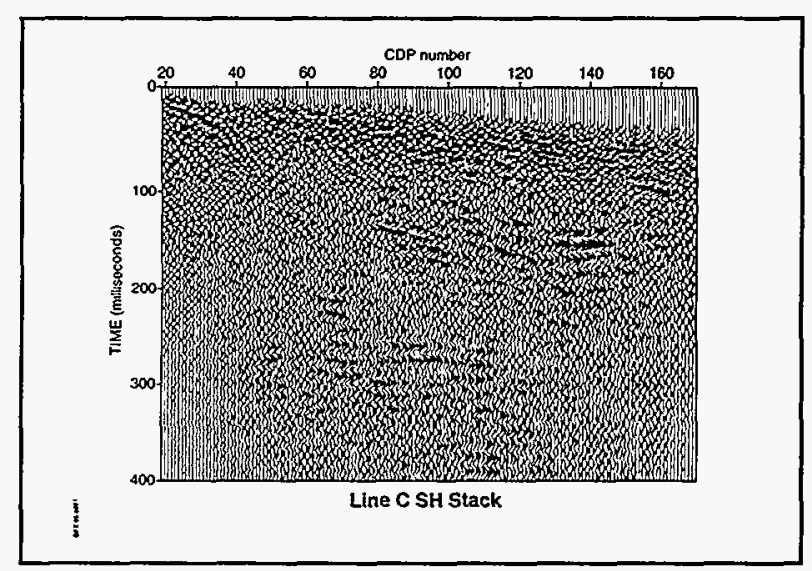

Figure 5.5c. Horizontally Polarized ShearWave Seismic Data. 


\section{COLLABORATION/TECHNOLOGY TRANSFER}

The joint participants within this task represent DOE, the private sector, academia, and another government agency. The joint participants will collaborate on the common goal to develop feasible near-surface 3D/3C seismic technology. Emphasis will be placed on providing technology to the private sector suitable for near-term application to specific DOE/EM programs. Bay Geophysical Associates, the private sector joint participant, will gain sufficient knowledge from this project to become a leader in the commercialization of the technology. The final reports written for this project will represent all accomplished work and will be vehicles for the transfer of this technology.

For further information, please contact:

James C. Hasbrouck

Principal Investigator

RUST Geotech, Inc.

P.O. Box 14000

Grand Junction, CO 81502

(303) 248-6714

\section{Daniel V. Varhus}

U.S. Department of Energy

Grand Junction Projects Office

P.O. Box 2597

Grand Junction, CO 81503

(303) 248-7768

\section{Dr. Caroline Purdy}

Program Manager, CMST-CP

U.S. Department of Energy

Cloverleaf Building

19901 Germantown Road

Germantown, MD 20874-1290

(301) 903-7672
TTP Number: AL941001

\section{BIBLIOGRAPHY OF KEY PUBLICATIONS}

Hasbrouch, J.C., Boyd, T.M., Dickenson, O, and Hasbrouch, W.P., Baseline 2D/1C and 3D/1C Seismic Technology Report in Support of U.S. Department of Energy 3D/3C Seismic for Site Characterization Technical Task Plan, U.S. Department of Energy Grand Junction Projects Office, Grand Junction, Colorado, 1994. 


\subsection{LA-ICP-AES USING A HIGH RESOLUTION FIBER-OPTIC INTERFEROMETER}

\section{TASK DESCRIPTION}

A high-resolution, compact, and portable interferometer system has been developed to provide isotopic and isobaric resolution and higher sensitivities for samples in complex matrices where detection limits are typically limited by low-level interferences. This system will be used in conjunction with solution nebulization and laser ablation (LA) inductively coupled plasma-atomic emission spectroscopy (ICP-AES) for analysis of environmental and process samples. The technology involves the use of an acousto-optic tunable filter (AOTF) and a high-finesse fiber-optic Fabry-Perot interferometer (FFP), two devices developed by the communications industry for high bandwidth laser communications. The small size, extreme ruggedness, and spectral ability of these devices make them wellsuited for use in a fieldable spectrometer system at a fraction of the cost, size, and weight of gratingbased spectrometer systems. The AOTF is used as a low resolution filter to select spectral regions to be resolved by multiple FFP filters. See Figure 5.6a. The AOTF is capable of switching between spectral regions in microseconds with no mechanical moving parts, and is also capable of simultaneous selection of several spectral regions.

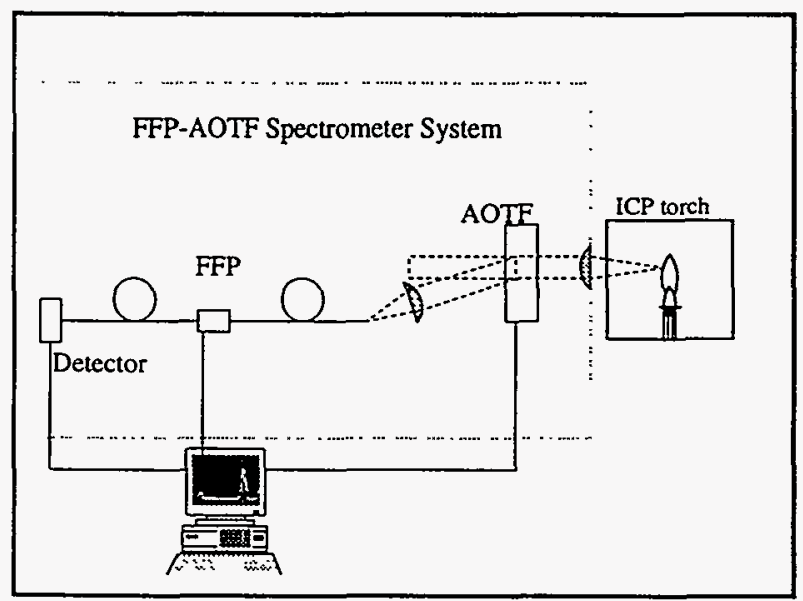

Figure 5.6a. Schematic of the AOTF-FFP Interferometer System.

\section{TECHNOLOGY NEEDS}

LA-ICP-AES has previously been shown to be a valuable tool for rapid, in situ environmental analysis. However, some limitations of this technique include sensitivity limited by the resolution of many emission lines for samples having complex matrices, lack of sufficient resolution to determine isotopic ratios for transuranic materials, and excessively large, expensive, and temperamental spectrometer systems. The ability to resolve isobaric interferences fills a technology gap because mass spectrometry is not capable of determining isotopes of the same atomic mass number. The AOTF-FFP system addresses all of these shortcomings with commercially available components developed for other uses.

\section{ACCOMPLISHMENTS}

An AOTF has been obtained for use in this system and initial tests have been performed using a lowresolution (finesse $=100$ ) bulk optics Fabry-Perot interferometer. A single AOTF accesses a $200 \mathrm{~nm}$ range of emission features. The bandwidth of the AOTF $(-1,000 \mathrm{GHz})$ and the desired spectral resolution $(-5 \mathrm{GHz})$ determined the specifications for the FFP (finesse $=200$ ) that was developed to scan

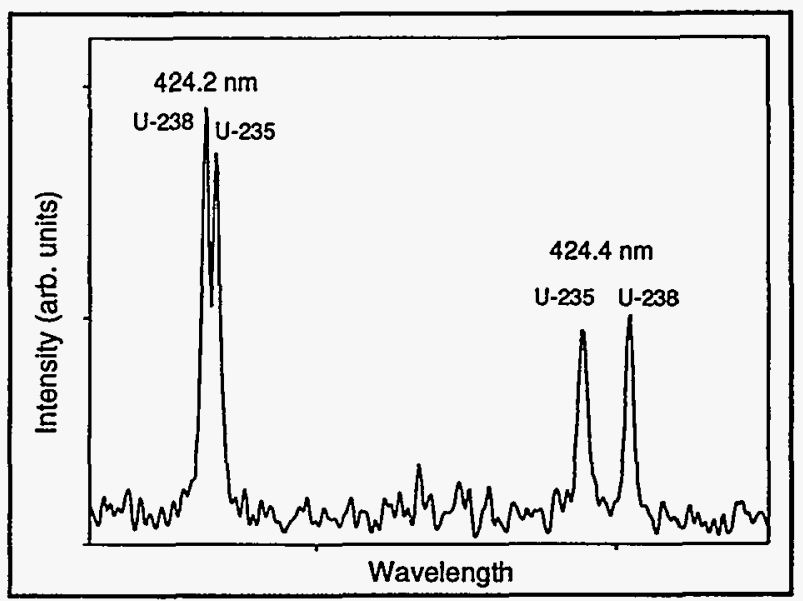

Figure 5.6b. ICP-AES Spectrum. 
the spectral window defined by the AOTF. The optical coatings used in the FFP do not cover the entire region accessed by the AOTF. Therefore, a system with full access at high resolution must utilize several FFPs, with a single AOTF for prefiltering and low-resolution survey scanning. The FFP technology had previously been developed for red and near infrared wavelengths. For this project, an FFP for use in the $400 \mathrm{~nm}$ (blue) wavelength region has been developed in collaboration with Micron Optics, Inc. (Atlanta, GA). The AOTFFFP system has been used to resolve uranium isotope emission features, as shown in Figure 5.6b.

\section{BENEFITS}

The AOTF-FFP is a compact, solid-state, highresolution spectrometer system that is capable of resolving isotopic and isobaric emission features in ICP-AES. Commercial ICP-AES spectrometer systems lack sufficient resolution to distinguish isotopes of actinide elements such as uranium, thorium, and plutonium. Commercial ICP-MS systems are subject to isobaric interferences, i.e., the inability to distinguish isotopes having the same atomic mass number. The compact size and stability of the AOTF-FFP system make it particularly well-suited for use in remote and field analytical applications. The AOTF-FFP spectrometer system may be used in LA - ICP-AES analyses of contaminated soil samples to provide rapid, on-site quantitative determinations. The AOTF-FFP may also be used for spectrometric measurements in on-line process environments where high resolution is required.

\section{COLLABORATION/TECHNOLOGY}

\section{TRANSFER}

This high-resolution AOTF-FFP interferometer system is capable of resolution comparable to that of commercial 1.5-meter spectrometer systems at considerably less cost, smaller package size, greater portability, and less sensitivity to external environmental factors. Its potential for use in portable spectrometric systems that require this combination of high resolution and spectral agility should make this system highly marketable. The commercial developer of the fiber-optic Fabry-Perot interferometer has an established marker in the communications industry and is exploring the spectroscopic industry through this collaborative work. Publication of the results of these investigations in spectroscopic and analytical chemistry journals will be the first step in widening interest in this technology. Iowa State University is in the process of obtaining a patent for this technology. An engineering prototype is currently being developed with input from industrial partners. Successful completion of the prototype will lead to the solicitation of a licensee(s) for the further development of this device. Further utilization of this system in future applications of the LA-ICP-AES and other spectroscopic applications within DOE will illustrate the usefulness of this system.

For further information, please contact:

\section{David P. Baldwin}

Principal Investigator

Ames Laboratory

Iowa State University

9 Spedding Hall

Ames, IA 50011

(515) 294-2069

James P. Corones

Technical Program Manager

Ames Laboratory

Iowa State University

329 Wilhelm Hall

Ames, IA 50011

(515) 294-9636

\section{Dr. Caroline Purdy}

Program Manager, CMST-CP

U.S. Department of Energy

Cloverleaf Building

19901 Germantown Road

Germantown, MD 20874-1290

(301) 903-7672

TTP Number: $\mathrm{CH} 141001$ 


\section{BIBLIOGRAPHY OF KEY PUBLICATIONS}

D.P.Baldwin, D.S.Zamzow, and A.P.D'Silva, High Resolution Fiber-Optic Interferometer: FY94 Final Report, Ames Laboratory Report No. IS-5116, October, 1994.

K. Hsu and C. Miller, Photonics Spectra 27, 135136, May, 1993.

Tech Memo on Fabry-Perot Interferometry, Burleigh Instruments, Inc.; Fishers, NY. 


\section{INDUCTIVELY-COUPLED PLASMA - MASS SPECTROMETRY (ICP-MS) FOR ANALYSIS OF MICROLITER SAMPLES AND SOLIDS}

\section{TASK DESCRIPTION}

ICP-MS is already a highly sensitive and selective method for elemental and isotopic analysis. This project will investigate the ability of a microscale nebulizer called a monodisperse dried microparticulate injector (MDMI), to improve the sensitivity, speed, accuracy, and precision of ICPMS is determining stable elements and radionuclides. A schematic diagram of the operating principles of the MDMI is shown in Figure 5.7a.
Essentially, a micropump creates uniform wet droplets that are dried carefully and then introduced into the plasma for conversion into atomic ions. There is little or no waste solution; 100 percent of the sample reaches the plasma. Exposure to radioactivity and waste cleanup problems during analysis will also be greatly reduced because the nebulizer requires only nano to microliter volumes of solution.

Specifically, two related projects are under study: (1) direct analysis of very small solution volumes, and (2) on-line calibration for laser ablation ICPMS, so that solids can be analyzed directly with better accuracy than is now achievable. This project is shown schematically in Figure 5.7b.

The analytical capabilities of MDMI-ICP-MS, such as detection limits and tolerance to concentrated sample matrices, will be evaluated thoroughly for real samples of interest in waste remediation. This sample introduction technology is porentially applicable to existing ICP-MS devices used for analyses that support waste cleanup. It should also be suitable for field use with a mobile ICP-MS device in a van. 


\section{TECHNOLOGY NEEDS}

This project will provide analytical technology needed to support a wide variety of remediation problems, such as: (1) real-time measurement of transuranic elements and other radionuclides, (2) rapid measurement of RCRA metals in a wide variety of aqueous or organic solutions, and (3) removing the general need for sample dissolution for accurate quantitative determination of metals. The overall cost of such analyses will also be reduced because the amount of radioactive waste sample will be greatly reduced to microliter quantities or less, which greatly simplifies containment concerns.

\section{ACCOMPLISHMENTS}

This project began in FY95. There are no major accomplishments as yet. The necessary laser ablation and ICP-MS facilities are in place.

\section{BENEFITS}

The major benefits are more sensitive measurement of radionuclides and stable elements with little waste solution, and direct analysis of solids with simple, accurate calibration procedures that do not require matrix-matched standards.

\section{COLLABORATION/TECHNOLOGY TRANSFER}

The MDMI is an advanced prototype donated by Perkin-Elmer SCIEX. They intend to offer the MDMI as a commercial product and are eager to collaborate with us to evaluate its suitability for these special applications. The Principal Investigator has been associated with SCIEX since the early days of ICP-MS (-1982).
For further information, please contact:

\author{
R. S. Houk \\ Principal Investigator \\ Ames Laboratory \\ Iowa State University \\ 108 Spedding Hall \\ Ames, IA 50011 \\ (515) 294-9462
}

\section{Jim Corones}

Technical Program Manager

Ames Laboratory

Iowa State University

329 Wilhelm Hall

Ames, IA 50011

(515) 294-9636

\section{Steve Webster}

Technical Program Officer

U.S. Department of Energy

Chicago Operations Office

9800 S. Cass Avenue

Argonne, IL 60439

(708) 252-2822

\section{Dr. Caroline Purdy \\ Program Manager, CMST-CP \\ U.S. Department of Energy \\ Cloverleaf Building \\ 19901 Germantown Road \\ Germantown, MD 20874-1290 \\ (301) 903-7672}

\section{TTP Number: $\mathrm{CH} 153003$}

\section{BIBLIOGRAPHY OF KEY PUBLICATIONS}

Houk, R. S., Accounts Chemical Research, 27, 333-339, 1994.

French, J. B., Etkin, B., Jong, R. Anal. Chem., 66, 685-691, 1994. 


\subsection{SECONDARY ION-MASS SPECTROSCOPY ANALYSIS: DEVELOPMENT AND EVALUATION}

\section{TASK DESCRIPTION}

Fast, inexpensive, and non-polluting instrumentation for the detection of surface contaminants is being developed at the Idaho National Engineering Laboratory using advanced Secondary Ion Mass Spectroscopy (SIMS) technology. The attributes of this technology make it extremely attractive for waste and environmental characterization:

- No sample preparation is required;

- No waste is generated;

- Analysis is rapid and simple;

- Capable of speciation, "fingerprinting";

- Amenable to almost any sample type; and

- Amenable to involatile organics, salts.

SIMS has a simple principle of operation: surfaces are bombarded with high-energy particles, which "sputter" the contaminants into the gas-phase, where they can be detected as ions.

The objective of the SIMS Analysis program is to develop instrumentation and chemical applications for the detection and chemical species identification of semivolatile, involatile, or adsorbed contaminants on the surfaces of soils, minerals, salts, rocks, and other difficult to handle sample-types. Three subtasks are being pursued to achieve this objective: (1) demonstration of chemical analyses using SIMS, which are relevant to DOE problems, (2) development of SIMS instrumentation that takes advantage of the most recent advances at INEL and in the mass spectrometer manufacturing industry, and (3) transferring the advanced SIMS technology.

\section{TECHNOLOGY NEEDS}

DOE has many contamination problems requiring the determination of contaminants that adhere tightly to waste, environmental, and industrial surfaces. There is a critical need in DOE and industry for characterization technologies that are fast, inexpensive, and can address surface contamination. An excellent example of this need is the detection of mercury on soil samples, and equally important, the identification of mercury species present. The mercury speciation issue is important because differing environmental mobility among the species alters risk assessment associated with mercury contamination. For example, mercury present as $\mathrm{Hg}\left(\mathrm{NO}_{3}\right)_{2}$ is highly mobile and would require containment; on the other hand, mercury present as $\mathrm{HgO}$ strongly adsorbs to soil and poses a much lower risk. At the present time, there is no facile means to make a distinction between these species on soil samples. See Figure 5.8a.

Another example of this need is characterization of core and particulate samples from radioactive waste in underground storage tanks, which currently costs an average of $\$ 750,000$ /core analysis. Technologies capable of determining chemical speciation are needed to reduce the number of analyses needed, and to improve the estimation of tank energy content (critical for risk assessment associated with tank characterization and remediation activities).

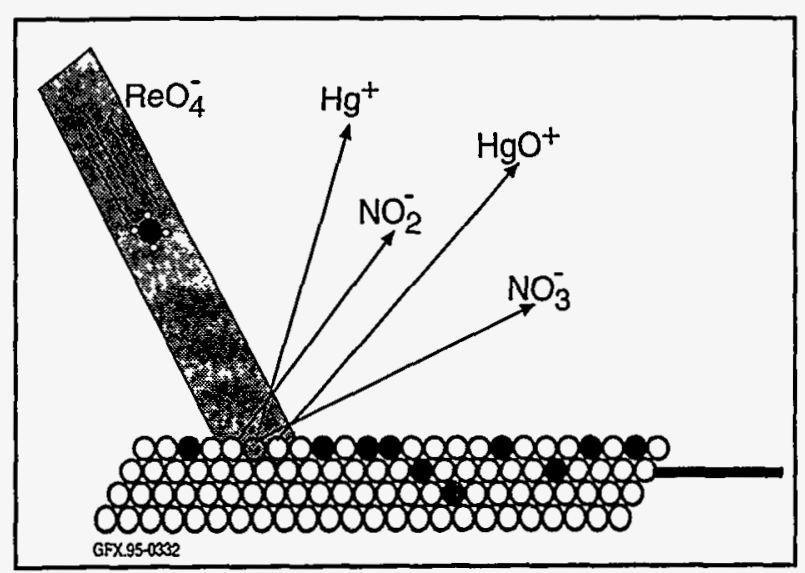

Figure 5.8a. Depiction of SIMS Bombardment of $\mathrm{Hg}$-Contaminated Soil. 


\section{ACCOMPLISHMENTS}

The rapid analysis of simulated salt cake samples was demonstrated using the laboratory-based SIMS instrument located at the INEL. The analyses required no sample preparation, and hence required less than 10 minutes; in addition, no waste was generated. A unique attribute of our R\&D 100 Award-winning, pulsed-extraction SIMS instrument is the ability to analyze cations and anions at the same time. This attribute is especially valuable for salt cake analyses because the salt samples contain both anion and cation species. Nitrite, nitrate, cyanide, and hydroxide anions, and iron, sodium, potassium, and nickel complexes were detected.

Since demonstrating SIMS for the characterization of salt cake, the SIMS analysis has been redirected toward the determination of metal speciation on soil samples. Initial studies have shown that, as in the case of the salt cake analyses, salient anions and cations can be readily detected on soil surfaces using SIMS. If mercury is detected simultaneously with anions, this would constitute powerful evidence for the existence of particular mercury salts present on the sample surface. In addition, experiments with copper halides indicate that mercuric anion complexes may survive intact during SIMS bombardment, which would be even stronger speciation evidence.

Instrument transportability, and improved sensitivity and selectivity are desired attribures of the instrumentation that will be constructed in this program. An ion trap mass spectrometer (ITMS) satisfies these requirements, and therefore this type of instrument was selected for interfacing with the OTD SIMS technology. An ITMS was procured in 1994, and modification will take place in 1995. The trend among ITMS manufacturers is toward decreased instrument size and improved transportability, which is in accord with the goals of the SIMS development program. It is anticipated that new, smaller ITMS instruments can be adapted to SIMS at a modest cost.

\section{TECHNOLOGY TRANSFER}

Technology transfer is presently being pursued with three vendors. Given the nature of the technology, the focus of the tech transfer activities has been on transfer of SIMS components, instead of a complete instrumental package, which would require the manufacturer to engineer their instrument from scratch. A license has been completed for data acquisition and instrument control software with Extrel (Pittsburgh, PA). Negotiations for transfer of ion gun and detector technology are underway with Teledyne (Mountain View, CA), and a nondisclosure agreement has been signed. Negotiations for transfer of ion gun technology are underway with Charles Evans \& Associates, Inc. (Redwood City, CA), and a non-disclosure agreement has been signed.

Figure $5.8 \mathrm{~b}$ is a schematic diagram of a protorype ion trap SIMS instrument being developed at INEL. The instrument will be capable of anion and cation acquisitions. Enhanced selectivity and sensitivity will result from MS/MS and selective ion storage capability. Negotiations are proceeding with Teledyne for the purpose of facilitating the interface of SIMS components with ion trap products currently in development.

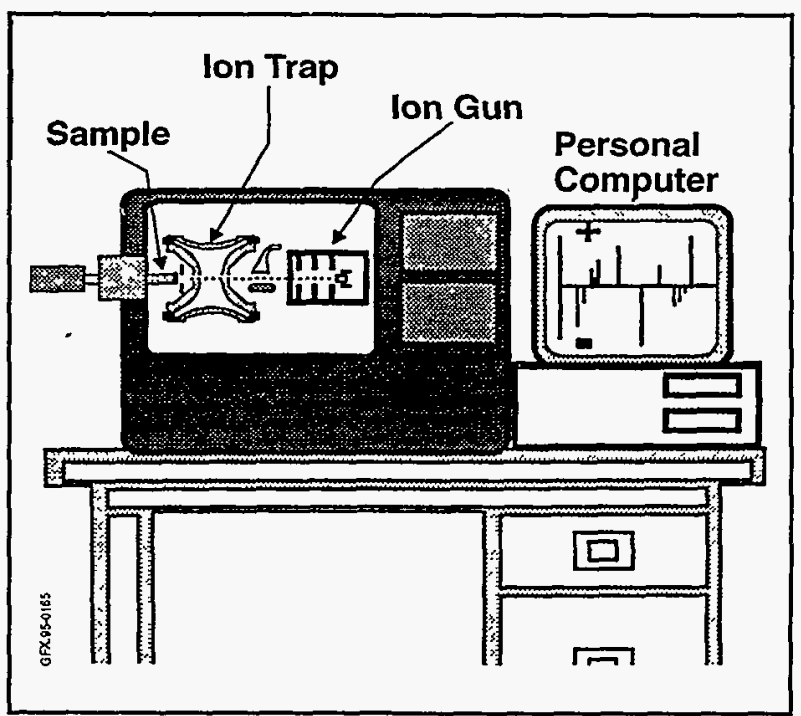

Figure 5.8b. Schematic Diagram of Prototype Ion Trap SIMS Instrument Being Developed at INEL. 
For further information, please contact:

James E. Delmore

Idaho National Engineering Laboratory

P.O. Box 1625

Idaho Falls, ID 83415-2208

Dr. Caroline Purdy

Program Manager, CMST-CP

U.S. Department of Energy

Cloverleaf Building

19901 Germantown Road

Germantown, MD 20874-1290

(301) 903-7672

\section{BIBLIOGRAPHY OF KEY PUBLICATIONS}

None at this time. 


\section{9 \\ RCRA METALS ANALYSIS BY LASER-INDUCED BREAKDOWN SPECTROSCOPY}

\section{TASK DESCRIPTION}

This project is developing a field-deployable instrument for rapid determination of hazardous metals in soils at hazardous and mixed waste sites. The data quality is expected to be suitable for use of the instrumentation as a field analytical method during site characterization. Elements specifically targeted are those of primary concern at the Component Development Integration Facility (CDIF) in Butte, MT. Primary analytes of interest at this facility are As, $\mathrm{Pb}, \mathrm{Cd}, \mathrm{Cu}$, and $\mathrm{Zn}$. In addition, $\mathrm{Ag}, \mathrm{Cr}, \mathrm{Fe}$, and $\mathrm{Mn}$ are also of interest due to regulatory drivers. The instrumentation will be based on laser-induced breakdown spectroscopy (LIBS). Using LIBS, it will be possible to determine rapidly both the concentration and location of elemental species at a waste site.

In LIBS, laser light is focused on a surface to vaporize a small amount of material. The vaporized material forms a short-lived plasma, which emits light that is collected, dispersed and analyzed. A schemaric of a LIBS apparatus is shown in Figure 5.9a. LIBS instrumentation can be made quite compact and only requires line-of-sight access to a material. The method thereby lends itself to integration with other instruments and several instru-

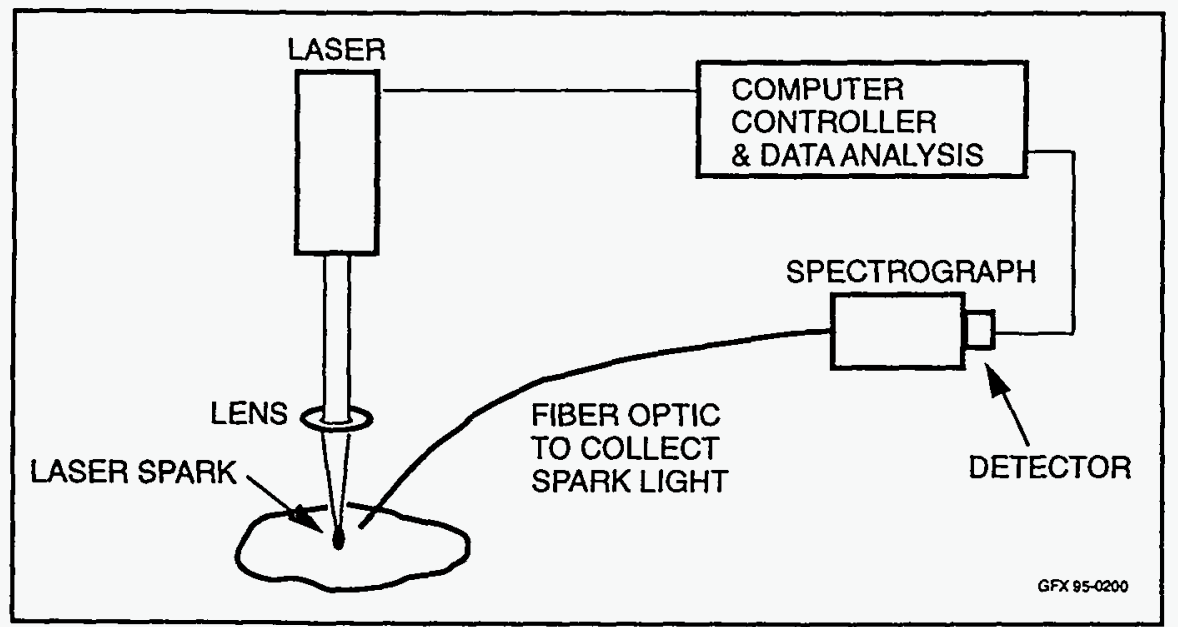

Figure 5.9a. Schematic Representation of a Basic Laser-Induced Breakdown Spectroscopy Instrument. ment configurations. The working head of one portable instrument constructed at LANL is four inches in diameter and eight inches in length. Using a fiber optic cable to guide the laser energy to soil will decrease the size requirements. Also, stand-off analyses of at least fifty feet are anticipated to be achievable. The final form of the prototype instrumentation will be designed to target the instrument configuration needs and data requirements of the CDIF.

A protorype instrument that will be capable of detecting many of the above mentioned elements is scheduled for delivery to the CDIF at the end of FY95.

\section{TECHNOLOGY NEEDS}

The basic technology being developed in this project has broad applications. The need for a field method that can provide expedited site characterization of hazardous waste sites is critical. Site remediation often becomes mired in the site characterization step due to slow turn around time of sample analyses. In addition, once a sample is removed from a location, its chemical integrity is always a concern. A method that minimizes sample handling and transport is needed to better ensure data quality. The LIBS instrumentation being developed and tested in this task is targeted to fulfill these needs. 


\section{ACCOMPLISHMENTS}

In FY94, we conducted laboratory experiments which:

- Identify spectral interferences from elements typically found in soils for the analytes of interest.

- Determine the detection limit, sensitivity,

- and precision of the best analytical line(s) in soils spiked with single elements of interest. The best instrument parameters that could still be incorporated into fieldable instrumentation were used.

A typical calibration curve is shown in Figure 5.9b.

\section{BENEFITS}

There is no baseline technology for in-the-field measurements of hazardous metals. The current method uses grab samples and laboratory analysis. The fieldable instrumentation developed in this project will increase the speed and efficiency of analyses, thereby decreasing the costs associated with evaluating and remediating hazardous and mixed-waste sites. We estimate that years will be saved in characterizing and remediating sites identified by EPA as falling under RCRA. Savings should include 80 percent of the sampling costs of using conventional laboratory techniques for all analyses, as well as savings resulting from reduced crew down time waiting for laboratory analyses. We also anticipate a reduction of $80-90$ percent in transportation and $80-90$ percent in the generation of new hazardous waste by sample analysis. In addition, this instrumentation will eliminate the exposure of personnel to potentially hazardous wastes.

Another benefit is the larger number of samples that can be analyzed and the greater accuracy in determining the analyte distribution throughout a site that this allows. Analysis at a single position at a site should take one minute or less. Thus, a site can be surveyed in less time, and with greater coverage than is achievable with conventional sample collection

\section{Calibration Curve for Lead}

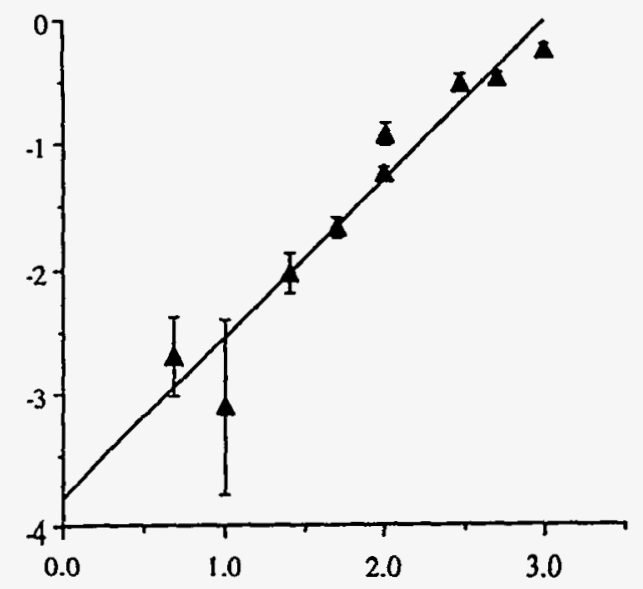

log [Spiked Pb Concentration (ppm)]

Figure 5.9b. Calibration Curve for Los Alamos Soil Spiked With Lead.

and analysis methods. Also, depth profiling by analysis of core samples is limited by the cost of analysis to one $10 \mathrm{~g}$ sample taken for every five-foot section. This is a very small fraction of the entire core and choosing a representative sample is a difficult but critical task. Using an instrument based on LIBS to scan the entire length of the core sample, in the field, will be a cost effective solution to this sampling problem.

\section{COLLABORATION/TECHNOLOGY}

\section{TRANSFER}

This project is being conducted in collaboration with MSE, Inc, the company in charge of the CDIF. This company will help evaluate the technology during FY95. At the conclusion of scheduled field tests, a portable instrument will be transferred to the CDIF. 
TTP Number: AL141006

For further information, please contact:

BIBLIOGRAPHY OF KEY PUBLICATIONS

Aaron Koskelo

Koskelo, Aaron and David A. Cremers RCRA

Principal Investigator

Los Alamos National Laboratory

P.O. Box 1663

Los Alamos, NM 87545

Metals Analysis by Laser-Induced Breakdown Spectroscopy: Detection Limits in Soils, Los Alamos National Laboratory Report, LA-UR-94-1544, 1994.

(505) 665-4463

\section{David Cremers}

Technical Program Officer

Los Alamos National Laboratory

P.O. Box 1663

Los Alamos, NM 87545

(505) $665-4180$

\section{Bruce Erdal}

Technical Program Manager

Los Alamos National Laboratory

P.O. Box 1663

Los Alamos, NM 87545

(505) 667-8914

Dr. Caroline Purdy

Program Manager, CMST-CP

U.S. Department of Energy

Cloverleaf Building

19901 Germantown Road

Germantown, MD 20874-1290

(301) 903-7672 


\section{DOE \\ BusINESS OPPORTUNITIES}

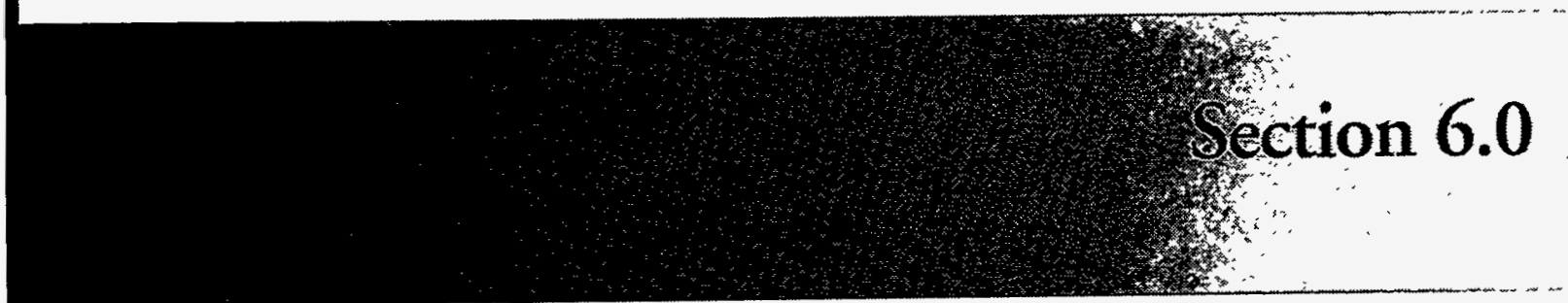




\section{WORKING WITH THE DOE OFFICE OF ENVIRONMENTAL MANAGEMENT}

DOE provides a range of programs and services to assist universities, industry, and other private-sector organizations and individuals interested in developing or applying environmental technologies. Working with DOE Operations Offices, as well as management and operating contractors, EM employs a number of mechanisms to identify, integrate, develop, and adapt promising emerging technologies. These mechanisms include contracting and collaborative arrangements, procurement provisions, licensing of technologies, consulting arrangements, reimbursable work for industry, and special consideration for small business. EM facilitates the development of subcontracts, $R \& D$ contracts, and cooperative agreements to work collaboratively with the private sector.

\section{COOPERATIVE RESEARCH AND DEVELOPMENT AGREEMENTS (CRADAS)}

CRADAs are mechanisms for collaborative $R \& D$. They are agreements between a $D O E R \& D$ laboratory and any non-federal source to conduct cooperative $R \& D$ that is consistent with the laboratory's mission. The partner may provide funds, facilities, people, or other resources. DOE provides the CRADA partner with access to facilities and expertise; however, external participants receive no federal funds. Rights to inventions and other intellectual property are negotiated between the laboratory and the participant. Certain generated data may be protected for up to five years. Several companies may combine their resources to address a common technical problem. Funds can be leveraged to implement a consortium for overall program effectiveness.

\section{PROCUREMENT MECHANISMS}

DOE-EM procurement mechanisms are for technology development in the form of unsolicited proposals and formal solicitations, although the latter are preferable. The principal contractual mechanisms used by EM for industrial and academic response include Research Opportunity Announcements (ROAs) and Program R\&D Announcements (PRDAs).

EM utilizes the ROA to seek advanced research and technologies for a broad scope of cleanup needs. The ROA supports applied research ranging from concept feasibility to full-scale testing. In addition, the ROA is open continuously for a full year following the date of issue and includes a partial procurement set-aside for small businesses. Typically, ROAs are published annually in the Federal Register, announced in the Commerce Business Daily, and provide multiple awards.

PRDAs are program announcements which solicit a broad mix of advanced development and demonstration proposals. A PRDA requests proposals for a wide-range of technical solutions to specific EM problem areas. Multiple awards, which may have distinct approaches or concepts, are generally made. Numerous PRDAs may be issued each year.

EM awards grants and cooperative agreements if $51 \%$ or more of the overall value of the effort is related to a public interest goal. Such goals include possible non-DOE or other federal agency participation and advancement of present/future U.S. capabilities in domestic and international environmental cleanup markets. They may also include technology transfer, advancement of scientific knowledge, or education and training of individuals as well as business entities. 
For more information about PRDAs and ROAs, contact:

\author{
Tom Martin \\ U.S. Department of Energy \\ Morgantown Energy Technology Center \\ P.O. Box 880, MS I07 \\ Morgantown, West Virginia 26507
}

(304) $285-4087$

\title{
LICENSING OF TECHNOLOGIES
}

DOE contractor-operated laboratories can license DOE/EM-developed technology and software. In situations where DOE retains the ownnership of a new technology, the Office of General Counsel will serve as the licensing agent. Licensing activities are conducted according to existing DOE intellectual property provisions.

\section{TECHNICAL PERSONNEL EXCHANGE ASSIGNMENTS}

Personnel exchanges provide opportunities for scientists from private industry and DOE laboratories to work together at various sites on environmental restoration and waste management problems. Private industry must contribute substantial cost-sharing for these personnel exchanges. To encourage such collaboration, the rights to any resulting patents go to the private sector company. These personnel exchanges, which can last from three to six months, tesult in the transfer of technical skills and knowledge.

\section{CONSULTING ARRANGEMENTS}

Laboratory scientists and engineers are available to consult in their areas of technical expertise. Most contractors which operate laboratories have consulting provisions. Laboratory employees who wish to consult can sign non-disclosure agreements, and are encouraged to do so.

\section{REIMBURSABLE WORK FOR INDUSTRY}

DOE laboratories are available to perform work for private industry and other federal agencies, as long as the work pertains to the mission of a respective laboratory and does not compete with the private sector. The special technical capabilities at DOE laboratories are incentives for the private sector to use DOE's facilities and contractor expertise. An advanced class patent waiver gives ownership of any inventions resulting from the research to the participating private sector company.

\section{INTERACTIONS WITH SMALL BUSINESSES}

EM seeks the participation of small businesses in its RDDT \&E programs (1) through collaborative efforts with the National Laboratories, or (2) directly via solicitations issued by the DOE Small Business Innovation Research (SBIR) Program Office and the Small Business Technology Transfer (T2) Pilot Program (STTR). EM also has established a partial procurement set-aside for small firms (500 employees or less) for applied research projects through its ROA. 
For further information about SBIR and STTR programs, please contact:

U.S. Department of Energy

Small Business Innovation Research Program Hotline

ER-16 GTN

Washington, D.C. 20585

(301) 903-5707

\section{EM CENTER FOR ENVIRONMENTAL MANAGEMENT INFORMATION}

The EM Center for Environmental Management Information is designed to provide ready access to prospective research and business opportunities in waste management, environmental restoration, and decontamination and decommissioning activities. The Center can identify links between industry technologies and program needs. It connects potential partners to an extensive complex-wide network of DOE headquarters and operations office contacts.

To reach the EM Center for Environmental Management Information, call 1-800-736-3282.

\section{OFFICES OF RESEARCH AND TECHNOLOGY APPLICATIONS}

The Offices of Research and Technology Applications (ORTA) serve as technology transfer agents for the federal laboratories. They coordinate technology transfer activities among laboratories, industry, and universities. ORTA offices license patents and foster communication between researchers and technology customers.

\section{ORTA Contacts:}

\section{Laboratory}

Ames Laboratory

Argonne National Lab

Brookhaven National Lab

Fermilab

Idaho National Engineering Lab

Lawrence Berkeley Lab

Lawrence Livermore National Lab

Los Alamos National Lab

Morgantown Energy Technology Ctr

National Renewable Energy Lab

Oak Ridge Institute/Science \& Ed

\section{Contact}

Todd Zdorkowski

Shari Zussman

Margaret Bogosian

John Vernard

Ann Rydalch

Cheryl Fragiadakis

Dave Conrad

Pete Lyons

Rodney Anderson

Dana Moran

Mary Loges
Phone Number

(515) $294-5640$

(708) 252-5361

(516) 282-7338

(708) 840-2529

(208) 526-1010

(510) 486-6467

(510) 422-7839

(505) 665-9090

(304) $285-4709$

(303) 275-3015

(615) 576-3756 
Laboratory

Oak Ridge National Lab

Pacific Northwest Lab

Pittsburgh Energy Technology Center

Princeton Plasma Physics Lab

Sandia National Lab

Savannah River Technology Center

Stanford Linear Accelerator Center

Westinghouse Hanford Company
Contact

Bill Martin

Marv Clement

Kay Downey

Lew Meixler

Warren Siemens

Jack Corey

Jim Simpson

Dave Greenslade
Phone Number

(615) $576-8368$

(509) $375-2789$

(412) $892-6029$

(609) 243-3009

(505) 271-7813

(803) $725-1134$

(415) $926-2213$

(509) $376-5601$ 


\section{ACRONYM Listing}

\section{Section 7.0}


ANL

Argonne National Laboratory

AOTF

Acousto-Optic Tunable Filter

API

Associated Particle Imaging

ARA

Applied Research Associates, Inc.

CAE

Clean Air Engineering

CBD

Commerce Business Daily

CCC

Comodity Credit Corporation

CDIF

Component Development Integration Facility

CEM

Continuous Emission Monitor

$\mathrm{CHC}$

Chlorinated Hydrocarbons

CERCLA

Comprehensive Environmental Response Compensation and Liability Act of 1980

CMST

Characterization, Monitoring, and Sensor Technology

CMST-CP

Characterization, Monitoring, and Sensor Technology Crosscutting Program

CPAC

Center for Process Analytical Chemistry

CPT

Cone Penetrometer Truck

CRADA

Cooperative Research and Development Agreement

CRC

Coleman Research Corporation

CSM

Colorado School of Mines

CT

Computerized Tomography

CVD

Chemical Vapor Deposited

$\mathrm{Cu}$

Copper

CZT

$\mathrm{CdZnTe}$

$\mathrm{D} \& \mathrm{D}$

Decontamination and Decommissioning

DFW

Data Fusion Workstation

DIAL

Diagnostic Instrumentation and Analysis Laboratory

DNAPL

Dense Non-Aqueous Phase Liquids

DoD

Department of Defense 
DOE Department of Energy

DST Double-shelled Underground Storage Tank

EM Office of Environmental Management

EM-30 Office of Waste Management

EM-40 Office of Environmental Restoration

EM-50 Office of Technology Development

EM-53 Office of Research and Development

EM-54 Office of Demonstration, Testing, and Evaluation

EM-60 Office of Facility Transition and Management

EMC Environmental Measurements Corporation

EMI Electromagnetic Induction

EPA Environmental Protection Agency

ER/WM Environmental Restoration/Waste Management

ERT Electrical Resistance Tomography

ES\&H Environmental, Safery, and Health

ESC

Expedited Site Characterization

ESP

Efficient Separations and Processing

$\mathrm{Fe}$

Iron

FFP

Fiber Optic Fabry-Perot Interferometer

FSU

Former Soviet Union

FTIR

Fourier Transform Infrared

FTIR-PAS Fourier Transform Infrared Photoacoustic Spectroscopy

FY

Fiscal Year

GC/MS

Gas Chromatography/Mass Spectrometry

GETE

Global Environmental Technology Enterprise

GETF

Global Environment and Technology Foundation

$\mathrm{GHz}$

Gigahertz

GIS

Geographic Information Systems

GJPO

Grand Junction Projects Office 


\begin{tabular}{|c|c|}
\hline GMS & Ground Modeling System \\
\hline GPER & Geophysics Performance Evaluation Range \\
\hline HLW & High-Level Waste \\
\hline ICP-AES & Inductively Coupled Plasma-Atomic Emission Spectroscopy \\
\hline ICP-MS & Inductively Coupled Plasma-Mass Spectrometry \\
\hline ID & Integrated Demonstration \\
\hline IP & Integrated Program \\
\hline IDW & Investigation Derived Waste \\
\hline IIA & Innovative Investment Area \\
\hline IMA & Immunoassay \\
\hline INEL & Idaho National Engineering Laboratory \\
\hline IT & Innovative Technologies \\
\hline ITMS & Ion Trap Mass spectrometry \\
\hline $\mathrm{KHz}$ & kilohertz \\
\hline LANL & Los Alamos National Laboratory \\
\hline LA & Laser Ablation \\
\hline LASS & Laser Spark Spectrometry \\
\hline LBL & Lawrence Berkeley Laboratory \\
\hline LIBS & Laser-Induced Breakdown Spectroscopy \\
\hline LIF & Laser-Induced Fluorescence \\
\hline LIFI & Laser-Induced Fluorescence Imaging \\
\hline LOGS & Laser Optogalvanic Spectroscopy \\
\hline LOW & Liquid Observation Well \\
\hline LSER & Linear Solvation Energy Relationships \\
\hline LSFA & Landfill Stabilization Focus Area \\
\hline $\mathrm{M} \& \mathrm{O}$ & Management and Operations \\
\hline MDMI & Monodisperse Dried Microparticulate Injector \\
\hline MMES & Martin Marietta Energy Systems \\
\hline $\mathrm{mg}$ & milligram \\
\hline
\end{tabular}




\begin{tabular}{|c|c|}
\hline $\mathrm{mg} / \mathrm{Kg}$ & milligram per kilogram \\
\hline MT & Marshalltown \\
\hline NAPL & Non-Aqueous Phase Liquid \\
\hline NJIT & New Jersey Institute of Technology \\
\hline $\mathrm{nL}$ & nanoliter \\
\hline $\mathrm{nm}$ & nanometer \\
\hline NEPA & National Environmental Policy Act \\
\hline NFA & No Further Action \\
\hline NSF & National Science Foundation \\
\hline OBG & Old Burial Ground \\
\hline ORNL & Oak Ridge National Laboratory \\
\hline ORTA & Offices of Research and Technology Applications \\
\hline OTD & Office of Technology Development \\
\hline $\mathrm{pCi} / \mathrm{g}$ & picocurie per gram \\
\hline $\mathrm{PAH}$ & Polynuclear Aromatic Hydrocarbons \\
\hline PAWS & Portable Acoustic Wave Sensor \\
\hline PCE & Perchloroethylene \\
\hline PCF & Plasma Centrifugal Furnace \\
\hline PI & Principal Investigator \\
\hline PLS & Partial Least Squares \\
\hline PNL & Pacific Northwest Laboratory \\
\hline ppm & parts per million \\
\hline PRDA & Program Research and Development Announcement \\
\hline QCM & Quartz Crystal Microbalance \\
\hline RCRA & Resource Conservation Recovery Act \\
\hline $\mathrm{R} \& \mathrm{D}$ & Research and Development \\
\hline RDDT\&E & Research, Development, Demonstration, Testing, and Evaluation \\
\hline ROA & Research Opportunity Announcement \\
\hline RTR & Real-Time Radiography \\
\hline
\end{tabular}


Scientific Applications International Corporation

Small Business Innovation Research

SCAPS

Site Characterization and Analysis Penetrometer System

SGI

Sol-Gel Indicator

SGR

Spectral Gamma-Ray

SH

Shear-wave

SIMS

Secondary Ion Mass Spectrometry

SNL

Sandia National Laboratory

SOPT

State-of-the-Practice Technologies

SRS

Savannah River Site

SST

Single-Shell Tank

STCG

Site Technology Coordination Group

STNG

Sealed Tube Neutron Generator

STTR

Small Business Technology Transfer Pilot Program

SVOC

Semi-Volatile Organic Compound

TCE

Tricholoroethylene

TDF

Technology Data File

TDR

Time Domain Reflectometry

TDGC/MS

Time Domain Gas Chromatography/Mass Spectrometry

TFA

Tank Focus Area

TFR

Thin Film Resonators

TIRS

Transient Infrared Spectroscopy

TPS

Technology Performance Specifications

TRU

Transuranic

TSCA

Toxic Substances Control Act

TTP

Technical Task Plans

TWRS

Tank Waste Remediation System

$\mu \mathrm{l}$

microliter 


$\begin{array}{ll}\mu \mathrm{m} & \text { micrometer } \\ \text { USDA } & \text { United States Department of Agriculture } \\ \text { USGS } & \text { United States Geological Survey } \\ \text { UST } & \text { Underground Storage Tank } \\ \text { VOC } & \text { Volatile Organic Compound } \\ \text { VOST } & \text { Volatile Organic Sampling Train } \\ \text { WES } & \text { Waterways Experiment Station } \\ \text { WETO } & \text { Western Energy Technology Office } \\ \text { WHC } & \text { Westinghouse Hanford Company }\end{array}$




\section{APPENDIX}

\section{Section 8.0}


Technical Task Plans (TTPs) identify and summarize funded work managed by OTD at headquarters, the field and the national laboratories. All tasks require a TTP number, which contains eight characters assigned by DOE Headquarters. The format consists of two alpha characters followed by six numerical characters. Characters 1 and 2 designate the DOE Operations Office/Funding Allotment Code. Character 3 denotes the laboratory/contractor/university designator. Character 4 denotes the fiscal year in which the task is first funded. The below characters reflect TTPs from FY94-95.

Characters $1,2 \& 3$

ALO Albuquerque Operations Office

ALl Los Alamos National Laboratory (LANL)

AL2 Sandia National Laboratory, Albuquerque (SNLA)/Martin Marietta

AL3 Sandia National Laboratory, Livermore (SNLL)

AL4 Kansas City Plant (KCP)/Allied-Signal Aerospace

AL9 RUST GEOTECH

$\mathrm{CHO}$ Chicago Operations Office

$\mathrm{CH} 1$ Ames Laboratory

$\mathrm{CH} 2$ Argonne National Laboratory (ANL)/University of Chicago

CH3 Brookhaven National Laboratory (BNL)/Associated Universities, Inc.

CH5 National Renewable Evergy Laboratory

FNO Fernald Environmental Management Project (FEMP)

FN1 Fluor Daniel Environmental Restoration Management Company

HQO OTD Headquarters

ID0 Idaho Operations Office

ID1 Idaho National Engineering Laboratory (INEL)/EG\&G

ID4 Westinghouse Idaho Nuclear Company

ID6 Babcock \& Wilcox, Inc

ID7 Lockheed Idaho Technology Company

ME0 Morgantown Energy Technology Center (METC)

NVo Nevadá Operations Office

OHO Ohio Operations Office 
OH1 Fernald Environmental Management Project (FEMP)

$\mathrm{OH} 2$ EG\&G Mound Applied Technologies

OR0 Oak Ridge Operations Office

ORI Martin Marietta Energy Systems (MMES)

OR3 Oak Ridge Institute for Science and Education

PE0 Pittsburgh Energy Technology Center

PE1 MSE, Inc.

RF0 Rocky Flats Environmental Technology Office

RF1 Rocky Flats Plant/EG\&G

RLO Richland Operations Office

RL2 Kaiser Engineers Hanford Company (KEH)

RL3 Pacific Northwest Laboratory (PNL)/Battelle Memorial Institute

RL4 Westinghouse Hanford Company

SF0 Oakland Operations Office

SF1 Lawrence Berkeley Laboratory (LBL)/University of California

SF2 Lawrence Livermore National Laboratory (LLNL)/University of California

SF3 Energy Technology Engineering Center (ETEC)

SR0 Savannah River Operations Office

SR1 Westinghouse Savannah River Company (WSRC) 
Character 4

1 FY 1991

2 FY 1992

3 FY 1993

4 FY 1994

5 FY 1995

6 FY 1996

$7 \quad$ FY 1997

$8 \quad$ FY 1998

9 FY 1999

0 FY 2000 